CLAUDIA TUMA HARMUCH

\title{
UMA ABORDAGEM PARA A DETERMINAÇÃO DO GRAU DE EXPOSIÇÃO A RISCOS EM PORTFOLIO DE PROJETOS
}

Dissertação apresentada à Escola Politécnica da Universidade de São Paulo para obtenção do título de Mestre em Engenharia 


\title{
UMA ABORDAGEM PARA A DETERMINAÇÃO DO GRAU DE EXPOSIÇÃO A RISCOS EM PORTFOLIO DE PROJETOS
}

\author{
Dissertação apresentada à Escola Politécnica \\ da Universidade de São Paulo para obtenção \\ do título de Mestre em Engenharia \\ Área de concentração: \\ Engenharia Naval e Oceânica \\ Orientador: \\ Prof. Dr. Bernardo Luis Rodrigues de Andrade
}


Este exemplar foi revisado e alterado em relação à versão original, sob responsabilidade única do autor e com anuência de seu orientador.

São Paulo, 16 de dezembro de 2009.

Assinatura do autor

Assinatura do orientador

\section{FICHA CATALOGRÁFICA}

Harmuch, Claudia Tuma

Uma abordagem para a determinação do grau de exposição a riscos em portfolio de projetos / C.T. Harmuch. -- ed.rev. -- São Paulo, 2009. $138 \mathrm{p}$.

Dissertação (Mestrado) - Escola Politécnica da Universidade de São Paulo. Departamento de Engenharia Naval e Oceânica.

1.Administração de projeto 2.Administração de portfolios (Projeto) 3.Administração de risco (Projeto) I.Universidade de São Paulo. Escola Politécnica. Departamento de Engenharia Naval e Oceânica. II.t. 


\section{AGRADECIMENTOS}

Ao meu orientador, Prof. Dr. Bernardo Luis Rodrigues de Andrade, pela paciência, apoio, sugestões e correções, que foram muito importantes no desenvolvimento desta pesquisa.

Ao diretor da área de projetos e aos gerentes de projeto da empresa pesquisada, sem os quais não teria sido possível a realização da parte prática deste trabalho.

Aos meus familiares, pela compreensão da minha ausência durante as horas incontáveis em frente ao computador.

E em especial ao meu marido, Onevair Ferrari, que, com incentivo constante e contribuições significativas, esteve sempre ao meu lado, no desafio de seguir em frente rumo à conclusão deste projeto. 


\section{RESUMO}

A composição de um portfolio de projetos é realizada de acordo com um conjunto de critérios de seleção e avaliação de projetos, que permite identificar quais projetos trazem maior valor, benefícios e alinhamento com as estratégias definidas pela organização, para um determinado horizonte de tempo. O grau de exposição a riscos do portfolio de projetos é um dos critérios mais importantes a ser considerado na composição e no balanceamento do portfolio, uma vez que indica a magnitude dos desvios a que o portfolio está sujeito em relação ao atendimento de seus objetivos. Este trabalho apresenta um procedimento para a avaliação do grau de exposição a riscos do portfolio de projetos, que parte dos riscos de cada projeto, e considera seus inter-relacionamentos, bem como outros riscos inerentes ao portfolio como um todo. O procedimento abrange a identificação, análise e tratamento dos riscos do portfolio e a determinação do grau de exposição a riscos no atendimento de cada objetivo e do portfolio com um todo. Através de um estudo de caso, realizado numa empresa multinacional do setor de máquinas e equipamentos, o procedimento foi testado num portfolio composto por nove dos maiores projetos de sua maior unidade de negócio. Foi possível determinar o grau de exposição a riscos do portfolio de projetos frente aos objetivos estratégicos a que se propunha atender - valores determinados de margem bruta média e faturamento para o ano fiscal corrente. $\mathrm{O}$ estudo de caso permitiu validar a aplicabilidade do procedimento. A identificação dos riscos em comum, das interdependências e de outros riscos abrangentes permitiu identificar causas comuns e proliferações entre os riscos dos projetos e, principalmente, racionalizar recursos no tratamento dos riscos.

Palavras-chave: Gerenciamento de portfolio de projetos. Gerenciamento de projetos. Gerenciamento de riscos em projetos. 


\begin{abstract}
When building a project portfolio, evaluation and selection criteria are used to recognize which projects bring greater value, benefits and alignment with the organization strategies defined for a given period of time. One of the most relevant criteria in project portfolio composition and balancing is the risk exposure, as it indicates the magnitude of slippages to which the organization objectives are susceptible. This work presents a procedure for the evaluation of the overall project portfolio risk exposure, considering the risks of each project, the inter-relationships among them, and also other risks inherent to the portfolio as a whole. The procedure encloses portfolio risks identification, analysis and treatment and the assessment of the risk exposure in the attendance of each objective as well as for the complete portfolio. Through a case study, carried through in a world class multinational company of the capital goods sector, the risk analysis procedure has been tested in a portfolio encompassing nine major projects from its main business unit. It has been possible to define the risk exposure related to the strategic objectives this portfolio should fulfill - average gross margin and revenues for the current fiscal year. The case study has allowed validating the applicability of the proposed procedure. The identification of common risks, interdependences and other overall portfolio risks has also allowed to recognize common causes, proliferation among projects and, mainly, to rationalize resources in treating these risks.
\end{abstract}

Key words: Project portfolio management. Project management. Project risk management. 


\section{LISTA DE FIGURAS}

Figura 1.1 - Objetivo do gerenciamento de portfolio e do gerenciamento de projetos

Figura 1.2 - Interação entre gerenciamento de portfolio e gerenciamento de projetos

Figura 1.3 - Organizações que gerenciam seus projetos como um portfolio .16

Figura 1.4 - Composição do portfolio de projetos 18

Figura 1.5 - Exposição a riscos: projeto x portfolio .20

Figura 3.1 - Relacionamentos entre projetos, programas e portfolios .33

Figura 3.2 - Planejamento estratégico e projetos 35

Figura 3.3 - Contexto organizacional do gerenciamento de portfolio. 37

Figura 3.4 - Estrutura de seleção de projetos para o portfolio .39

Figura 3.5 - As três partes do processo de decisão no gerenciamento de portfolio .42

Figura 3.6 - Visão geral do modelo Stage-Gate®. .44

Figura 3.7 - Relacionamentos dos processos de gerenciamento de portfolio numa organização 46

Figura 3.8 - Processos de gerenciamento de portfolio .47

Figura 3.9 - As três grandes fases do gerenciamento de portfolio de projetos .51

Figura 3.10 - Popularidade dos métodos utilizados no gerenciamento de portfolios 53

Figura 3.11 - Apetite e tolerância a riscos .57

Figura 3.12 - Gerenciamento de riscos na organização .59

Figura 3.13 - Exemplo de estrutura analítica de riscos. .64

Figura 3.14 - Exemplo de matriz de impacto e probabilidade 69

Figura 3.15 - A exposição a riscos e as fases do gerenciamento de portfolio de projetos .77

Figura 3.16 - Estratégias de distribuição de orçamento e perfil de risco ……….......78

Figura 3.17 - Exemplo de diagrama de bolhas risco/benefício 81

Figura 4.1 - Procedimento para determinação do grau de exposição a riscos de um portfolio de projetos .83

Figura 4.2 - Contexto do procedimento proposto .84

Figura 4.3 - Exemplo de representação da tolerância a riscos para o portfolio de projetos 


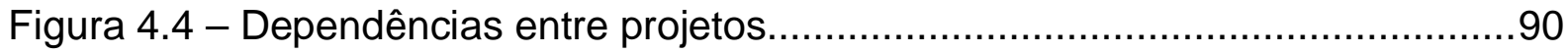

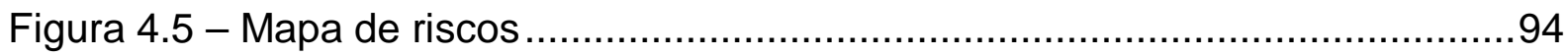

Figura 4.6 - Exposição a riscos do objetivo do portfolio x tolerância definida............98

Figura 4.7 - Grau de exposição a riscos de um portfolio ........................................99

Figura 5.1 - Ciclo de vida do projeto da Empresa.............................................103

Figura 5.2 - Avaliação de riscos durante o ciclo de vida do projeto......................... 106

Figura 5.3 - Avaliação de riscos de um projeto candidato ....................................107

Figura 5.4 - Instrumentos para avaliação qualitativa de riscos do projeto ...............108

Figura 5.5 - Mapa de riscos para margem bruta..................................................114

Figura 5.6 - Mapa de riscos para faturamento ...............................................115

Figura 5.7 - Mapa de riscos para severidade ponderada ......................................116

Figura 5.8 - Exposição a riscos dos objetivos do portfolio ....................................118

Figura 5.9 - Comparação dos desvios no projeto e no portfolio ............................ 120

Figura 5.10 - Comparação entre benefícios e exposição a riscos ..........................121 


\section{LISTA DE TABELAS}

Tabela 2-1 - Problemas explorados na pesquisa …………………………....25

Tabela 2-2 - Situações relevantes para diferentes estratégias de pesquisa..............28

Tabela 3-1 - Visão comparativa entre gerenciamento de projeto, programa e portfolio

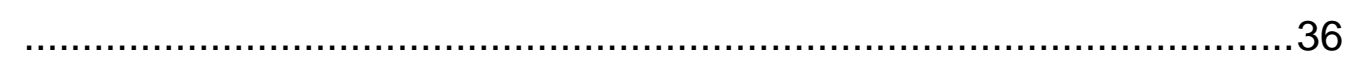

Tabela 3-2 - Estágios e técnicas recomendadas no gerenciamento de portflio........54

Tabela 3-3 - Fontes típicas de riscos em projetos ................................................63

Tabela 3-4 - Visão geral dos processos de gerenciamento de riscos em projetos...65

Tabela 4-1 - Relacionamento entre os projetos e os objetivos estratégicos do

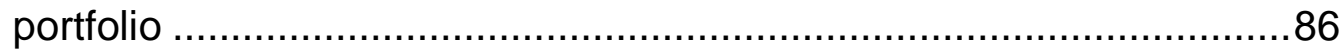

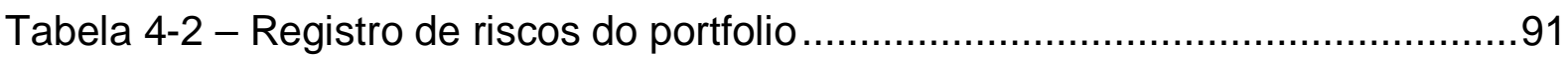

Tabela 4-3 - Exemplo de critérios de classificação de severidade dos riscos ..........93

Tabela 4-4 - Registro de riscos do portfolio de projetos .......................................94

Tabela 4-5 - Exemplo de avaliação da severidade ponderada para o risco $n$...........95

Tabela 4-6 - Exemplo de critérios de classificação de severidade ponderada dos

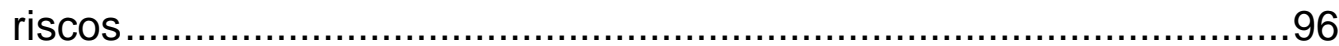

Tabela 4-7 - Escala de classificação do grau de exposição a riscos do portfolio .....98

Tabela 5-1 - Caracterização dos projetos da Empresa.........................................102

Tabela 5-2 - Benefícios esperados dos projetos para os objetivos estratégicos do

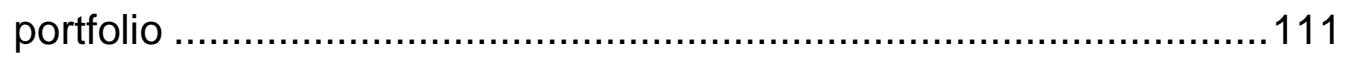

Tabela 5-3 - Tolerância a riscos para o portfolio ……………………………....112

Tabela 5-4 - Registro de riscos do portfolio .....................................................117

Tabela 5-5 - Avaliação do grau de exposição a riscos do portfolio..........................119

Tabela 5-6 - Critérios de classificação do grau de exposição a riscos do portfolio.119 


\section{SUMÁRIO}

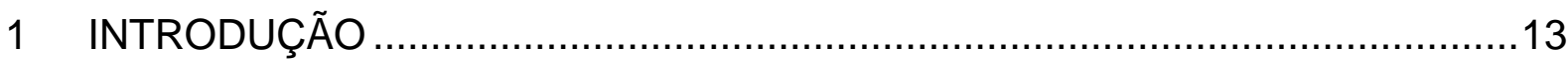

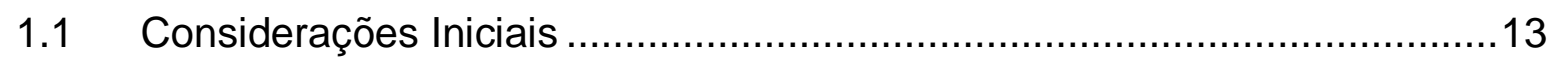

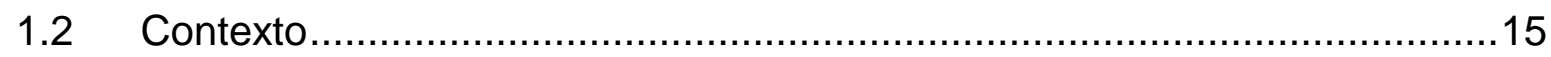

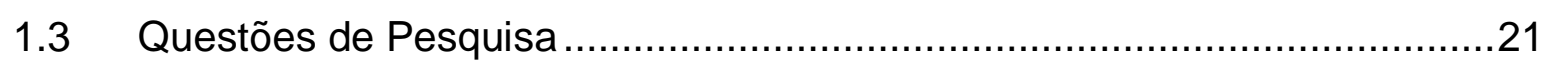

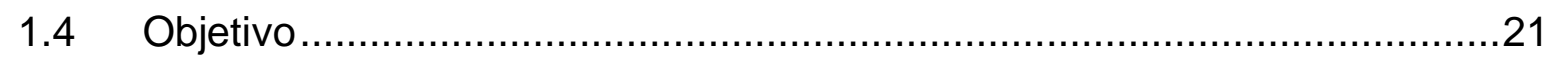

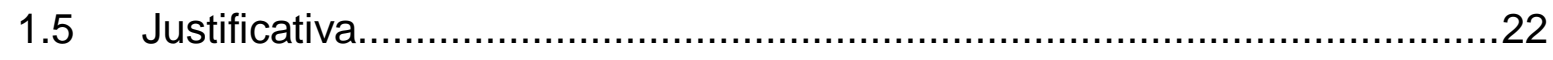

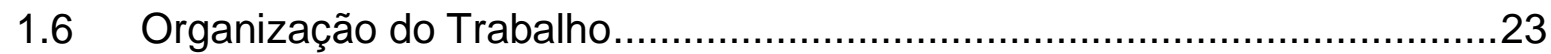

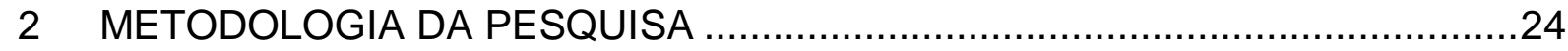

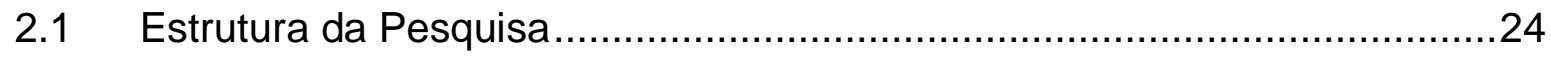

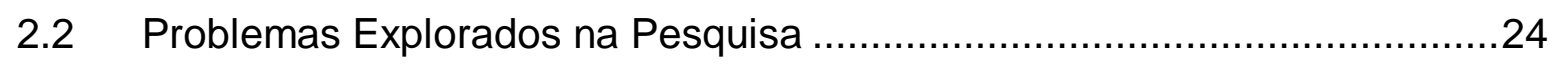

2.3 Classificação da Pesquisa ...............................................................25

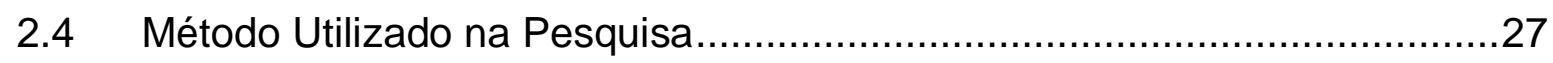

2.5 A Escolha da Organização para o Estudo de Caso ...................................28

2.6 Protocolo e Procedimentos Considerados na Pesquisa ...........................30

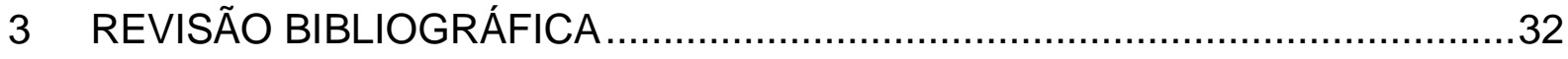

3.1 Operações, Projetos, Programas e Portfolios …….....................................

3.2 Planejamento Estratégico e Portfolio de Projetos …….................................34

3.3 Modelos de Gerenciamento de Portfolio de Projetos .................................37

3.3.1 O Modelo de Archer e Ghasemzadeh..................................................38

3.3.2 O Modelo de Cooper, Edgett e Kleinschmidt ......................................41

3.3.3 O Modelo do Project Management Institute ......................................45

3.3.4 As Três Grandes Fases do Gerenciamento de Portfolio de Projetos...51

3.4 Métodos Utilizados no Gerenciamento de Portfolios.................................52

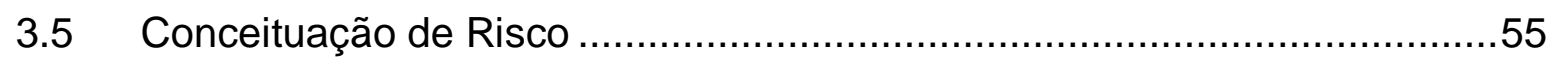

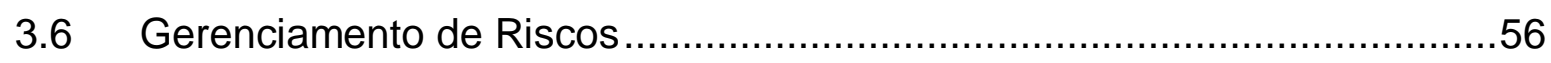

3.6.1 As Dimensões do Gerenciamento de Riscos....................................58

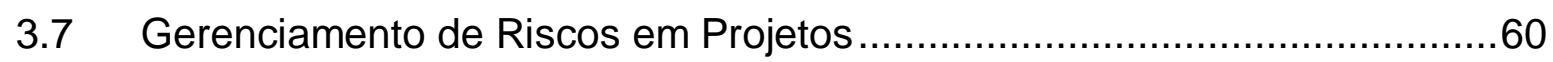

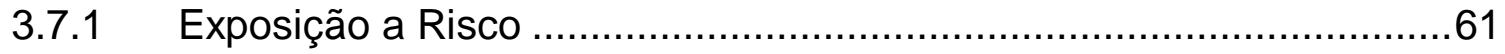

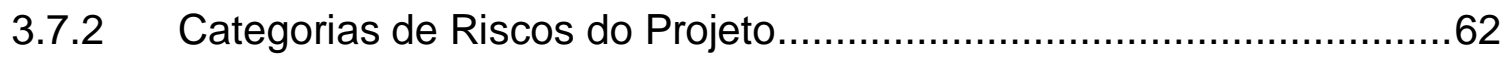

3.7.3 Processos de Gerenciamento de Riscos em Projetos .........................64

3.7.3.1 Planejamento do Gerenciamento de Riscos .................................66 
3.7.3.2 Avaliação dos Riscos .66

3.7.3.3 Planejamento de Respostas aos Riscos .....................................71

3.7.3.4 Monitoramento e Controle dos Riscos...........................................72

3.7.4 Exposição de um Projeto a Riscos .................................................73

3.8 Gerenciamento de Riscos em Portfolio de Projetos ...................................74

3.8.1 A Exposição a Riscos e as Fases de Gerenciamento de Portfolio .......77

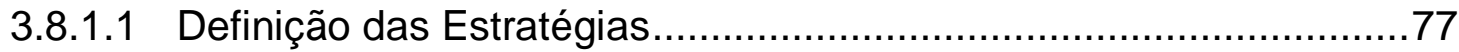

3.8.1.2 Avaliação Individual dos Projetos .................................................

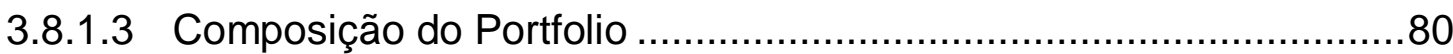

4 PROCEDIMENTO PARA DETERMINAÇÃO DO GRAU DE EXPOSIÇÃO A RISCOS DO PORTFOLIO DE PROJETOS .......................................................

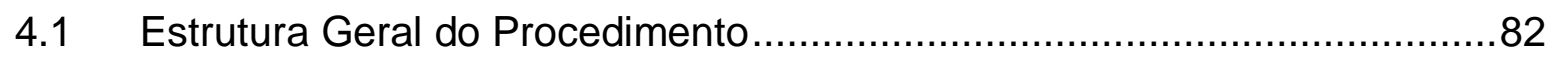

4.2 Identificação dos Objetivos Estratégicos do Portfolio de Projetos.................85

4.3 Identificação da Tolerância a Riscos para o Portfolio de Projetos ...............86

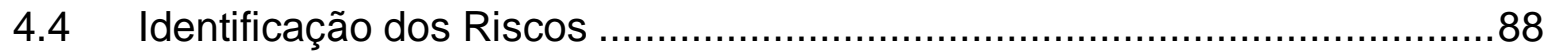

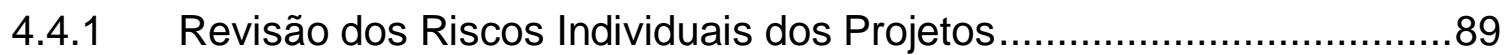

4.4.2 Identificação dos Riscos de Interdependências ..................................90

4.4.3 Identificação dos Riscos Abrangentes ..............................................

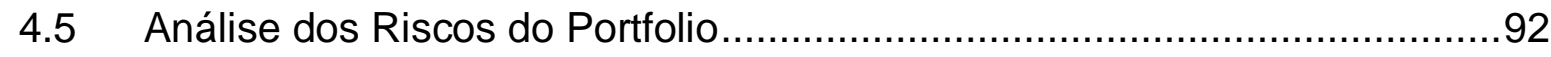

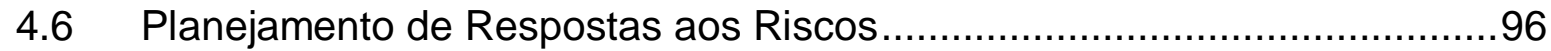

4.7 Determinação do Grau de Exposição de um Objetivo Estratégico...............97

4.8 Determinação do Grau de Exposição a Riscos do Portfolio.........................98

4.8.1 Monitoramento e Controle dos Riscos do Portfolio ................................99

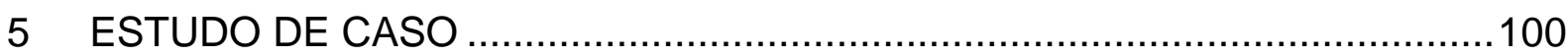

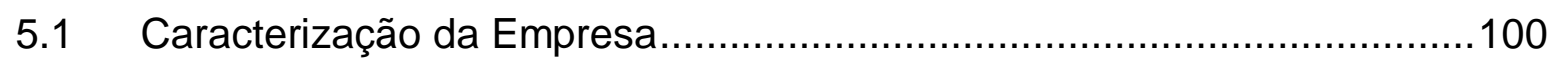

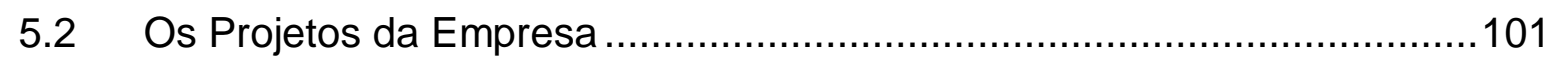

5.3 Portfolio de Projetos Externos ............................................................ 101

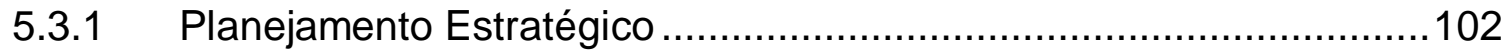

5.3.2 Gerenciamento de Projetos …................................................... 102

5.3.3 Gerenciamento de Portfolio de Projetos ............................................104

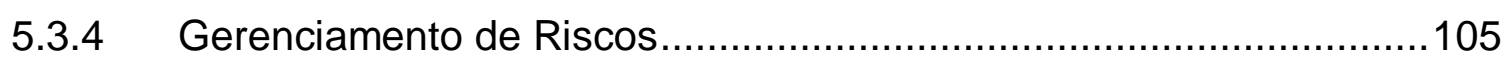

5.3.4.1 Avaliação de Riscos como Critério de Filtragem ............................107

5.3.4.2 Avaliação de Riscos como Critério de Monitoramento Individual ...108

5.4 Aplicação do Procedimento 


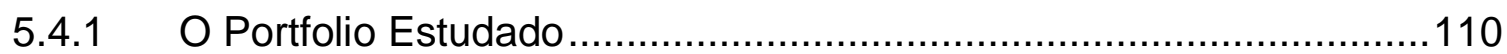

5.4.2 Objetivos Estratégicos do Portfolio ………….............................110

5.4.3 Tolerância a Riscos para o Portfolio …………………………...... 112

5.4.4 Identificação dos Riscos do Portfolio de Projetos .............................112

5.4.5 Análise dos Riscos do Portfolio de Projetos.....................................113

5.4.6 Planejamento de Respostas aos Riscos do Portfolio de Projetos......116

5.4.7 Exposições a Riscos dos Objetivos Estratégicos..............................117

5.4.8 Grau de Exposição a Riscos do Portfolio........................................118

5.4.9 Representatividade dos Projetos nos Desvios Esperados do Portfolio 119

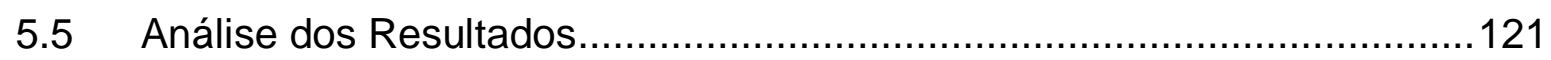

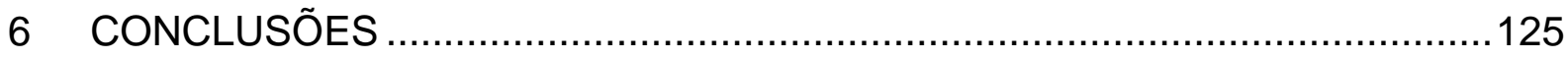

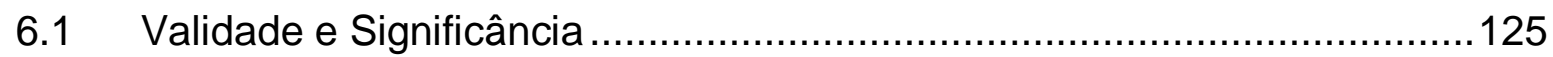

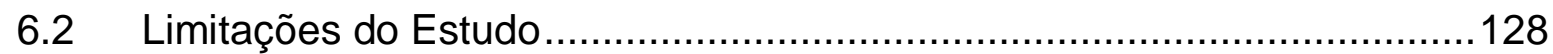

6.3 Recomendações para Futuros Trabalhos ...........................................129

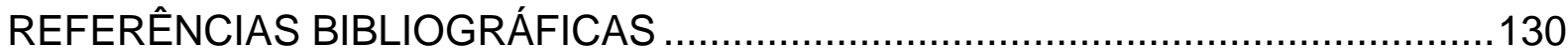

APÊNDICE A Questionário de Apoio à Pesquisa ............................................136

APÊNDICE B Roteiro de Aplicação do Procedimento ........................................138 


\section{INTRODUÇÃO}

\subsection{Considerações Iniciais}

O reconhecimento da importância da estruturação e aplicação dos conhecimentos, técnicas e ferramentas de gerenciamento de projetos ganhou corpo significativo nos últimos anos, nas organizações dos diversos setores.

De fato, esta disciplina, que há algumas décadas era pouco difundida, passou a ser alvo de crescente interesse. O reflexo deste interesse pode ser verificado na expansão de instituições dedicadas ao desenvolvimento deste conhecimento como a Association for Project Management (APM), a International Project Management Association (IPMA) e o Project Management Institute (PMI) e na valorização das certificações profissionais emitidas por estas instituições.

Kerzner (2006) reporta os benefícios da utilização das práticas de gerenciamento de projetos, comprovados por diversas organizações, como por exemplo: Hewlett Packard, 3M, Daimler e Departamento de Defesa dos Estados Unidos. Pesquisas recentes, como a de Thomas e Mullaly (2008), apontam que as organizações reconhecem que a utilização adequada das práticas de gerenciamento de projetos facilita a obtenção dos resultados esperados dos projetos, com os requisitos especificados, dentro das restrições de prazos e de recursos.

Paralelamente à intensificação no uso das práticas de gerenciamento de projetos, as atenções têm se voltado para o fato de que o gerenciamento dos projetos isoladamente não é suficiente para garantir o sucesso da organização, já que realizar os projetos de forma certa não significa necessariamente que os projetos certos estejam sendo realizados (PMI, 2006a).

Por um lado, o desenvolvimento tecnológico, as condições mais competitivas do mercado globalizado e a maior exigência dos clientes e consumidores têm levado as organizações à necessidade de realizar um número cada vez maior de projetos. Por outro lado, as limitações de recursos e prazos permitem que apenas uma parte destes projetos seja efetivamente executada, o que leva à necessidade de

selecionar os projetos que melhor atendam aos interesses da organização. É 
necessário, ainda, que os projetos selecionados estejam alinhados aos objetivos estratégicos e que os investimentos representados por eles sejam justificáveis em relação aos benefícios esperados (KERZNER, 2006).

Como destaca Levine (2005), a falta de integração entre os projetos e as operações do negócio pode levar ao desperdício de recursos, que são drenados para a realização de projetos que não contribuirão para o sucesso do negócio: projetos com riscos excessivos, projetos que tenham sido aprovados unicamente pela força política de seu patrocinador, que perderam a janela de oportunidade ou cujos resultados deixaram de ser importantes em virtude de modificações no cenário em que foram aprovados.

Para eliminar esta lacuna, uma nova disciplina vem sendo desenvolvida: o gerenciamento de portfolio de projetos, cujo foco é gerenciar o conjunto de projetos da empresa - o portfolio de projetos - através de práticas que integram os projetos ao negócio como um todo (LEVINE, 2005).

O gerenciamento do portfolio de projetos transcende o gerenciamento de múltiplos projetos, oferecendo uma abordagem estruturada para decidir qual conjunto de projetos deve ser realizado, levando em conta a capacidade de execução frente à disponibilidade de recursos humanos, materiais e financeiros, e alinhando este conjunto com a estratégica de negócio, conforme ilustra a Figura 1.1. Assim, o gerenciamento de portfolio de projetos tem o objetivo de maximizar a contribuição dos projetos para a prosperidade e o sucesso da organização (RAJEGOPAL; MCGUIN; WALLER, 2007); (LEVINE, 2005).

Figura 1.1 - Objetivo do gerenciamento de portfolio e do gerenciamento de projetos

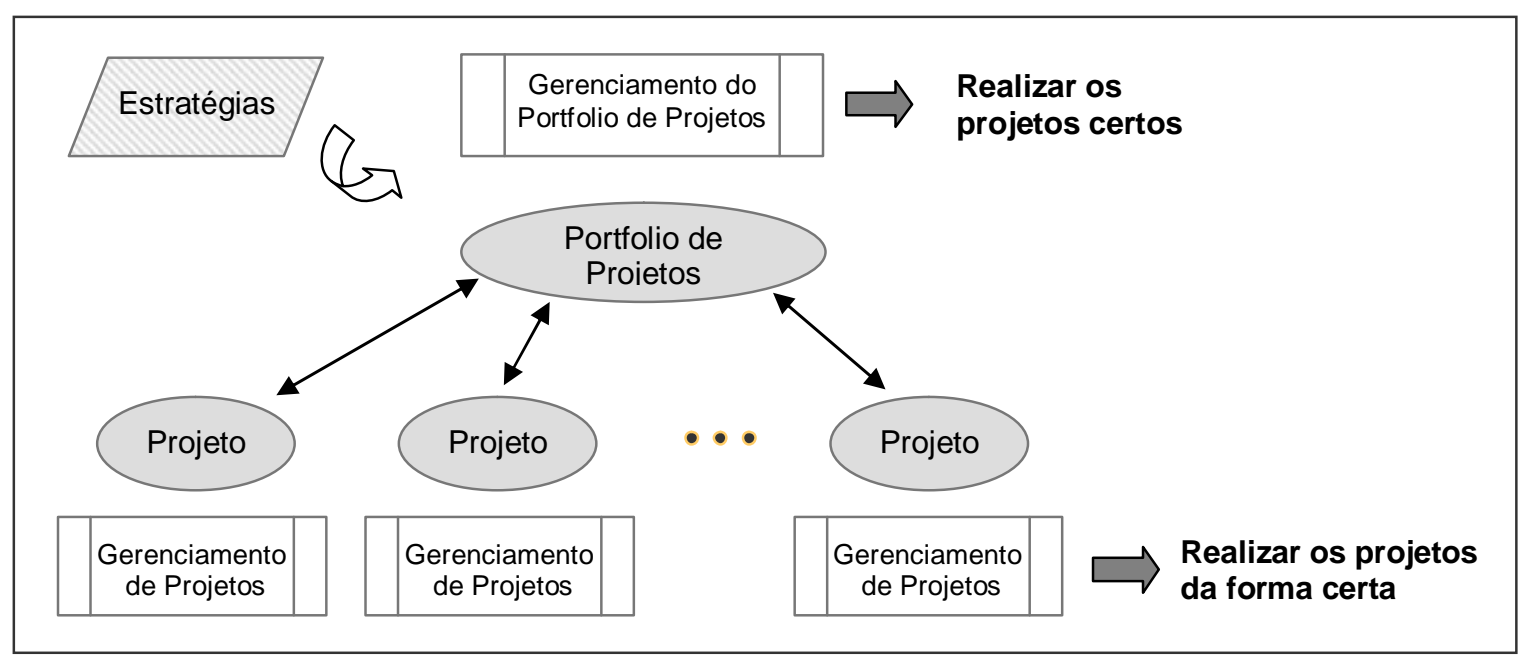

Fonte: Elaborado pela autora 
A adoção do gerenciamento de portfolio de projetos não substitui o gerenciamento de projetos. Ao contrário, suas práticas são complementares e precisam estar integradas. As informações detalhadas de cada projeto alimentam as decisões tomadas no âmbito do portfolio, que por sua vez realimentam as decisões no âmbito dos projetos. Ao avaliar cada projeto, é importante considerar, além de suas características individuais, também as influências do conjunto dos projetos que compõem o portfolio naquele momento. A Figura 1.2 ilustra esta interação.

Figura 1.2 - Interação entre gerenciamento de portfolio e gerenciamento de projetos

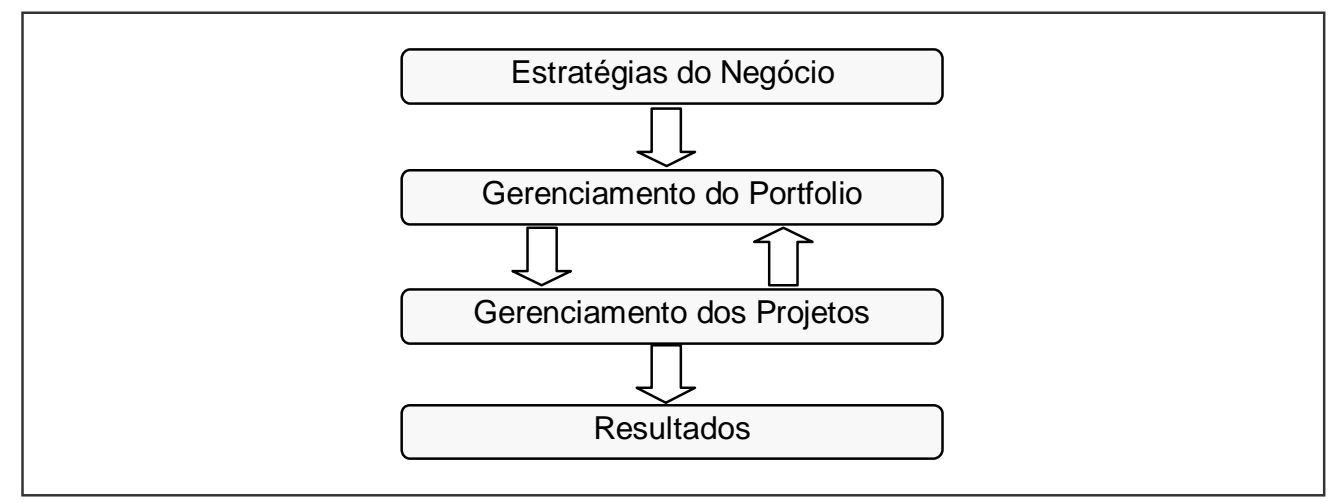

Fonte: Elaborado pela autora

\subsection{Contexto}

Levine (2005) afirma que o surgimento do gerenciamento de portfolio de projetos como um conjunto de práticas reconhecidas pode ser considerado o maior salto na tecnologia de gerenciamento de projetos desde o desenvolvimento do PERT nos anos 50 .

Pennypacker e Sepate (2005) reportam a importância crescente que as organizações têm atribuído às práticas de gerenciamento de portfolio de projetos e argumentam que, independentemente de seu porte, todas as organizações precisam selecionar e gerenciar seus investimentos e executar seus projetos de forma a obter o máximo benefício.

Entretanto, o gerenciamento de portfolio de projetos é ainda um assunto emergente. Pesquisas como as do Center for Business Practices (2003; 2005) apontam que ainda é pequena a porcentagem de organizações que gerenciam seus projetos 
efetivamente como um portfolio (ver Figura 1.3), e que, mesmo entre elas, mais de 90\% ainda se encontram nos estágios iniciais de maturidade.

Figura 1.3 - Organizações que gerenciam seus projetos como um portfolio

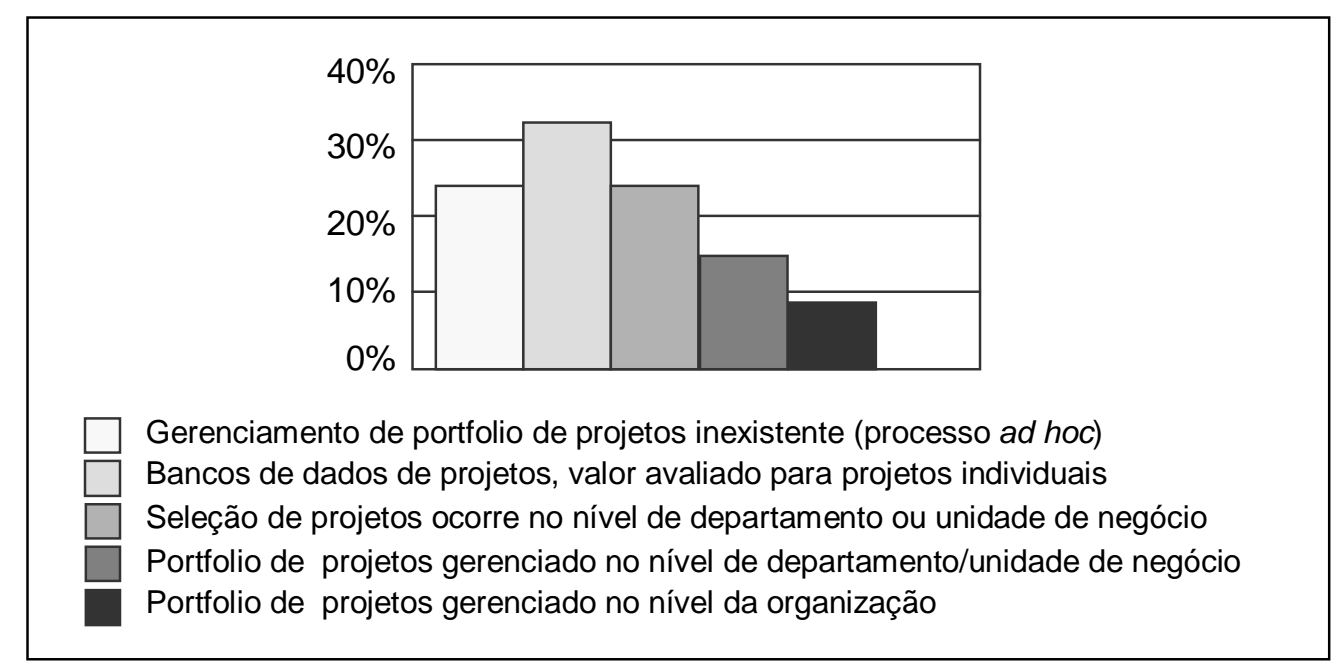

Fonte: Adaptado de Center for Business Practices (2003)

Mesmo na bibliografia de gerenciamento de projetos, a abordagem do gerenciamento de portfolio de projetos é relativamente recente. O próprio Project Management Institute lançou apenas em 2006 o The Standard for Portfolio Management, organizando este campo do conhecimento em processos que representam as melhores práticas reconhecidas atualmente no gerenciamento de portfolios de projetos.

Os efeitos da aplicação das técnicas de gerenciamento de portfolio de projetos, porém, já podem ser percebidos. Segundo o Center for Business Practices (2005), as organizações que utilizam o gerenciamento de portfolio de projetos têm obtido como maiores benefícios: o melhor alinhamento de seus projetos com as estratégias de negócio e a alocação de recursos nos projetos certos (com índices de 3,5 e 3,9 respectivamente, numa escala de 1 a 5 ).

A composição do portfolio é realizada de acordo com um conjunto de critérios de seleção e avaliação de projetos que permite identificar quais projetos trazem maior valor, benefícios e alinhamento com as estratégias definidas para um determinado horizonte de tempo. Alguns exemplos destes critérios de seleção são: retorno sobre o investimento, satisfação dos clientes e aumento da produtividade. 
O portfolio é dinâmico, já que novos projetos surgem, projetos se encerram, prioridades mudam e até mesmo as estratégias podem mudar, em ciclos definidos pela alta administração ou ainda pelas forças de mercado. O desempenho de cada projeto em andamento e o desempenho do portfolio como um todo são medidos ciclicamente, utilizando um conjunto de indicadores que, tanto podem apontar para a manutenção dos projetos atuais, como levar a mudanças de prioridades ou mesmo a alterações na composição do portfolio. Os indicadores utilizados para estas avaliações podem incluir, por exemplo: margem, receita e probabilidade de sucesso.

Os critérios e indicadores bem como as técnicas de seleção e medição de desempenho utilizados no gerenciamento do portfolio são escolhidos pela organização de acordo com a tipologia dos projetos, seu foco de negócio e suas estratégias atuais e, portanto, podem variar de organização para organização.

Um dos principais critérios a ser considerado no gerenciamento do portfolio de projetos é o grau de exposição a riscos de cada projeto e do portfolio como um todo, em cada momento de avaliação. Levine (2005) ressalta a necessidade de se considerar os riscos como parte dos processos de avaliação e seleção dos projetos para compor o portfolio de projetos, e também como parte dos processos de medição de desempenho que conduzirão a possíveis alterações do portfolio. Williams e Parr (2004) apontam o gerenciamento dos riscos do portfolio como um componente central do gerenciamento do portfolio de projetos. Para McFarlan (2001), a seleção dos projetos e o gerenciamento do portfolio de projetos devem utilizar uma abordagem baseada em riscos. Archer e Ghasemzadeh (1999) afirmam que a exposição a riscos é muito importante ao se considerar a inclusão de um projeto no portfolio e, ainda, que o portfolio deve ser balanceado para evitar muitos projetos com alto grau de risco, o que pode comprometer o futuro da organização.

Risco é um evento incerto ou um conjunto de circunstâncias que, se ocorrerem, terão impacto no atendimento de objetivos desejados (WIILIAMS; PARR, 2004).

Alguns autores como Kerzner (2003) e Pritchard (2001) associam o termo risco a efeitos negativos. Outros autores como Cooper e Chapman (1987), Williams e Parr (2004) e PMI (2004) ressaltam que riscos podem, também, ter impactos positivos no atendimento dos objetivos desejados. 
No contexto deste trabalho, o termo risco é empregado para designar um evento incerto que, se ocorrer, causa um efeito negativo no atendimento dos objetivos desejados, enquanto o termo oportunidade é empregado para designar um evento incerto que, se ocorrer, causa um efeito positivo no atendimento destes objetivos.

A exposição a um risco, também chamada de perda esperada, é a perda média associada ao risco ((KERZNER, 2003); (SMITH; MERRITT, 2002)), ou a provisão de perda para um risco (WARD, 2000).

Como destacam Rajegopal, Mcguin e Waller (2007), a composição adequada do portfolio deve levar a um conjunto de projetos com grau de exposição a riscos diferentes, respeitando o grau de risco que a organização se dispõe a correr e os demais critérios de decisão eleitos.

A Figura 1.4 ilustra como a exposição a riscos pode ser considerada em conjunto com os demais critérios de seleção e avaliação no gerenciamento do portfolio de projetos.

Figura 1.4-Composição do portfolio de projetos

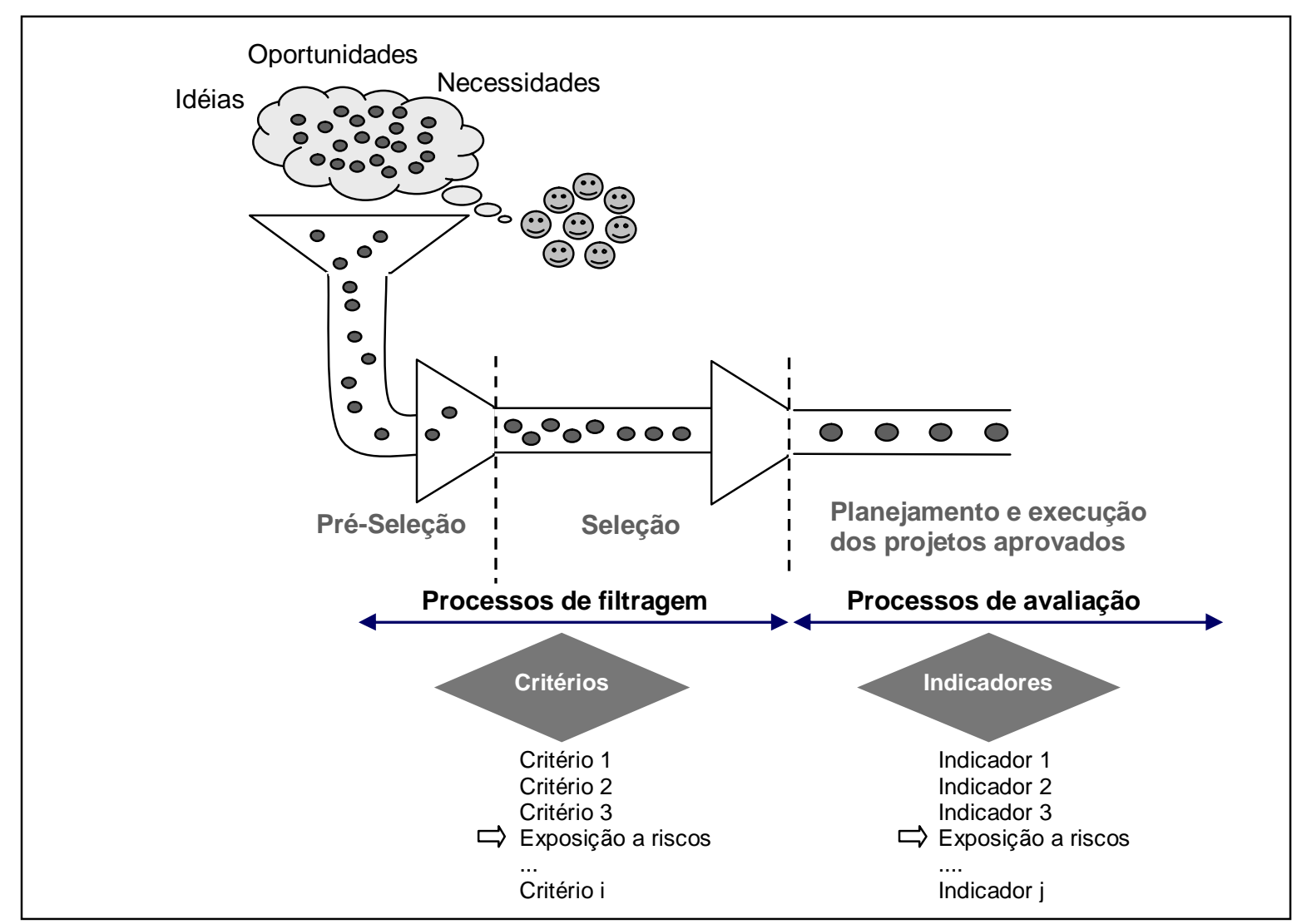

Fonte: Adaptado de Wideman (2004) 
A adoção do grau de exposição a riscos como um critério de decisão no gerenciamento de portfolio tem como pré-requisito a utilização de meios que permitam a sua estimativa. Esta estimativa é direcionada pela sensibilidade e pela tolerância a riscos da organização e deve considerar não só os riscos individuais de cada projeto do portfolio, como também os inter-relacionamentos entre os riscos dos diversos projetos e ainda os riscos surgidos pela própria composição do portfolio.

No âmbito dos projetos, os riscos estão associados a desvios no atendimento dos objetivos do projeto, o que torna o gerenciamento de riscos um aspecto capital no gerenciamento de projetos. Gray e Larson (2003) ressaltam que todos os esforços de gestão de projetos podem ser direcionados de acordo com os riscos que podem levar parte do projeto ou todo o projeto a não ser bem sucedido. Já no âmbito do portfolio, os riscos estão associados a desvios no atendimento dos objetivos do portfolio.

Existem metodologias para a identificação, análise e tratamento dos riscos de um projeto isoladamente. No entanto, estas tarefas tornam-se mais complexas ao se considerar os riscos dos vários projetos que compõem um portfolio. No portfolio de projetos podem ocorrer interações, convergências e propagações dos riscos de cada projeto em relação aos demais projetos do portfolio, tornando necessária uma abordagem integrada e aumentando a complexidade do gerenciamento de riscos. A Figura 1.5, a seguir, sumariza este relacionamento.

A pesquisa bibliográfica realizada no presente trabalho revelou também que, embora haja unanimidade no reconhecimento da importância do gerenciamento de riscos em portfolios de projetos, encontra-se, porém, muito mais destaque para a importância de realizá-lo do que propriamente para as técnicas de aplicação (LEVINE, 2005); (KERZNER, 2006); (RAD; LEVIN, 2006); (RAJEGOPAL; MCGUIN; WALLER, 2007); (COOPER; EDGETT; KLEINSCHMIDT, 2001).

Confirmando esta lacuna, o Federal Cio Council (2002) e Hillson (2006) sugerem o gerenciamento de riscos em portfolio de projetos como um tema a ser desenvolvido. 
Figura 1.5 - Exposição a riscos: projeto x portfolio

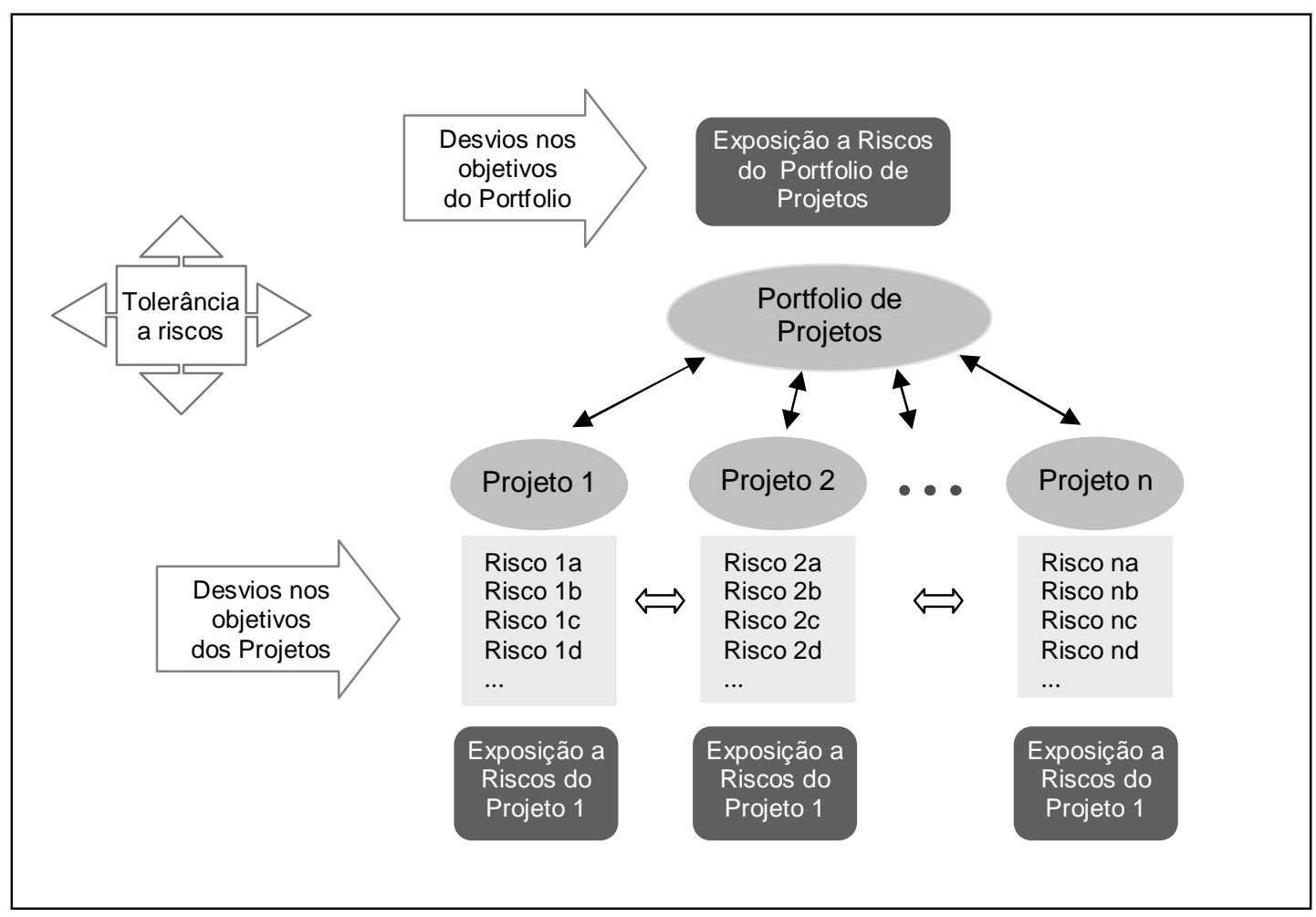

Fonte: Elaborado pela autora

Mesmo no âmbito dos projetos, apesar do reconhecimento de sua importância, as práticas de gerenciamento de riscos nem sempre são adequadamente aplicadas e, algumas vezes, nem sequer são aplicadas (CHARETTE, 2006). A falta do gerenciamento de riscos conduz à necessidade de ações reativas para minimizar as conseqüências de eventos de risco não previstos ou não tratados, muitas vezes prejudicando outros aspectos do projeto.

Alguns dos motivos apontados para esta situação decorrem do fato de que, em geral, os gerentes de projeto e o time do projeto têm uma visão excessivamente otimista, acreditando que serão capazes de enfrentar qualquer problema. Existe uma tendência sociológica a enfatizar a necessidade de atitudes positivas, encarando problemas como oportunidades, riscos como desafios a serem superados e suprimindo socialmente os pensamentos negativos. Neste contexto, destacar os riscos muitas vezes é visto como uma atitude negativa e não contributiva (ROYER, 2000).

Royer (2000) faz uma análise interessante sobre o ambiente do projeto na fase de planejamento, destacando que, embora este seja o momento mais propício para a avaliação de riscos, isto frequentemente não ocorre devido às seguintes razões: 
- a quantificação de riscos pode impedir a obtenção de recursos para o projeto;

- a organização não quer despender tempo e energia nessa tarefa;

- a organização, naquele momento, não acredita em riscos e

- a organização quer um planejamento simples.

Um outro aspecto que influencia o gerenciamento de riscos é que, na maior parte dos projetos, dificilmente se dispõe das informações necessárias para uma análise muito detalhada, bem como posteriormente, dos recursos necessários ao tratamento adequado dos riscos (CHARETTE, 2006).

Além disso, muitas das organizações, não dispõem, ainda, do conhecimento das técnicas e ferramentas de gerenciamento de riscos, e especialmente das técnicas matemáticas necessárias para a análise quantitativa de riscos (HILLSON, 2007).

\subsection{Questões de Pesquisa}

Em face do contexto de necessidades e dificuldades expostas, foram selecionadas as seguintes questões chave para orientar o trabalho de pesquisa:

- Como determinar o grau de exposição a riscos de um portfolio de projetos?

- Que mecanismos poderiam ser utilizados para considerar simultaneamente os riscos individuais e as inter-relações entre os riscos de cada projeto na determinação do grau de exposição a riscos do portfolio?

\subsection{Objetivo}

Com base nas questões acima propostas, este trabalho tem por objetivos:

- propor um procedimento estruturado que permita avaliar o grau de exposição a riscos de um portfolio de projetos, considerando os inter-relacionamentos entre os riscos dos projetos individuais e outros riscos decorrentes da composição do portfolio e

- testar a aplicabilidade do procedimento proposto através de um estudo de caso. 
O trabalho está fundamentado na combinação de três aspectos complementares do gerenciamento de projetos:

- Gerenciamento de portfolio de projetos

- Gerenciamento de riscos em projetos

- Gerenciamento de riscos em portfolio de projetos

\subsection{Justificativa}

As dificuldades identificadas para a aplicação do gerenciamento de riscos em projetos, e que são ampliadas quando se trata de portfolio de projetos, conduziram o foco deste trabalho para a utilização das técnicas mais simples de análise de riscos, mesclando aspectos qualitativos e quantitativos, com o intuito de produzir uma sistemática de fácil implementação.

Ainda que não leve à obtenção de valores absolutos e exatos, a análise qualitativa permite classificar os riscos, estabelecer prioridades e direcionar esforços para o tratamento dos riscos identificados, de forma rápida e com baixo custo (PMI, 2004). De acordo com Rhoads ${ }^{1}$ (2006), se o gerenciamento de riscos não for bem sucedido, o gerenciamento de portfolio de projetos também não será. $E$ neste sentido, a adoção de processos consistentes torna-se mais importante do que o rigor matemático.

O interesse por este tema foi despertado pelo artigo publicado por Royer (2000) que sugere uma abordagem interessante para a avaliação de riscos em projetos, baseada numa análise qualitativa, e que produz, também, um índice para representar a exposição a riscos de um projeto.

Este interesse foi reforçado pelo artigo de Hillson (2007b), que chama a atenção para o fato de que, comumente, as referências de gerenciamento de riscos focam os riscos individuais dos projetos e poucas abordam a avaliação da exposição a riscos do projeto como um todo, afirmação que pode também ser estendida para a exposição a riscos do portfolio.

\footnotetext{
${ }^{1}$ Rebeca Rhoads é CIO da empresa americana Raytheon
} 
Os fatores que contribuíram para o interesse no desenvolvimento do tema deste trabalho são, em síntese:

- o gerenciamento de portfolio de projetos é um assunto emergente e de crescente interesse;

- o gerenciamento de riscos integrado, no âmbito do portfolio de projetos é um tema pouco explorado na literatura científica;

- nem sempre se dispõe de cultura, recursos, informações e conhecimento suficientes para um tratamento quantitativo de riscos em projetos e

- a adoção de uma metodologia simples e objetiva pode viabilizar a análise de riscos no gerenciamento de portfolio de projetos.

\subsection{Organização do Trabalho}

O primeiro capítulo deste trabalho apresenta a contextualização da pesquisa, destacando a importância do tema, definindo os objetivos do trabalho e as justificativas para sua realização.

O segundo capítulo apresenta os procedimentos metodológicos que orientaram a pesquisa.

O terceiro capítulo contém a revisão da bibliografia, conceituando o gerenciamento de portfolio e sua relação com a estratégia das organizações e os principais aspectos do gerenciamento de riscos.

O quarto capítulo descreve o procedimento proposto para a avaliação do grau de exposição a risco em portfolio de projetos.

O quinto capítulo apresenta o caso eleito para o estudo e os resultados da pesquisa de campo.

O sexto capítulo contém as conclusões do trabalho, as contribuições e as limitações da pesquisa, com recomendações e sugestões de continuidade. 


\section{METODOLOGIA DA PESQUISA}

\subsection{Estrutura da Pesquisa}

A estrutura da presente pesquisa é constituída de cinco etapas principais:

- definições iniciais: que abrangem a identificação e proposição do tema do estudo, dos objetivos, justificativas, elaboração das questões-chave, além da escolha da classificação, método e técnicas a serem utilizadas no trabalho de campo;

- pesquisa bibliográfica: com o objetivo de buscar na literatura o referencial teórico de sustentação para o problema em estudo;

- elaboração do procedimento para a determinação do grau de exposição a riscos de portfolio de projetos: baseado nas idéias dos vários autores sobre o tema, com foco para a facilidade de aplicação;

- pesquisa de campo: com o objetivo de validar o procedimento descrito, testandoo numa organização, bem como refiná-lo, estendendo interativamente parte da etapa de pesquisa bibliográfica e

- análise e apresentação dos resultados: com a apresentação das conclusões a respeito da validade e significância do procedimento proposto, bem como das deficiências e limitações da pesquisa, apresentando, ainda, recomendações de aprimoramento e sugestões para continuidade de trabalhos complementares que podem contribuir para o desenvolvimento do tema.

\subsection{Problemas Explorados na Pesquisa}

Para Gil (1988) a pesquisa é necessária quando não há informações disponíveis suficientes para responder a um determinado problema, ou quando a informação disponível encontra-se não organizada e não pode ser adequadamente relacionada ao problema. Este autor define pesquisa como o procedimento racional e sistemático cujo objetivo é proporcionar respostas a problemas propostos. 
Ainda segundo Gil (1988), toda pesquisa se inicia com algum tipo de problema ou indagação ao qual um tratamento científico pode ser aplicado, devendo ser passível de verificação empírica, com variáveis suscetíveis de observação ou manipulação.

A dissertação de mestrado é um estudo teórico de natureza reflexiva, que consiste na ordenação de idéias sobre determinado tema, ao qual é aplicada uma teoria já existente para analisar um problema (LAKATOS; MARCONI, 1992).

A formulação clara de problemas científicos nem sempre é fácil. Para auxiliar nesta tarefa, Gil (1988) sugere que o problema seja formulado como pergunta, que seja claro e preciso, que seja empírico, que seja passível de solução e que seja delimitado a uma dimensão viável.

Assim, o problema a ser estudado no contexto deste trabalho foi sintetizado pelas seguintes questões-chave:

Tabela 2-1 - Problemas explorados na pesquisa

Questões Chave

Como determinar o grau de exposição a riscos de um portfolio de projetos?

Que mecanismos poderiam ser utilizados para considerar simultaneamente os riscos individuais e as inter-relações entre os riscos de cada projeto na determinação do grau de exposição a riscos do portfolio?

Fonte: Elaborado pela autora

\subsection{Classificação da Pesquisa}

Tanto Gil (1988) quanto Blaxter, Hughes e Tight (1996) destacam que é importante classificar a pesquisa para que se possa planejar adequadamente os próximos passos, aplicando o melhor tratamento conceitual, a abordagem ou método a ser seguido e os procedimentos técnicos adequados.

Gil (1988) classifica as pesquisas em três grupos: 
- pesquisas exploratórias: que têm como objetivo proporcionar maior familiaridade com o problema e o aprimoramento de idéias;

- pesquisas descritivas: que têm como objetivo descrever as características de determinado fenômeno e

- pesquisas explicativas: que têm como objetivo identificar os fatores que determinam ou que contribuem para a ocorrência dos fenômenos.

Numa outra abordagem Blaxter, Hughes e Tight (1996) classificam as pesquisas em duas dimensões. Numa primeira dimensão, as autoras dividem as pesquisas em:

- pesquisas quantitativas: que focam a coleta e a análise de dados de maneira numérica e

- pesquisas qualitativas: que focam análises não estritamente numéricas, explorando mais detalhes, normalmente com um universo menor de amostragem ou exemplos.

Numa segunda dimensão, Blaxter, Hughes e Tight (1996) classificam as pesquisas como:

- pesquisas de trabalho de mesa: consistem de atividades cuja realização não demanda a ida a campo e

- pesquisas de trabalho de campo: envolvem informações que requerem que o pesquisador vá a campo.

Conforme as definições descritas, a pesquisa realizada no presente trabalho pode ser classificada como uma pesquisa exploratória, qualitativa, com trabalho de campo, uma vez que busca o aprimoramento de idéias, foca análises não estritamente numéricas e demanda a ida a campo para validação.

Gil (1988) lembra ainda que, embora a estruturação das pesquisas exploratórias seja bastante flexível, na maioria dos casos estas pesquisas envolvem levantamento bibliográfico, entrevistas com pessoas que tiveram experiências práticas com o problema pesquisado e análise de exemplos que estimulem a compreensão.

Nakano e Fleury (1996) ressaltam que, comparada à pesquisa quantitativa, a pesquisa qualitativa apresenta maior ênfase na interpretação do entrevistado, maior importância do contexto da organização pesquisada e quadro teórico e hipóteses menos estruturadas. Segundo Bryman (1995), na pesquisa qualitativa o ambiente é 
a fonte de informações, múltiplas fontes de dados são utilizadas, o pesquisador é o instrumento fundamental e tem proximidade com o fenômeno a ser estudado.

\subsection{Método Utilizado na Pesquisa}

Marconi e Lakatos (2003) definem método como "o conjunto de atividades sistemáticas e racionais que, com maior segurança e economia, permite alcançar o objetivo - conhecimentos válidos e verdadeiros -, traçando o caminho a ser seguido, detectando erros e auxiliando as decisões do cientista".

Blaxter, Hughes e Tight (1996) sugerem quatro métodos ou abordagens para a realização de uma pesquisa: experimentos, levantamentos, estudo de casos e pesquisa-ação.

De forma bastante semelhante, Gil (1988) descreve as seguintes possibilidades para - procedimento a ser adotado para a coleta de dados de uma pesquisa: experimento, levantamento, estudo de caso, pesquisa-ação e pesquisa participante, além das fontes bibliográficas e documentais.

Yin (2004) elenca as seguintes estratégias de pesquisa: estudo de caso, experimentos, levantamentos, pesquisas históricas e análise de informações em arquivos, e assinala que a definição da estratégia de pesquisa depende de três condições:

- o tipo de questão de pesquisa proposto;

- a extensão de controle que o pesquisador tem sobre eventos comportamentais e

- o enfoque de acontecimentos históricos em oposição a acontecimentos contemporâneos.

A Tabela 2-2 relaciona as condições citadas com as estratégias de pesquisa.

Considerando as características descritas acima, o estudo de casos foi escolhido como o método mais adequado para os objetivos deste trabalho.

Yin (2004) considera que o estudo de caso é uma investigação empírica de um fenômeno contemporâneo, dentro do contexto da vida real, especialmente quando os limites entre o fenômeno e o contexto não são claramente definidos. O autor 
complementa, ainda, que o estudo de caso trata de mais variáveis de interesse do que pontos de dados, baseia-se em várias fontes de evidência e beneficia-se do desenvolvimento prévio de proposições teóricas para conduzir a coleta e análise de dados.

Tabela 2-2 - Situações relevantes para diferentes estratégias de pesquisa

\begin{tabular}{llll}
\hline Estratégia & $\begin{array}{l}\text { Forma da questão } \\
\text { de pesquisa }\end{array}$ & $\begin{array}{l}\text { Exige controle } \\
\text { sobre eventos } \\
\text { comportamentais? }\end{array}$ & $\begin{array}{l}\text { Focaliza } \\
\text { acontecimentos } \\
\text { contemporâneos? }\end{array}$ \\
\hline Experimento & Como, por quê & Sim & Sim \\
\hline Levantamento & $\begin{array}{l}\text { Quem, o quê, onde, } \\
\text { quantos, quanto }\end{array}$ & Não & Sim \\
\hline $\begin{array}{l}\text { Análise de } \\
\text { arquivos }\end{array}$ & $\begin{array}{l}\text { Quem, o quê, onde, } \\
\text { quantos, quanto }\end{array}$ & Não & Sim/Não \\
\hline $\begin{array}{l}\text { Pesquisa } \\
\text { histórica }\end{array}$ & Como, por quê & Não & Não \\
\hline Estudo de caso & Como, por quê & Não & Sim \\
\hline
\end{tabular}

Fonte: Yin (2004)

Ainda segundo Yin (2004), o estudo de caso pode ser aplicado nas pesquisas de avaliação para:

- explicar vínculos causais em intervenções da vida real que são complexas para outras estratégias;

- descrever uma intervenção e o contexto na vida real em que ela ocorre;

- ilustrar certos tópicos dentro de uma avaliação de modo descritivo;

- explorar situações nas quais a intervenção avaliada não apresenta um conjunto simples e claro de resultados e

- ser uma meta-avaliação, ou seja, o estudo de um estudo de caso.

\subsection{A Escolha da Organização para o Estudo de Caso}

Para atender o objetivo do trabalho - testar o procedimento para a determinação do grau de exposição a riscos de um portfolio de projetos - foi necessário encontrar uma organização onde o estudo de caso pudesse ser conduzido. 
A escolha da organização foi guiada pelo atendimento das seguintes características, ligadas aos pressupostos adotados no procedimento proposto neste trabalho:

- ter um plano estratégico com estratégias claras e mensuráveis;

- contar com pelo menos um portfolio de projetos em andamento, ligado às estratégias definidas no planejamento estratégico;

- utilizar técnicas de gerenciamento de portfolio de projetos;

- utilizar técnicas de gerenciamento de projetos, incluindo o gerenciamento dos riscos dos projetos, mesmo que de forma simplificada e

- ter interesse no tema e disponibilidade de informações para a condução da pesquisa.

A natureza do tema da pesquisa - ligado a aspectos estratégicos - limitou as opções de escolha a empresas com as quais a autora já tinha um relacionamento de confiança profissional, o que proporcionaria maior facilidade de interfaceamento com as pessoas que efetivamente detinham as informações necessárias para a pesquisa.

Cinco empresas foram pré-selecionadas.

Com cada uma das empresas pré-selecionadas foi realizada uma reunião inicial com gestores de portfolio para explicar os objetivos do trabalho e fazer o convite para participar da pesquisa.

As duas primeiras empresas consultadas demonstraram grande interesse em participar do estudo, porém quando submetida à aprovação de níveis superiores, a decisão, em ambos os casos, resultou em negativa de participação, justificada como decorrente da indisponibilidade de recursos humanos para acompanhar e fornecer as informações necessárias para a condução da pesquisa.

Em outras duas empresas a pesquisa foi iniciada, mas não pode ser completada. As interrupções foram motivadas pela indisponibilidade de tempo das pessoas designadas para acompanhar o trabalho e pela impossibilidade de acesso a informações necessárias consideradas confidenciais.

Somente na quinta empresa o trabalho pode ser completamente desenvolvido. 


\subsection{Protocolo e Procedimentos Considerados na Pesquisa}

Para Yin (2004) é muito importante que se estabeleça um protocolo para o desenvolvimento do estudo de casos, que servirá ao pesquisador para manter o foco do estudo, com o objetivo de estabelecer a relação entre o pesquisador e o ambiente da pesquisa, além de aumentar a confiabilidade da pesquisa. O protocolo deve conter os procedimentos a serem observados no desenvolvimento da pesquisa, além do próprio instrumento de coleta de dados. Yin (2004) salienta que ao elaborar o protocolo, o pesquisador pode antecipar muitos dos possíveis problemas com que pode se deparar mais tarde.

O estudo de caso caracteriza-se por sua grande flexibilidade, o que dificulta o estabelecimento de um roteiro rígido válido para qualquer pesquisa. Segundo Gil (1988), entretanto, na maioria dos estudos de casos é possível distinguir quatro fases: determinação da unidade-caso, coleta de dados, análise e interpretação dos dados e redação do relatório.

Para a coleta de dados na realização de uma pesquisa, Blaxter, Hughes e Tight (1996) sugerem as seguintes técnicas: revisão documental, entrevistas, observação e questionários. A coleta de dados deve ser sustentada pelo que Yin (2004) chama de fontes de evidências, tais como: documentação, registros em arquivos, entrevistas, observação direta, observação participante e artefatos físicos.

Nesta pesquisa foram utilizadas todas as técnicas de coleta de dados sugeridas por Blaxter, Hughes e Tight (1996).

Para a condução dos trabalhos era importante que os entrevistados tivessem uma visão estratégica da organização - preferencialmente participassem do planejamento estratégico - e conhecessem bem os processos de gerenciamento de projetos e de portfolios praticados na organização.

As informações necessárias para a condução do estudo de caso desenvolvido neste trabalho foram obtidas junto ao gestor do portfolio de projetos da empresa escolhida, que exerce cargo de diretor, com o apoio de gerentes de projeto, através de entrevistas semi-estruturadas, apoiadas por roteiro em forma de questionário. 
Em função das compreensíveis restrições de agenda dos entrevistados, devidas às funções que exercem, foram necessárias diversas entrevistas, em diferentes datas.

As entrevistas visaram atender os seguintes passos:

- obtenção das informações atualizadas de caracterização da empresa: negócio, mercado, histórico, volume de faturamento e funcionários;

- levantamento das informações sobre as características dos projetos e dos portfolios, de como são gerenciados e seu relacionamento com o planejamento estratégico, para garantir a viabilidade e delimitar a abrangência da aplicação do procedimento;

- levantamento dos dados para a aplicação do procedimento e

- apresentação e validação dos resultados.

O questionário utilizado nas entrevistas encontra-se no APÊNDICE A deste documento. No APÊNDICE $B$ encontra-se o roteiro que guiou a aplicação do procedimento proposto neste trabalho sobre os dados obtidos nos levantamentos.

Como parte da garantia de confidencialidade, a identificação da empresa pesquisada foi preservada e, neste sentido, nas descrições do estudo de caso, a empresa foi denominada apenas como EMPRESA e os projetos foram identificados com nomes genéricos. Além disso, os valores apresentados foram tratados, mantendo, porém, a proporcionalidade com os valores reais, o que garante a consistência dos resultados apresentados. 


\section{REVISÃO BIBLIOGRÁFICA}

\subsection{Operações, Projetos, Programas e Portfolios}

Em muitas das áreas de aplicação, as fronteiras entre projetos e operações nem sempre ficam claras, causando por vezes desgastes que poderiam ser evitados com uma definição mais precisa da extensão do projeto, desde as fases iniciais.

Em geral, as empresas são sustentadas por suas operações que, como define o Project Management Institute - PMI (2004) são execuções contínuas de atividades que produzem o mesmo produto ou fornecem um serviço repetitivo.

As operações visam manter o negócio da empresa e, através de seu gerenciamento, busca-se alcançar a máxima lucratividade do negócio e garantir a sua continuidade. Bertrand e Fransoo (2002) definem gerenciamento das operações como o processo de desenhar, planejar, controlar e executar as operações em indústrias de manufatura e serviços.

Os projetos diferem das operações. Projeto é um esforço temporário - com início e fim definidos -, empreendido para criar um produto, serviço ou resultado exclusivo, com características ou atributos que o diferem de outros produtos existentes. $O$ objetivo do projeto é produzir o produto do projeto e, então, se encerrar (PMI, 2004).

Uma característica importante do projeto é que sua elaboração geralmente ocorre de forma progressiva, já que nem todas as informações necessárias podem estar disponíveis logo no início. Isto quer dizer que seu planejamento é detalhado continuamente à medida em que mais informações vão se tornando disponíveis.

Os projetos tipicamente requerem a combinação do trabalho de vários especialistas e a forma como os projetos são conduzidos se reflete diretamente em seu grau de êxito. Neste sentido, é importante a utilização de processos de gerenciamento de projetos que, como destaca Kerzner (2003), definem como as funções de planejamento, organização, motivação, direção e controle serão conduzidas em conformidade com os recursos do projeto. 
Por outro lado, há situações em que, para se alcançar um objetivo complexo, é necessário desenvolver um grupo de projetos relacionados entre si, cujo conjunto de objetivos individuais está interligado, compondo o objetivo final. Neste caso, o objetivo final só é passível de ser atingido se este conjunto de projetos for gerenciado de forma coordenada. Este esforço é chamado de programa (PMI, 2006b).

Gerenciar múltiplos projetos no contexto de programa requer cuidados suplementares ao gerenciamento dos projetos isoladamente, uma vez que a interdependência entre os projetos gera uma preocupação adicional com a integração entre eles e a necessidade de otimização dos efeitos conjuntos das tomadas de decisão. Desta forma, o gerenciamento de programas adiciona outros temas ao gerenciamento de projetos, tais como gerenciamento dos benefícios, gerenciamento diferenciado dos envolvidos no programa, governança do programa, alinhamento estratégico ao negócio, otimização e nivelamento de recursos e compatibilização dos diversos fluxos de caixa.

Por sua vez, um conjunto de projetos e programas em andamento na organização num determinado momento é chamado de portfolio de projetos.

O PMI (2004) define portfolio como um conjunto de projetos ou programas, não necessariamente interdependentes, agrupados para facilitar o gerenciamento e atingir os objetivos estratégicos do negócio. A Figura 3.1 ilustra o relacionamento entre projetos, programas e portfolios.

Figura 3.1 - Relacionamentos entre projetos, programas e portfolios

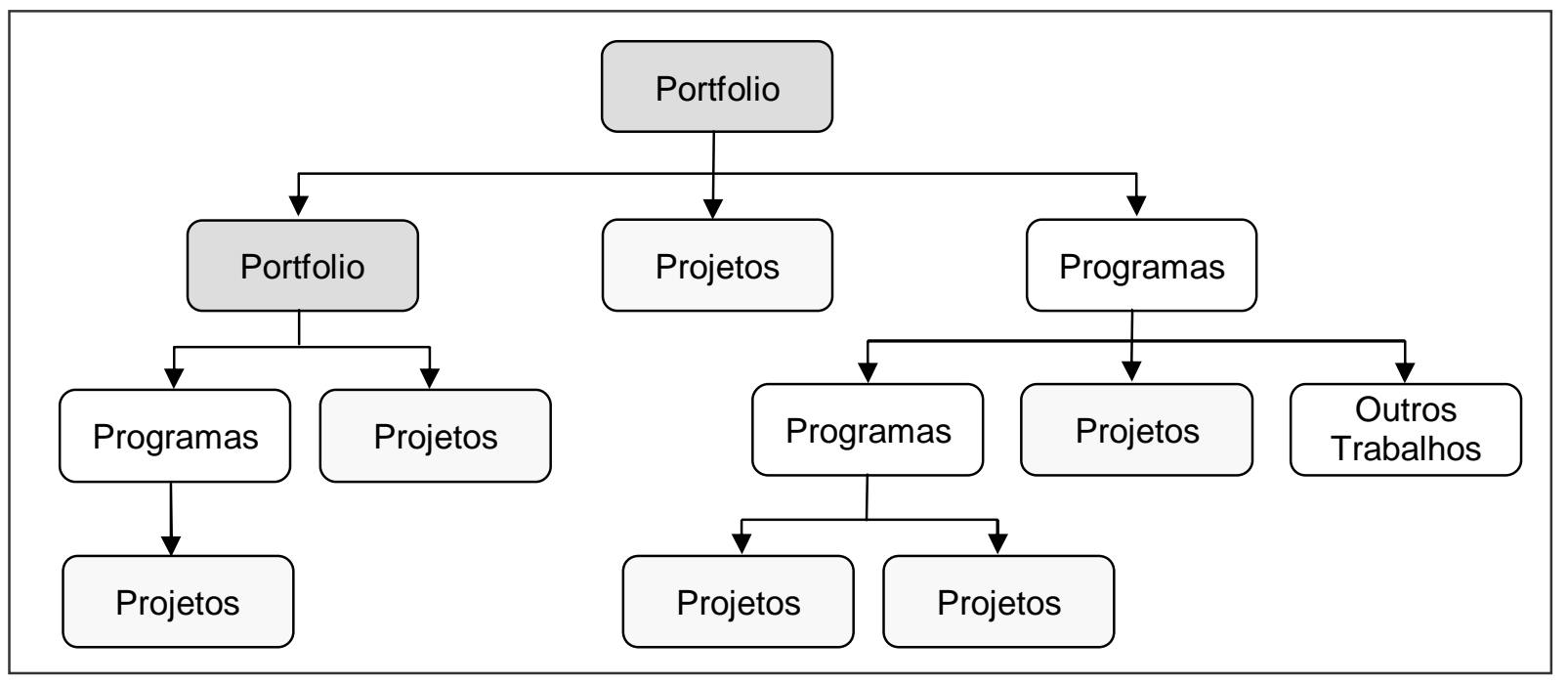

Fonte: Project Management Institute (2006a) 


\subsection{Planejamento Estratégico e Portfolio de Projetos}

O termo estratégia é amplamente utilizado, embora não tenha uma definição única. Segundo Gray e Larson (2003), a estratégia descreve como a organização pretende competir com os recursos disponíveis no ambiente atual e no ambiente percebido para o futuro. Porter (1986) define estratégia competitiva como a combinação dos fins (metas) que a empresa busca e dos meios (políticas) pelas quais ela está buscando chegar lá. Tregoe e Zimmerman (1980) afirmam que estratégia é o que norteia as escolhas que determinam a natureza e a direção de uma organização. No âmbito deste trabalho, o termo estratégia é utilizado como os meios para atingir os objetivos da organização.

Segundo Gray e Larson (2003), o planejamento estratégico é o processo de avaliar "o que somos" e decidir e implementar "o que queremos ser e como chegaremos lá". $\mathrm{O}$ conjunto de estratégias a serem implementadas tem o objetivo de manter e aumentar o valor das operações e, consequentemente, o desempenho do negócio.

Yelin (2005) lembra que a sequência típica das atividades do processo de gerenciamento estratégico inclui:

- rever e definir a missão da organização, compreendendo o conjunto de serviços, clientes, mercados, aspectos geográficos, canais, tecnologias (fim);

- definir objetivos e metas de longo prazo (fim);

- analisar e formular estratégias para atingir estes objetivos (meios);

- elaborar planos específicos para atingir as estratégias definidas (como).

A implementação das estratégias requer a realização de uma série de ações bem definidas, num prazo determinado e com recursos limitados. Muitas destas ações se traduzem em projetos. Os projetos são, portanto, o meio de atingir os objetivos estratégicos da organização, conforme representado na Figura 3.2.

As oportunidades ou demandas por projetos geralmente excedem a capacidade de executá-los, levando as organizações à necessidade de selecionar, no universo de projetos candidatos, um subconjunto cuja execução seja suportada pela disponibilidade de recursos no período. 
Figura 3.2 - Planejamento estratégico e projetos

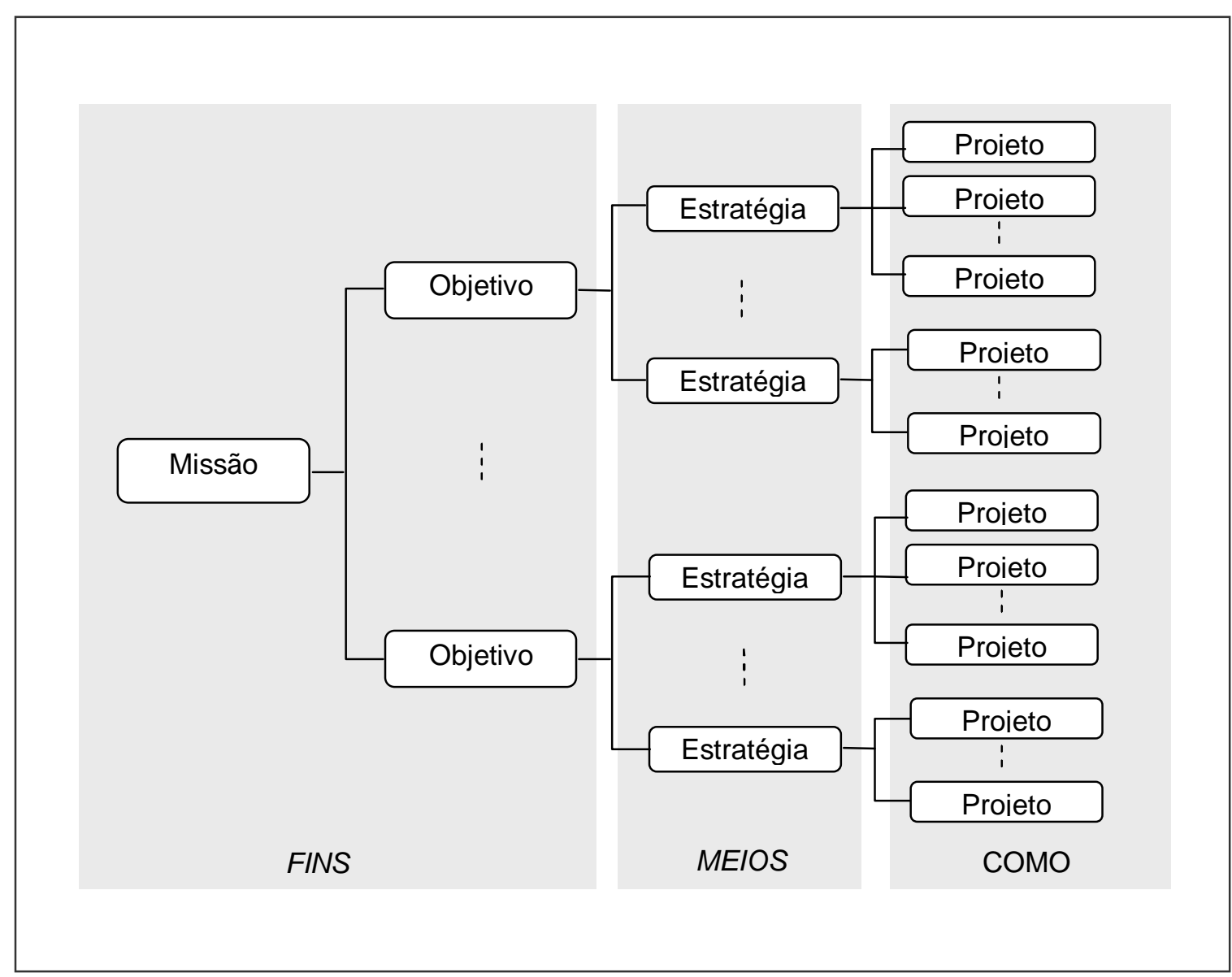

Fonte: Adaptado de Yelin (2005)

Quando adequadamente selecionado, o portfolio de projetos reflete os investimentos realizados ou planejados pela organização, alinhados com seus objetivos e metas estratégicas (PMI, 2006a).

O gerenciamento centralizado de um ou mais portfolios adiciona ainda outros temas ao gerenciamento de projetos e ao gerenciamento de programas, incluindo a identificação, priorização, autorização, gerenciamento e controle dos projetos, programas e outros trabalhos relacionados, para atingir os objetivos estratégicos específicos do negócio (PMI, 2006a).

A Tabela 3-1 mostra um comparativo entre as principais características de gerenciamento de projetos, de programas e de portfolios. 
Tabela 3-1 - Visão comparativa entre gerenciamento de projeto, programa e portfolio

Projeto

Programa
Portfolio

Projetos têm um escopo estreito com entregas específicas.
Programas têm um escopo abrangente que pode ter que mudar para atingir as expectativas de benefícios da organização.
O gerente de projeto tenta manter as mudanças no nível mínimo.
Gerentes de programa têm que esperar mudanças e mesmo abraçá-las.
Portfolios têm um escopo de negócio que muda com as metas estratégicas da organização.

Gerentes de portfolio monitoram continuamente as mudanças num ambiente abrangente.
O sucesso é medido em relação aos produtos entregues dentro do orçamento, no prazo e de acordo com as especificações.

$O$ estilo de liderança é focado na entrega das atividades e diretivas para atingir o critério de sucesso.
O sucesso é medido em termos de Retorno do Investimento (ROI), novas capacidades e benefícios.

O sucesso é medido em termos do desempenho agregado dos componentes do portfolio.

O estilo de liderança é focado em gerenciar relacionamentos e resolver conflitos. Os gerentes de programa precisam facilitar e gerenciar os aspectos políticos do gerenciamento dos

O estilo de liderança é focado em adicionar valor à tomada de decisão do portfolio. envolvidos.

Os gerentes de projetos Os gerentes de programa Os gerentes de portfolio podem gerenciam técnicos, gerenciam gerentes de projetos. especialistas, etc. gerenciar ou coordenar o pessoal envolvido no gerenciamento do portfolio.

Os gerentes de portfolio são líderes que proporcionam inspiração e síntese.
Os gerentes de projeto são Os gerentes de programa são focados no time que motivam líderes proporcionando visão e usando seus conhecimentos e liderança. habilidades.

\begin{tabular}{|c|c|c|}
\hline $\begin{array}{l}\text { Os gerentes de projeto } \\
\text { conduzem um planejamento } \\
\text { detalhado para gerenciar a } \\
\text { entrega dos produtos do projeto. }\end{array}$ & $\begin{array}{l}\text { Os gerentes de programa criam } \\
\text { planos de nível macro, } \\
\text { proporcionando direção aos } \\
\text { projetos, onde os planos } \\
\text { detalhados são criados. }\end{array}$ & $\begin{array}{l}\text { Os gerentes de portfolio criam e } \\
\text { mantêm os processos e a } \\
\text { comunicação necessários } \\
\text { relativos ao portfolio agregado. }\end{array}$ \\
\hline $\begin{array}{l}\text { Os gerentes de projeto } \\
\text { monitoram e controlam tarefas e } \\
\text { o trabalho de produzir os } \\
\text { produtos do projeto. }\end{array}$ & $\begin{array}{l}\text { Os gerentes de programa } \\
\text { monitoram projetos e trabalho } \\
\text { em andamento através das } \\
\text { estruturas de governança. }\end{array}$ & $\begin{array}{l}\text { Os gerentes de portfolio } \\
\text { monitoram o desempenho e os } \\
\text { indicadores de valor agregados. }\end{array}$ \\
\hline
\end{tabular}

Fonte: Project Management Institute (2006a)

A ligação entre o gerenciamento de portfolio de projetos e a estratégia organizacional é representada na Figura 3.3 
Figura 3.3 - Contexto organizacional do gerenciamento de portfolio

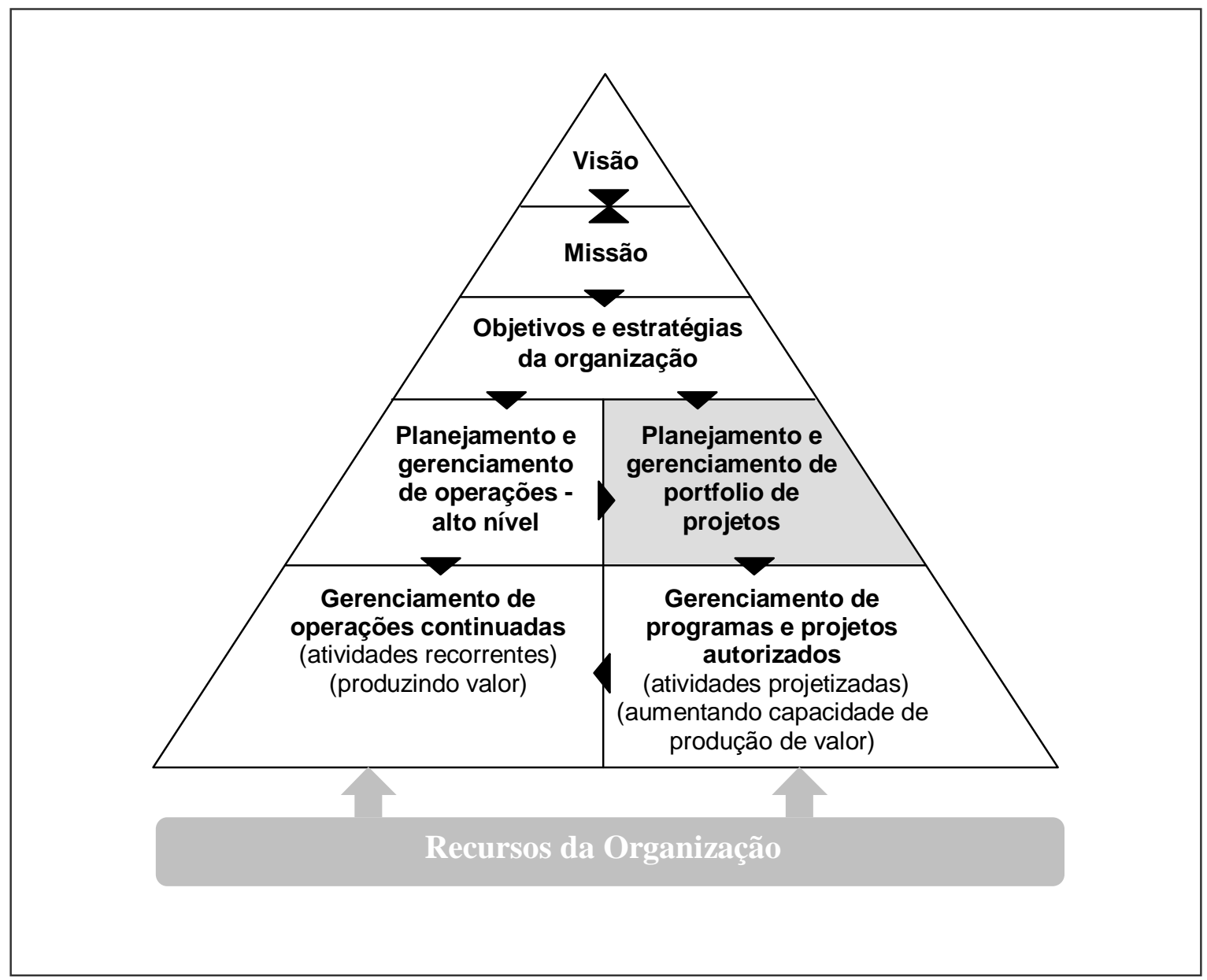

Fonte: Project Management Institute (2006a)

\subsection{Modelos de Gerenciamento de Portfolio de Projetos}

Vários modelos de gerenciamento de portfolio de projetos são descritos na literatura acadêmica (ARCHER; GHASEMZADEH, 1999); (COOPER; EDGETT; KLEINSCHMIDT, 2001); (PATERSON; FENOGLIO, 1999); (PMI, 2006a); (SHTUB; BARD; GLOBERSON, 1994); (SOUDER, 1988).

A seguir são apresentados três dos modelos mais reconhecidos. 


\subsubsection{O Modelo de Archer e Ghasemzadeh}

Archer e Ghasemzadeh (1999) definem gerenciamento de portfolio como uma coleção de projetos desenvolvidos sob a administração de uma unidade organizacional. Os projetos podem ser independentes ou inter-relacionados, no entanto, devem fazer parte de objetivos estratégicos determinados, buscando a alocação dos recursos da organização por meio de uma concentração estratégica, isto é, o estabelecimento da execução de poucos projetos em áreas prioritárias.

Os autores propõem um modelo de gerenciamento de portfolio completo, apoiado em onze proposições descritas a seguir:

1. As decisões estratégicas a respeito do portfolio e do orçamento total devem ser tomadas antes da seleção do portfolio, num contexto amplo, levando em conta fatores internos e externos do negócio.

2. O modelo de gerenciamento do portfolio deve ser flexível, de modo que os envolvidos no processo possam escolher as técnicas e metodologias a serem utilizadas na análise dos dados e nas decisões.

3. O processo de seleção de projetos do portfolio deve ser organizado em estágios, permitindo aos gestores percorrerem um caminho lógico na direção dos projetos com maior probabilidade de seleção, baseado em modelos teóricos conhecidos.

4. Os gestores não devem ser sobrecarregados com dados desnecessários, mas devem poder acessar dados relevantes quando for preciso.

5. Devem ser escolhidas métricas comuns, que possam ser calculadas separadamente para cada projeto, permitindo uma comparação equânime dos projetos durante o processo de seleção do portfolio.

6. Projetos em andamento devem ser reavaliados em determinados pontos juntamente com os novos projetos considerados para seleção, permitindo a geração de um portfolio combinado de acordo com as restrições de recursos. Isto deve ser feito em intervalos regulares, devido à finalização ou abandono de projetos, proposição de novos projetos, mudanças estratégicas, revisões da disponibilidade de recursos e modificações no ambiente. 
7. Uma avaliação inicial baseada em critérios cuidadosamente pré-definidos deve ser realizada para eliminar alguns projetos antes mesmo que o processo de seleção seja iniciado.

8. As interações entre os projetos devem ser consideradas na seleção do portfolio, por meio da dependência direta ou competição por recursos.

9. A seleção do portfolio deve levar em consideração que a utilização dos recursos disponíveis varia ao longo do tempo.

10. Os gestores devem ter mecanismos iterativos para controlar e alterar a seleção do portfolio gerada por qualquer algoritmo ou modelo e devem conhecer as conseqüências de tais mudanças.

11. A seleção de projetos para o portfolio deve ser adaptável a ambientes que apóiam a decisão em grupo.

O modelo de Archer e Ghasemzadeh (1999), em forma de fluxo contínuo de ações, destaca a influência do desenvolvimento estratégico da organização e da metodologia de seleção de projetos escolhida. Este modelo é apresentado na Figura 3.4.

Figura 3.4 - Estrutura de seleção de projetos para o portfolio

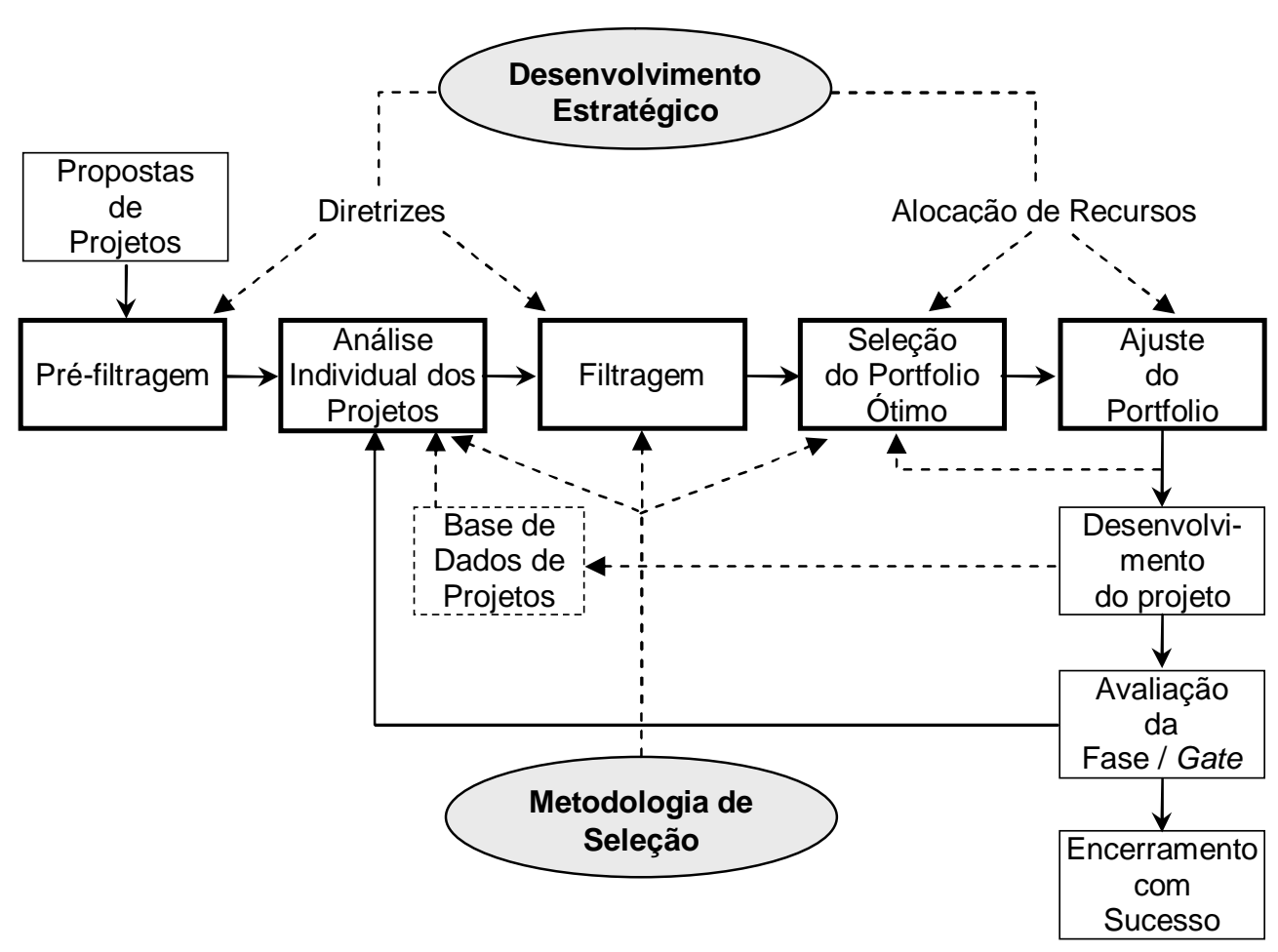

Fonte: Archer e Ghasemzadeh (1999) 
Os processos representados pelas elipses (desenvolvimento estratégico e metodologia de seleção) devem ser executados anteriormente e fornecem o direcionamento estratégico e técnico. O banco de dados de projetos representa uma estrutura de tecnologia de informação usada como apoio para o processo de gerenciamento do portfolio.

O modelo é composto pelas seguintes etapas:

- Pré-filtragem: tem o objetivo de realizar uma primeira filtragem no universo de possíveis projetos, para garantir que os mesmos atendam a determinados requisitos considerados essenciais e que estejam alinhados com o objetivo estratégico do portfolio. Nesta etapa, são realizadas a análise de viabilidade técnica e comercial de cada projeto proposto, as estimativas dos parâmetros para avaliação de cada proposta, a identificação de um responsável que pode fornecer informações adicionais e a identificação dos projetos cuja execução é obrigatória (por exemplo, em função de legislação).

- Análise individual dos projetos: tem o objetivo de produzir as estimativas para o conjunto de parâmetros de avaliação (critérios) escolhido, tanto para os projetos candidatos a entrar no portfolio como para os projetos já em andamento (reavaliação). Os critérios a serem avaliados devem ser os mesmos para todos os projetos e dependem da metodologia de seleção escolhida. Geralmente são utilizados: valor presente líquido de cada projeto, retorno sobre o investimento, grau de risco, pontuação resultante de pesos e notas (scoring), avaliação de benefícios, checklist.

- Filtragem: tem o objetivo de reduzir o número de projetos candidatos através da análise do atendimento aos critérios de avaliação que foram estimados na etapa anterior. Os projetos que não atendem os requisitos mínimos são descartados, excetuando-se aqueles cuja execução é obrigatória ou que são interdependentes com outros já em execução.

- Seleção do portfolio ótimo: tem o objetivo de identificar o portfolio ótimo. Num primeiro passo é determinado o benefício total relativo de cada projeto utilizando-se uma abordagem comparativa. No segundo passo são analisadas as interações entre os diversos projetos, incluindo interdependências, competição por recursos, prazos e outras restrições, procedendo-se à otimização de um modelo matemático, 
geralmente através de ferramentas computacionais. Os autores destacam que a combinação de certos projetos pode produzir um benefício total maior do que projetos isolados com maiores benefícios individuais.

- Ajuste do portfolio: tem o objetivo de produzir um balanceamento entre os projetos selecionados através de análises interativas em certas dimensões do portfolio, tais como riscos, tamanho dos projetos e horizontes de curto e longo prazo. Os projetos selecionados sofrem ajustes de prioridade e recursos para, então, serem efetivamente desenvolvidos.

Durante o desenvolvimento os projetos são avaliados, com objetivo de verificar seu alinhamento com as metas propostas, tornando o processo iterativo, sendo repetido até que os resultados desejados sejam atingidos.

\subsubsection{O Modelo de Cooper, Edgett e Kleinschmidt}

Cooper; Edgett e Kleinschmidt (2001) afirmam que gerenciamento de portfolio de projetos é um processo dinâmico, cuja lista de projetos é constantemente atualizada e revisada.

Segundo estes autores, neste processo novos projetos são avaliados, selecionados e priorizados; projetos existentes podem ser acelerados, eliminados ou postergados; e recursos são alocados e realocados para os projetos ativos. O processo de decisão do portfolio é caracterizado por informações incertas e voláteis, oportunidades dinâmicas, múltiplas metas e considerações estratégicas, interdependência entre projetos, múltiplos decisores e múltiplos locais.

Para eles, os objetivos do gerenciamento do portfolio são: maximizar o valor do portfolio, atingir o balanceamento correto e a distribuição (mix) correta entre os projetos, e garantir o alinhamento estratégico sem sobrecarga de recursos.

Apesar de focado no desenvolvimento de produtos, o modelo destes autores pode também ser estendido para o gerenciamento de portfolio de projetos de naturezas diversas. 
Cooper (2005) afirma que o gerenciamento de portfolio e a alocação de recursos podem ser tratados como um processo hierárquico, com dois níveis de tomadas de decisão, conforme ilustrado na Figura 3.5.

As decisões no nível estratégico respondem às questões:

- onde a organização deve alocar seus recursos?

- como os recursos devem ser divididos entre os diferentes tipos de projetos, mercados, tecnologias e categorias?

- em quais iniciativas ou plataformas principais a organização deve concentrar seus recursos?

As decisões do nível tático focam-se nos projetos individualmente, mas seguem as decisões estratégicas, referindo-se às questões:

- quais projetos especificamente a organização deve empreender?

- qual sua prioridade?

- quais recursos devem ser alocados a eles?

Figura 3.5 - As três partes do processo de decisão no gerenciamento de portfolio

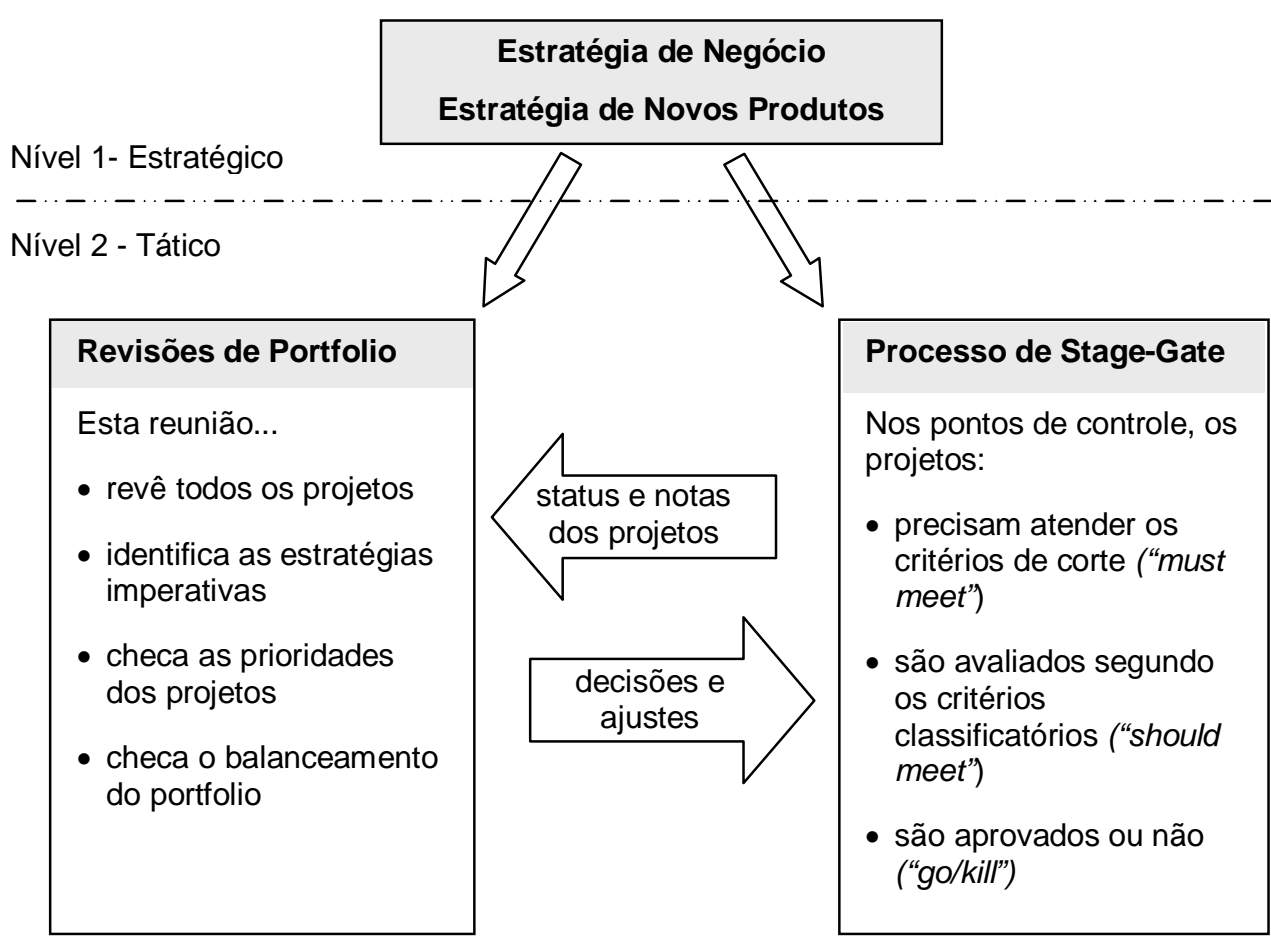

Fonte: Adaptado de Cooper; Edgett e Kleinschmidt (2001) 
No nível estratégico duas ferramentas são recomendadas: a definição de road maps e o estabelecimento de buckets estratégicos.

O road map é um método de alocação de recursos com enfoque estratégico, na forma de desdobramentos ou top-down, para garantir que a lista de projetos contribui ou é essencial para a realização dos objetivos e estratégias de negócio. Ele define as principais iniciativas ao longo do tempo necessárias para implementar as estratégias, estabelece as metas para estas iniciativas e reserva recursos para elas. São também identificadas as competências técnicas e tecnológicas que irão suportar as iniciativas identificadas.

O modelo de buckets estratégicos opera com o princípio de que implementar estratégias equivale a gastar recursos em projetos específicos. O método inicia com a estratégia do negócio e visa guiar a escolha de como gastar os recursos escassos considerando múltiplas dimensões. Os projetos são classificados por categorias ou "envelopes de recursos" (buckets), os recursos são divididos por bucket e os projetos são priorizados em cada bucket, compondo assim o portfolio final de projetos - aquele que espelha as estratégias para o negócio. As dimensões consideradas para a divisão em buckets podem variar de organização para organização. As mais comuns são: metas estratégicas, arenas estratégicas (produtos, mercados, áreas tecnológicas, etc.), linhas de produto, tipos de projetos, aspectos geográficos, estágios de desenvolvimento dos projetos.

No nível tático, são recomendados dois processos de seleção de projetos que interagem: o modelo Stage-Gate® e o de revisão de portfolio.

O modelo Stage-Gate ${ }^{\circledR}$ divide o processo de desenvolvimento de produtos em estágios (stages), cada um deles consistindo de uma série de atividades prédeterminadas, multifuncionais e paralelas. A entrada para cada estágio é um portão (gate), onde o processo e a qualidade são controlados e onde também são tomadas as decisões de continuar ou abortar o projeto. O fluxo geral do modelo é mostrado na Figura 3.6. Através deste modelo, cada projeto é submetido às seguintes ações:

- verificação do atendimento a critérios obrigatórios (must meet) ou critérios de corte: se o projeto não atender a estes critérios (alinhamento estratégico, retorno financeiro, viabilidade técnica, etc.) ele é desclassificado; 
- avaliação segundo critérios classificatórios (should meet): os projetos que passaram na etapa anterior recebem notas segundo critérios pré-estabelecidos;

- priorização segundo as notas obtidas na etapa anterior: a alocação de recursos para os projetos aprovados é realizada.

Figura 3.6 - Visão geral do modelo Stage-Gate®

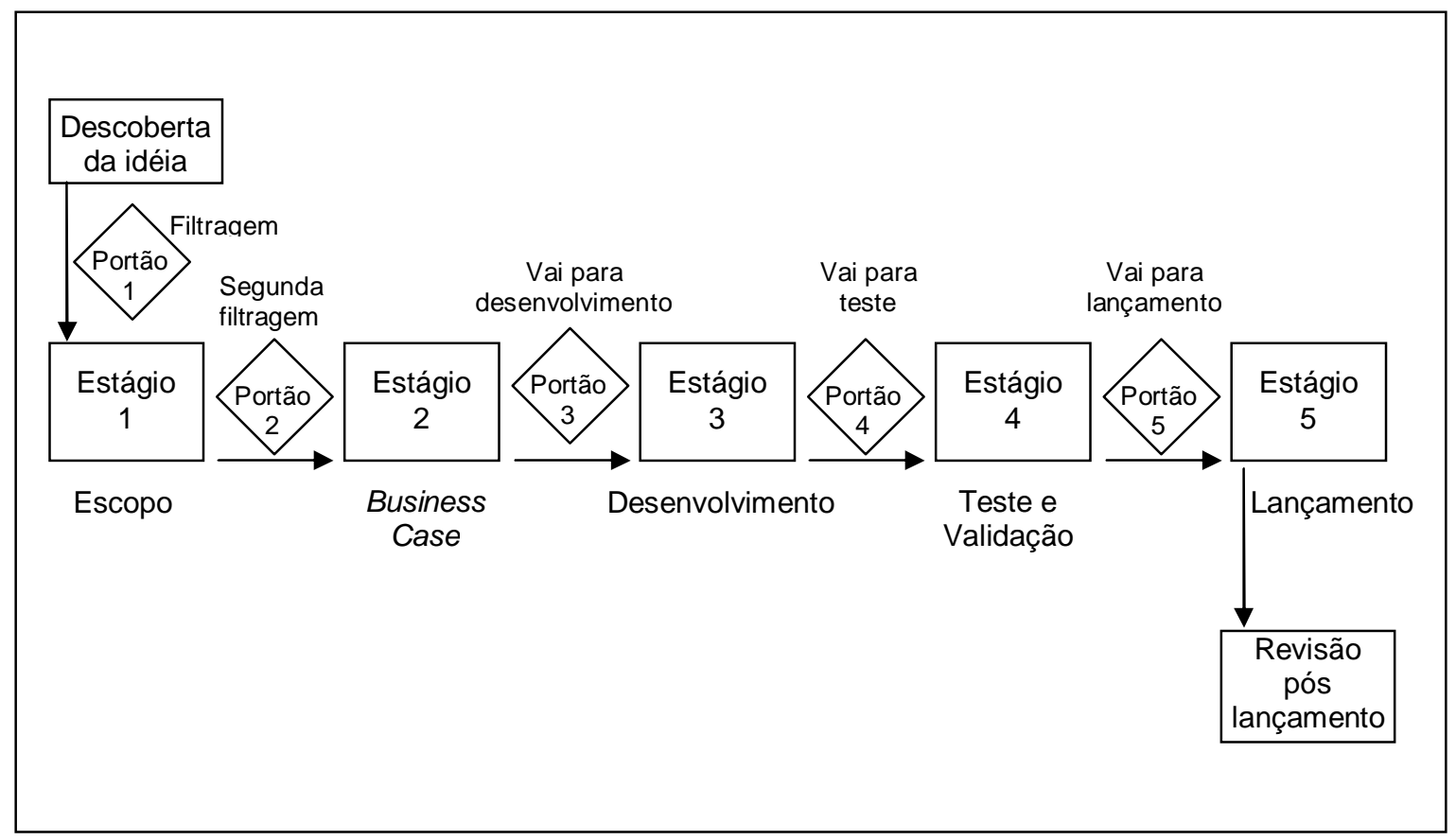

Fonte: Cooper; Edgett e Kleinschmidt (2001)

O segundo processo de decisão é o de revisão periódica do portfolio. A alta administração da organização se reúne duas a quatro vezes ao ano para revisar o portfolio de projetos completo. Aqui também são tomadas as decisões de continuar ou abortar, bem como a priorização de cada projeto. Todos os projetos são considerados conjuntamente e as seguintes questões são colocadas:

- os projetos estão alinhados com a estratégia?

- as prioridades entre projetos estão corretas?

- há projetos que devem ser encerrados ou acelerados?

- o balanceamento entre os projetos está correto? a composição (mix) está correta?

- há recursos suficientes para realizar todos os projetos? 
Através deste modelo, o conjunto dos projetos é submetido às seguintes ações:

- identificação dos projetos estratégicos;

- comparação conjunta entre os projetos estratégicos identificados, projetos ativos e os projetos suspensos através de indicadores-chave;

- priorizaçao destes projetos para assegurar que o conjunto está de acordo com as diretrizes estratégicas e balanceado entre os segmentos previamente selecionados (mercado, tecnologia, produtos, etc.) e

- caso necessário, são feitos ajustes no modelo de decisão utilizado nos gates de projeto com objetivo de corrigir distorções de alinhamento ou balanceamento.

Segundo os autores, os dois processos de decisão descritos são necessários. O Stage-Gate® é específico do projeto e proporciona uma revisão completa de cada projeto em profundidade e em tempo real. Já as revisões de portfolio são holísticas analisam todos os projetos conjuntamente, considerando, porém, menos detalhes em cada projeto.

\subsubsection{O Modelo do Project Management Institute}

O Project Management Institute lançou, em 2006, o The Standard for Portfolio Management, um documento que descreve as melhores práticas reconhecidas em gerenciamento de portfolio de projetos na forma de um conjunto de processos. Os processos descritos são bastante abrangentes e aplicam-se a todos os tipos de organização e de negócio.

O PMI (2006a) define portfolio como um conjunto de projetos, programas e outros tipos de trabalho, agrupados para facilitar o gerenciamento e de forma a atingir os objetivos estratégicos. Estes projetos, programas e outros tipos de trabalho são denominados componentes do portfolio. Os componentes, não necessariamente interdependentes, são quantificáveis, isto é, podem ser medidos, classificados e priorizados.

O PMI (2006a) define, ainda, que gerenciamento do portfolio é uma abordagem para atingir objetivos estratégicos através da seleção, priorização, avaliação e 
gerenciamento dos componentes baseado no seu alinhamento e contribuição aos objetivos e estratégias da organização.

O gerenciamento do portfolio combina:

- o foco da organização em garantir que os projetos selecionados para investimento atinjam a estratégia do portfolio e

- o foco no gerenciamento de projetos, para entregar projetos efetivamente e dentro da sua contribuição planejada para o portfolio.

Segundo este documento, o gerenciamento de portfolio é um dos métodos de governança corporativa ${ }^{2}$. Além de interagir com o planejamento estratégico, o gerenciamento do portfolio interage também com o gerenciamento das operações e com o gerenciamento dos projetos.

Estes relacionamentos são representados na Figura 3.7 a seguir.

Figura 3.7 - Relacionamentos dos processos de gerenciamento de portfolio numa organização

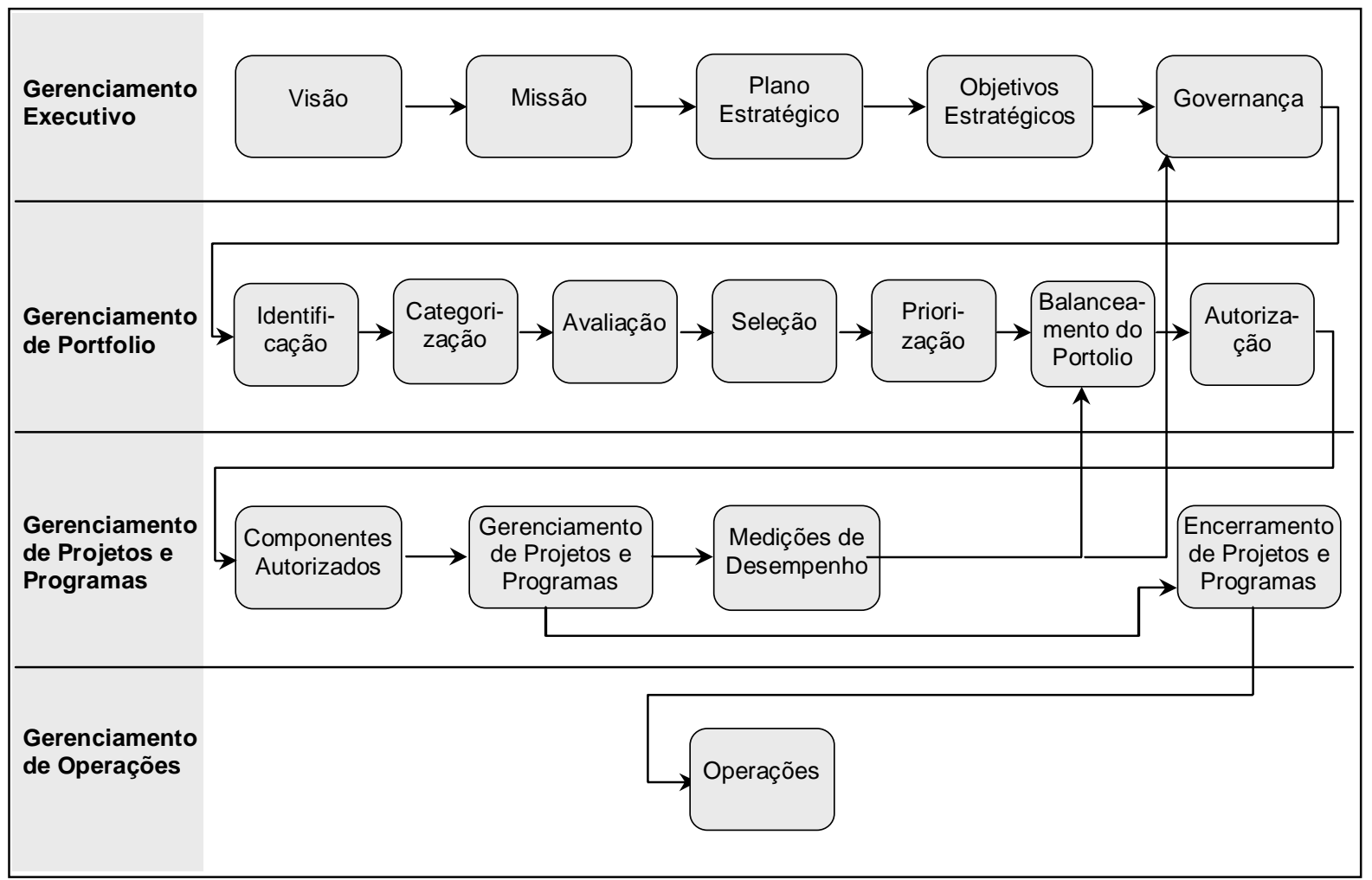

Fonte: Project Management Institute (2006a)

${ }^{2}$ Governança é o ato de criar e utilizar um modelo para alinhar, organizar e executar atividades de forma coerente e inteligente de modo a atingir metas, estabelecendo os limites de poder, regras de conduta e protocolos de trabalho (PMI, 2006a). 
No modelo do PMI (2006a), os processos de gerenciamento de portfolio são agregados em dois grupos:

- Grupo de processos de alinhamento: cujo objetivo é determinar como os componentes serão divididos em categorias, avaliados, selecionados para o portfolio e gerenciados. Este grupo garante a disponibilidade das informações a respeito das estratégicas que o portfolio irá suportar e estabelece um mecanismo estruturado para manter a composição adequada do portfolio.

- Grupo de processos de monitoramento e controle: cujo objetivo é assegurar que o portfolio, como um todo, está com desempenho de acordo com as métricas pré-definidas pela organização, avaliando os indicadores de desempenho periodicamente para manter o alinhamento com os objetivos estratégicos.

A Figura 3.8 sumariza os processos de gerenciamento de portfolio e sua interação com o plano estratégico e com os processos de gerenciamento de projetos.

Figura 3.8 - Processos de gerenciamento de portfolio

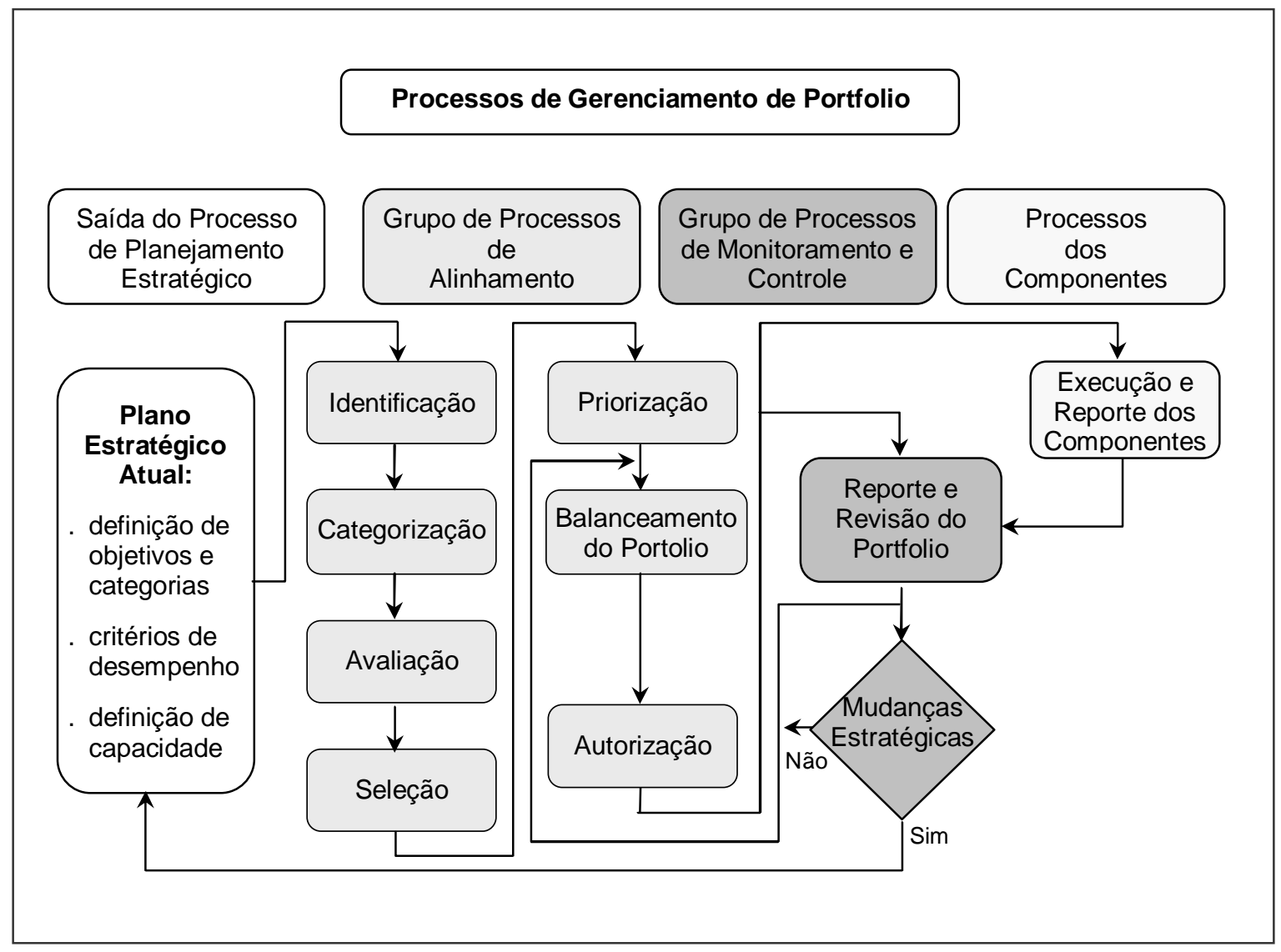

Fonte: Adaptado de Project Management Institute (2006a) 


\section{Grupo de Processos de Alinhamento}

Este grupo é composto pelos seguintes processos:

- Identificação: neste processo é criada uma lista com as informações atualizadas sobre os componentes em andamento no portfolio e novos componentes candidatos a entrar. Todos os componentes são descritos através de um mesmo conjunto de atributos - chamados de caracterizadores - para que seja possível compará-los, avaliá-los e selecioná-los. Cada caracterizador tem um nível de aceitação prédeterminado, que atua como um filtro preliminar. Assim, os componentes que não atendem os requisitos mínimos são rejeitados.

- Categorização: neste processo os componentes identificados são agrupados em categorias derivadas do plano estratégico, para cada qual um conjunto comum de filtros e critérios de decisão pode ser aplicado para avaliação, seleção, priorização e balanceamento. A categorização dos componentes permite à organização balancear seus investimentos e riscos entre todas as categorias e objetivos estratégicos. São exemplo de categorias: aumento de lucratividade, redução de riscos, melhorias na eficiência, exigências legais, aumento do market share, melhorias de processo, melhoria contínua, exigências do negócio.

- Avaliação: este é o processo de obtenção e organização de todas as informações necessárias para avaliar e comparar os componentes categorizados, com o propósito de facilitar o processo seguinte de seleção. Os componentes são avaliados em relação a um conjunto de critérios pré-definidos. Estes critérios de avaliação são valores, medidas ou condições pré-determinados usadas em modelos de pontuação para medir o alinhamento com os objetivos específicos. São exemplos de critérios de avaliação: critérios de negócio (produtividade, vantagem competitiva, satisfação do cliente, etc), critérios de benefício financeiro (crescimento de receitas, redução de custos, taxa interna de retorno, valor presente líquido, retorno sobre o investimento, etc.), critérios relacionados a risco (riscos do negócio, riscos de tecnologia, riscos de gestão de projetos, etc.), critérios de adequação legal/regulamentar, critérios relacionados a recursos humanos, critérios de marketing, critérios técnicos, entre outros.

- Seleção: neste processo são selecionados, dentre os componentes avaliados, aqueles que irão compor o portfolio e que serão posteriormente priorizados. 
Utilizando-se os resultados da avaliação realizada no processo anterior, os componentes que não se enquadram nos limites definidos para os critérios prédeterminados são eliminados. Neste processo também é realizada a análise de capacidade de recursos (humanos, físicos e financeiros), considerando que os recursos disponíveis são fatores limitantes para quantidade e tipo de projetos que a organização pode executar.

- Priorização: o objetivo deste processo é escolher, por categoria, quais componentes serão priorizados em relação a outros para inclusão em determinado momento no portfolio balanceado. São utilizados os mesmos critérios usados no processo de avaliação, entretanto, neste caso, os componentes serão comparados como sendo parte de um todo, devendo atender tanto critérios isolados como critérios combinados, num esforço para priorizá-los de forma coerente e garantindo o melhor alinhamento com o plano estratégico. Como exemplo, os componentes selecionados podem ser ordenados por prioridade sob a perspectiva de categoria estratégica (inovação, redução de custos, crescimento, manutenção, operação), horizonte de investimento (longo prazo, curto prazo), risco e perfil de retorno, foco organizacional (cliente, fornecedor, interno), dentre outros.

- Balanceamento: o objetivo deste processo é selecionar os componentes que efetivamente vão compor o portfolio otimizado de forma a assegurar o melhor alinhamento possível com o plano estratégico. O balanceamento do portfolio viabiliza os benefícios básicos da gestão de portfolio: planejar e alocar recursos (financeiros, físicos e humanos) de acordo com a direção estratégica, e maximizar o retorno do portfolio dentro do perfil de risco desejado pré-definido pela organização. $O$ balanceamento envolve a revisão dos componentes selecionados e priorizados levando em conta os critérios pré-definidos de gestão de portfolio, o perfil de risco suportado pela organização, as métricas de desempenho de portfolio e as restrições de capacidade. A seleção da composição ideal do portfolio visando atingir o retorno desejado também deve levar em conta as similaridades e sinergias existentes entre os componentes, o que inclui relações de interdependências. Explorar estas interconexões pode alavancar o portfolio, gerando máximo retorno com mínimo investimento. Os componentes são balanceados geralmente dentro da mesma categoria, usando uma variedade de métodos qualitativos e quantitativos bem como ferramentas de software para auxiliar o processo de tomada de decisão e alocação 
de orçamento. Ao final do processo são geradas recomendações para manter o portfolio como está ou para ajustar o portfolio adicionando, eliminando ou repriorizando componentes.

- Autorização: os objetivos deste processo são alocar ou realocar formalmente os recursos humanos e financeiros entre os componentes balanceados e comunicar formalmente as decisões de balanceamento do portfolio, inclusive as expectativas de desempenho para cada componente.

\section{Grupo de Processos de Monitoramento e Controle}

Este grupo é composto pelos seguintes processos:

- Reporte e Revisão do Portfolio: o objetivo deste processo é obter e fornecer informações sobre o desempenho, bem como reavaliar periodicamente o portfolio para assegurar o alinhamento com a estratégia organizacional e a utilização eficaz dos recursos. Baseado em seu desempenho e alinhamento com a estratégia definida, os componentes podem ser mantidos, adicionados, repriozados ou excluídos. A revisão periódica abrange todos os componentes e é executada em intervalos de tempo especificados pela organização. Cada ciclo pode conter várias revisões com diferentes focos, profundidade de análise e indicadores chaves de desempenho (Key Performance Indicators - KPI). Os KPI são métricas usadas para determinar se um determinado componente está progredindo como esperado e se os resultados estão em linha com a expectativa da organização. O propósito das revisões é garantir que a organização continue a investir apenas naqueles componentes que suportam os objetivos estratégicos definidos e verificar se estes investimentos se mantêm alinhados com os mesmos.

. Mudanças Estratégicas: este processo garante que o gerenciamento de portfolio possa responder a mudanças na estratégia da organização. Estas mudanças podem resultar em novas diretrizes estratégicas e impactar a categorização ou a priorização de componentes, requerendo o rebalancemento do portfolio. Pode ser necessário eleger novos critérios ou pesos para reavaliar e realinhar o portfolio. Qualquer mudança estratégica deve desencadear uma revisão pontual. Quando uma mudança maior ocorre, como, por exemplo, uma aquisição ou reorganização do 
mercado, a organização pode também rever seus critérios de seleção e prioridades para todo o conjunto de componentes.

\subsubsection{As Três Grandes Fases do Gerenciamento de Portfolio de Projetos}

A revisão bibliográfica referente aos modelos de gerenciamento de portfolio de projetos mostrou que, apesar de organizados com quantidade e nomenclatura de etapas ou processos diferentes, há grande similaridade entre eles. Num nível mais abrangente, três grandes fases podem ser identificadas no gerenciamento de portfolio de projetos:

- definição das estratégias: na qual são determinados o foco estratégico; a alocação do orçamento geral para o portfolio; os critérios, técnicas e indicadores para composição e avaliação de desempenho do portfolio;

- avaliação individual dos projetos: na qual cada projeto é avaliado, independentemente dos demais;

- composição do portfolio: baseada na análise individual dos projetos, incluindo, agora, as interações com outros projetos através de restrições de recursos ou outras formas de interdependências.

Estas são as fases utilizadas como base para a proposição do procedimento para a determinação do grau de exposição a riscos do portfolio de projetos, descrito no capítulo 4 deste trabalho.

A Figura 3.9 apresenta estas fases e seus principais resultados.

Figura 3.9 - As três grandes fases do gerenciamento de portfolio de projetos

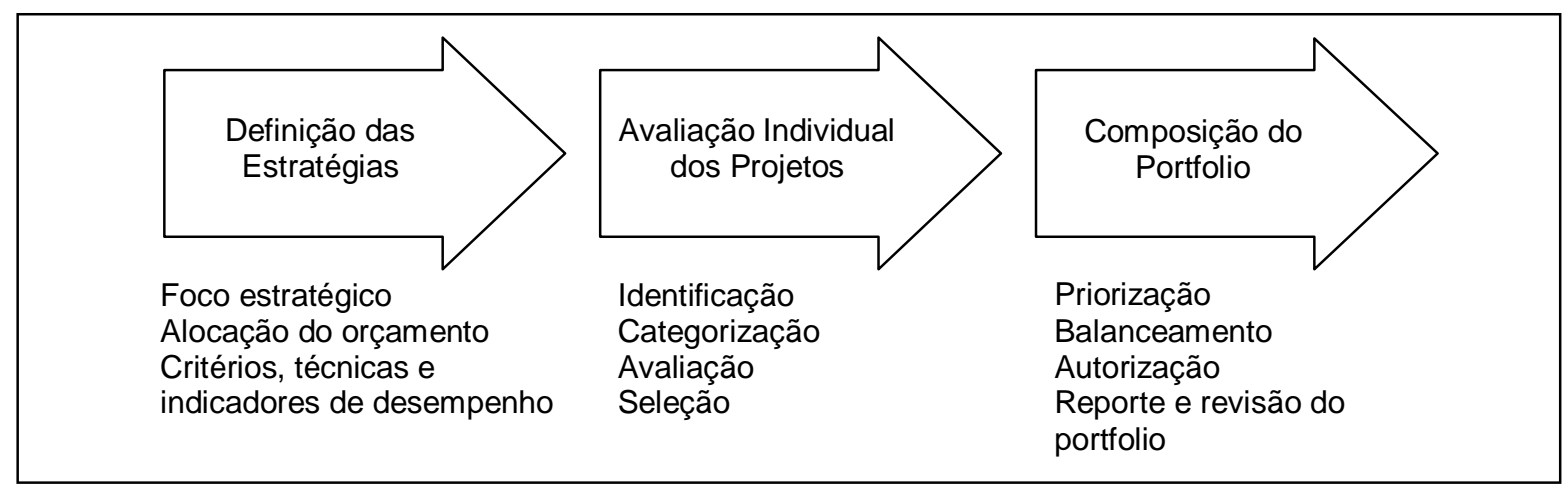

Fonte: Elaborado pela autora 


\subsection{Métodos Utilizados no Gerenciamento de Portfolios}

Cooper; Edgett e Kleinschmidt (1999) lembram que o gerenciamento de portfolios de projetos envolve uma série de processos complexos de tomadas de decisões, como por exemplo, a escolha dos projetos que irão compor o portfolio, as decisões pela continuidade ou não de cada projeto e as decisões de alocação dos recursos entre os projetos.

Os processos de tomada de decisões em gerenciamento de portfolio devem ser estruturados. Cooper; Edgett e Kleinschmidt (1999) elencam alguns dos métodos de apoio à decisão em gerenciamento de portfolio de projetos que têm sido mais utilizados nos últimos anos:

- Modelos e índices financeiros: que vão desde a classificação e seleção de projetos baseado no método tradicional de valor presente líquido (VPL), taxa interna de retorno (TIR) e método do payback até outros índices mais sofisticados.

- Modelos financeiros probabilísticos: que incluem a simulação de Monte Carlo e árvores de decisão com análise do valor esperado.

- Teoria de opções reais: que trata cada estágio do projeto como uma compra de ações no mercado futuro de investimentos.

. Abordagens estratégicas: onde a seleção do portfolio é influenciada basicamente pelas estratégias do negócio, que norteiam a divisão dos recursos entre diferentes categorias (tipos de projeto, mercados, linhas de produto) e dominam as decisões de realizar ou não os projetos.

. Índice de produtividade: onde os projetos são avaliados conforme um índice que indica o valor presente líquido ajustado pela probabilidade de sucesso e dividido pelo custo de desenvolvimento remanescente.

- Modelos de pontuação (scoring models) e checklists: aos projetos são atribuídas notas decorrentes da pontuação ponderada de critérios pré-estabelecidos.

- Abordagens de hierarquia analítica (AHP): ferramentas de decisão baseada na comparação aos pares, tanto dos projetos como dos critérios de avaliação, para chegar ao conjunto ideal de projetos. 
- Abordagens comportamentais: ferramentas tais como Q-Sort e método de Delphi, desenhadas para que um grupo de gestores chegue a um consenso sobre quais os projetos empreender, com aplicação bastante útil nos estágios iniciais em que apenas informações qualitativas estão disponíveis.

- Abordagens de mapeamento ou diagramas de bolha: são instrumentos gráficos e de fácil visualização, onde os projetos são representados por bolhas; estas bolhas são capazes de representar um conjunto e parâmetros combinados (eixo x, eixo y, tamanho da bolha, cor da bolha).

Cooper; Edgett e Kleinschmidt (1999) realizaram um estudo com 205 empresas americanas, visando identificar os métodos mais utilizados para a seleção e balanceamento de portfolio projetos, o grau de satisfação das empresas com estes métodos e o desempenho obtido com as diferentes abordagens. A Figura 3.10 apresenta os métodos mais utilizados na média das empresas pesquisadas.

Figura 3.10 - Popularidade dos métodos utilizados no gerenciamento de portfolios

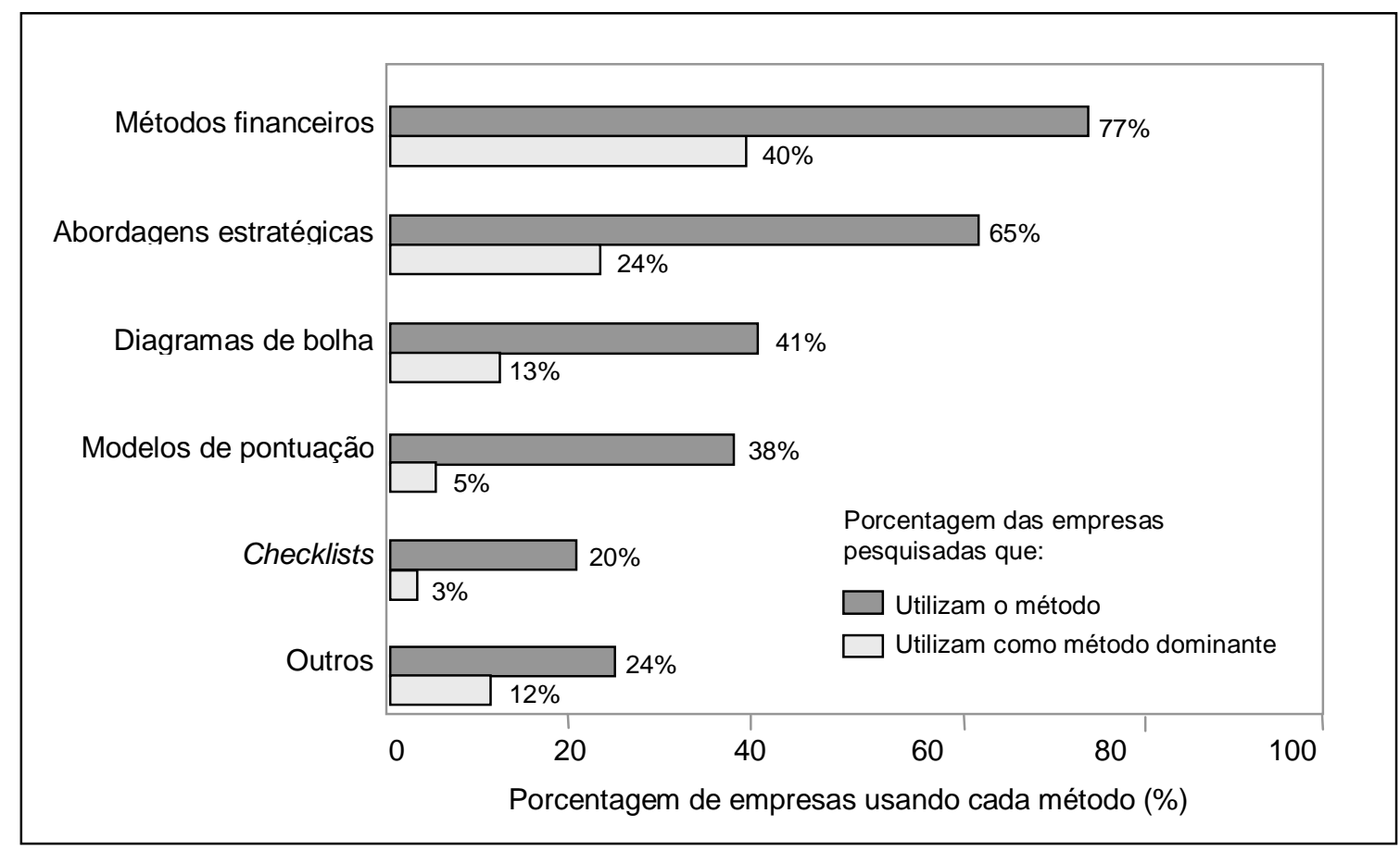

Fonte: Adaptado de Cooper; Edgett e Kleinschmidt (1999)

Quando o desempenho do portfolio destas empresas foi avaliado, entretanto, os autores constataram que a popularidade do método utilizado não está 
necessariamente associada a bons resultados. As empresas que utilizaram fortemente os métodos financeiros na seleção de seus projetos tiveram a pior avaliação, com um portfolio desbalanceado, composto de projetos de baixo valor e não alinhados com a estratégia. Os autores concluem que este fato não está ligado à falhas dos métodos, mas à qualidade dos dados utilizados no momento da avaliação. Em contrapartida, as abordagens estratégicas conduzem a um portfolio balanceado e estrategicamente alinhado; os modelos de pontuação se destacam na seleção de projetos com maior valor e também conduzem a um portfolio balanceado; e os diagramas de bolha também conduzem a um portfolio balanceado e estrategicamente alinhado.

Por fim os autores afirmam que nenhum dos métodos é auto-suficiente e que uma abordagem híbrida é recomendada.

Archer e Ghasemzadeh (1999) também apontam as técnicas potenciais a serem utilizadas de acordo com o estágio do gerenciamento do portfolio, sumarizadas na Tabela 3-2.

Tabela 3-2 - Estágios e técnicas recomendadas no gerenciamento de portflio

\begin{tabular}{lll}
\hline Estágio & Atividade & Possíveis Técnicas \\
\hline Pré-filtragem dos projetos & $\begin{array}{l}\text { Rejeição de projetos que não } \\
\text { estejam alinhados com a } \\
\text { orientação estratégica }\end{array}$ & $\begin{array}{l}\text { Foco estratégico, estudo de } \\
\text { viabilidade, critérios aplicados } \\
\text { manualmente. }\end{array}$ \\
\hline $\begin{array}{l}\text { Análise individual de cada } \\
\text { projeto }\end{array}$ & $\begin{array}{l}\text { Cálculo de parâmetros comuns } \\
\text { para cada um dos projetos }\end{array}$ & $\begin{array}{l}\text { Árvore de decisão, estimativas } \\
\text { de risco, VPL, ROI, } \\
\text { necessidade de recursos, etc. }\end{array}$ \\
\hline Filtragem & Rejeição de projetos inviáveis & $\begin{array}{l}\text { Técnicas } \text { Ad-hoc (por exemplo } \\
\text { perfis) }\end{array}$ \\
\hline Seleção do portfolio & $\begin{array}{l}\text { Considerações integradas dos } \\
\text { atributos de cada projeto, } \\
\text { restrições de recursos, sinergias e } \\
\text { interações entre os projetos }\end{array}$ & $\begin{array}{l}\text { AHP, opções reais, modelos } \\
\text { de pontuação, análise de } \\
\text { sensibilidade, análise marginal }\end{array}$ \\
\hline Ajustes finais do portfolio & $\begin{array}{l}\text { Alterações manuais após a } \\
\text { otimização }\end{array}$ & $\begin{array}{l}\text { Matrizes de projetos, análise } \\
\text { de sensibilidade }\end{array}$ \\
\hline Portfolio final & Desenvolvimento dos projetos & $\begin{array}{l}\text { Técnica de gerenciamento de } \\
\text { projetos, coleta de dados, } \\
\text { indicadores de projetos }\end{array}$ \\
\hline
\end{tabular}




\subsection{Conceituação de Risco}

Markowitz (1959) define risco como a medida da dispersão entre o possível retorno de um ativo e o que se espera efetivamente ganhar. Para Bernstein (1997), o risco é a medida da ignorância e é inerente à natureza humana, que tem uma aversão calculada e não instintiva ao risco. Cooper e Chapman (1987) definem risco como a exposição à possibilidade de perda ou ganho econômico ou financeiro, danos físicos ou morais, ou ainda, atraso, como consequência da incerteza associada com a tentativa de realizar um curso de ações determinadas. Para Williams e Parr (2004), risco é um evento incerto ou um conjunto de circunstâncias que, se ocorrerem, terão impacto, positivo ou negativo, no atendimento de objetivos desejados.

Meredith e Mantel (2000) chamam à atenção sobre a importância de diferenciar risco de incerteza. Segundo estes autores, o resultado de uma decisão depende de dois fatores: o que o decisor faz e o que a natureza ${ }^{3}$ faz. Quando se conhece a probabilidade de cada um dos estados da natureza e também cada um dos resultados decorrentes, a tomada de decisão é baseada em condições de risco. Quando estas informações são incompletas ou não estão disponíveis, a tomada de decisão é baseada em condições de incerteza.

As organizações enfrentam diversos tipos de riscos tanto em suas operações quanto em seus projetos.

Os riscos do negócio estão associados às perdas e ganhos decorrentes do ambiente em que a organização opera. Neste universo, incluem-se as iniciativas dos concorrentes, o comportamento dos consumidores, as ações de governo, as influências climáticas e todos os demais intervenientes do mercado.

Os riscos do negócio estão mais relacionados à operação, mas podem também incidir e influenciar os projetos, já que os projetos estão alinhados aos objetivos do negócio e viabilizam muitas das mudanças, aprimoramentos e adequações necessárias e desejáveis ao sucesso das operações. Grande parte dos riscos do negócio está fora do alcance da organização, que deve, porém, estar continuamente

\footnotetext{
${ }^{3}$ Natureza aqui se refere ao conjunto de fatores exógenos que interagem com o curso das ações do decisor para produzir um resultado.
} 
atenta e desenvolver mecanismos adequados de percepção dos sinais e das ocorrências destes riscos.

Os riscos do projeto estão associados a desvios nos objetivos do projeto, ou seja, à entrega de determinado produto ou serviço, num prazo específico, por um custo específico, atendendo requisitos específicos de funcionalidade e desempenho. Riscos no projeto estão, portanto, ligados às metas de escopo, prazos, custo e qualidade (KERZNER, 2003).

Os riscos do programa estão associados não só aos desvios dos objetivos dos projetos que o compõem, mas aos desvios dos objetivos conjuntos de benefício global que o programa se propõe a realizar (WIDEMAN, 1992).

Os riscos do portfolio de projetos englobam os riscos individuais dos programas e projetos que o compõem, bem como os desvios ligados ao atendimento dos objetivos do portfolio, ou seja, as estratégias às quais visa atender (LEVINE, 2005).

\subsection{Gerenciamento de Riscos}

Gerenciamento de riscos é um conjunto de ações estruturadas de forma sistêmica para lidar com riscos. O gerenciamento de riscos melhora o processo de tomada de decisão através da redução da incerteza. Seu propósito não é eliminar todos os riscos, mas reduzir ao máximo o grau de exposição a eles. Isto é possível através:

- da identificação e análise dos riscos frente aos objetivos e restrições da organização;

- da seleção e implementação de ações para eliminar ou reduzir os riscos, à luz da criticidade do risco e da tolerância a riscos da organização, e

- do monitoramento contínuo destas ações, com os ajustes necessários.

Muitas vezes o gerenciamento de riscos é associado apenas a dois fatores: processos e ferramentas. Williams e Parr (2004) descrevem o gerenciamento de riscos, porém, como dependente de cinco fatores: pessoas, processos, ferramentas, estrutura e informação, todos guiados pela cultura e mentalidade da organização e dos envolvidos. 
O tipo de organização, o posicionamento no mercado e a expectativa dos acionistas são alguns dos principais determinantes do foco, cultura e mentalidade do gerenciamento de riscos. Estes, por sua vez, determinarão o apetite (grau de risco alvo) e a tolerância (limites de aceitação) a riscos, que levarão à escolha da abordagem mais adequada e calibrarão a sensibilidade e a criticidade na avaliação dos riscos. Geralmente a busca por maiores retornos requer a aceitação de maiores riscos e a demanda pela realização rápida de benefícios é incompatível com a ênfase em minimização de custos, o que é sintetizado na Figura 3.11.

Figura 3.11 - Apetite e tolerância a riscos

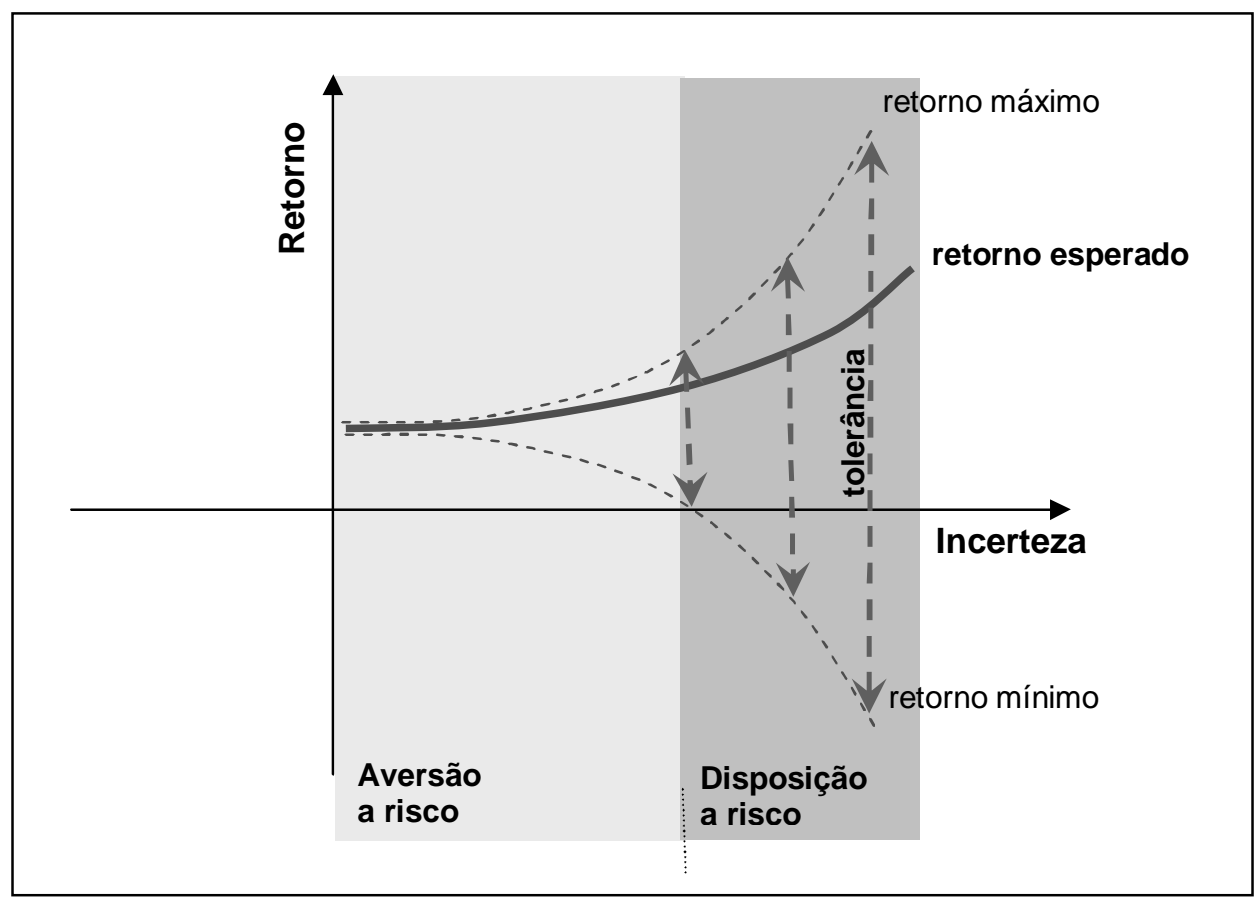

Fonte: Adaptado de Williams e Parr (2004)

Se por um lado os processos são essenciais para dar a informação certa à pessoa certa no tempo certo, também a competência e motivação das pessoas envolvidas são igualmente importantes para o sucesso do gerenciamento de riscos. Inconsistências, deficiências de conhecimento e habilidades, motivação e treinamento devem ser tratados para permitir que os processos funcionem. Além disso, boas ferramentas podem facilitar e agilizar o gerenciamento de riscos. A estrutura do gerenciamento de riscos deve ser enxuta e ter apenas o tamanho necessário para atingir seus objetivos. Por fim, a disponibilidade de informações atualizadas e acuradas e a habilidade de analisar e agregar são fatores determinantes no processo de tomada de decisão do gerenciamento de riscos. 


\subsubsection{As Dimensões do Gerenciamento de Riscos}

O gerenciamento de riscos pode e deve ser aplicado a todos os níveis da organização: ao nível estratégico, aos portfolios, aos programas e aos projetos.

Entretanto, como destacam Williams e Parr (2004), cada nível requer uma abordagem diferenciada, já que cada um deles tem propósito, escopo e aplicação diferentes. Em cada um destes níveis, a integração com os riscos da operação não deve ser esquecida.

No nível da organização, o gerenciamento de riscos foca a avaliação e gerenciamento dos riscos de estratégia tanto no âmbito das operações como no âmbito dos portfolios, programa e projetos, visando reconhecer e integrar dependências e sinergias.

No âmbito do portfolio, o foco se volta para o potencial dos programas e projetos em implementar as estratégias do negócio de forma eficiente e eficaz. O gerenciamento de riscos do portfolio preocupa-se com questões como:

- estamos fazendo as coisas certas?

- estamos fazendo o suficiente?

- estamos obtendo os benefícios?

- estamos fazendo da forma certa?

- as coisas estão bem feitas?

Ainda segundo Williams e Parr (2004), o tratamento dos riscos do portfolio inclui a agregação e integração dos riscos individuais dos projetos e programas, bem como os riscos de alinhamento deficiente, conflitos, omissões e duplicações. O gerenciamento de riscos nos níveis do portfolio e da organização representam um pilar para o gerenciamento estratégico do portfolio, possibilitando a contínua sintonia com os objetivos e a consequente otimização do portfolio, enquanto o ambiente competitivo é monitorado.

No nível dos programas, o foco do gerenciamento de riscos está voltado para o balanceamento entre 0 investimento e a obtenção dos benefícios esperados. $A$ preocupação aqui é com a otimização e nivelamento dos recursos de forma integrada entre todos os projetos que compõem o programa (WIDEMAN, 1992). 
No nível dos projetos, o foco está nos desvios ligados ao alcance das metas de escopo, prazo, custo e qualidade definidas para cada projeto. (KERZNER, 2003).

O gerenciamento de riscos de cada nível deve identificar e transferir para o gestor do nível superior os riscos cujos impactos transcendam a sua responsabilidade.

Como mostra a pesquisa de Charette (2006), o gerenciamento de riscos em projetos é atualmente uma disciplina bem documentada e de reconhecida importância. É uma das nove áreas de conhecimento com que o Project Management Institute organiza o gerenciamento de projetos em seu guia $A$ guide to the project management body of knowledge (PMBOK Guide).

Programas são compostos por projetos e portfolios são compostos por programas e projetos. Assim, os processos, técnicas e ferramentas de gerenciamento de projetos são igualmente aplicáveis ao gerenciamento de programas e de portfolios de projetos; requerem, porém, a necessária adequação ao foco de cada um destes níveis. A Figura 3.12 representa os níveis de gerenciamento de riscos e a abrangência da utilização dos processos, técnicas e ferramentas de gerenciamento de riscos em projetos.

Figura 3.12 - Gerenciamento de riscos na organização

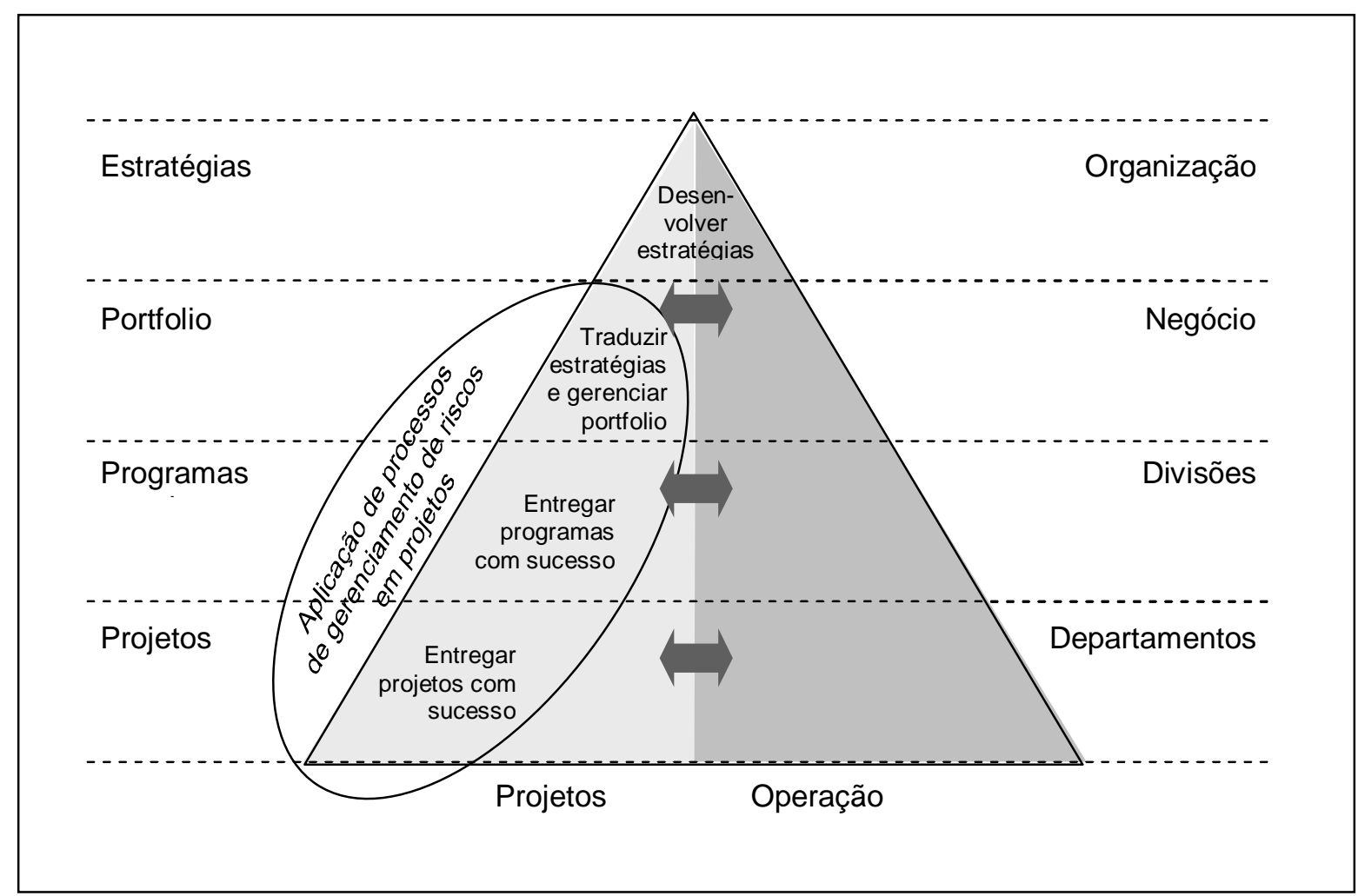

Fonte: Adaptado de Williams e Parr (2004) 
A eficácia do gerenciamento de riscos pode ser percebida através da contribuição que ela traz às decisões do negócio. A tomada de decisões eficaz é crítica para o atendimento dos objetivos desejados, sejam eles no nível estratégico, de portfolio, de programa ou de projeto.

\subsection{Gerenciamento de Riscos em Projetos}

Os riscos são inerentes à natureza dos projetos e mesmo um planejamento minucioso não pode eliminar a possibilidade de que algo indesejado aconteça. Com alguns cuidados sistêmicos, a possibilidade de alguns destes eventos indesejados acontecer, pode ser identificada antes mesmo do início do projeto; outros eventos podem ser identificados durante a realização do projeto e, outros ainda, nem sequer podem ser imaginados, até acontecerem. No entanto, os riscos em projetos podem e devem ser gerenciados através de metodologias que permitam a sua identificação, análise e tratamento.

Meredith e Mantel (2000) lembram que a maioria das decisões no gerenciamento dos projetos é tomada sob condição de incerteza. É possível agir, porém, como se estas decisões fossem tomadas em condições de risco. Isto é realizado através da estimativa das probabilidades de ocorrência dos eventos e dos vários possíveis resultados destas ocorrências (probabilidades subjetivas). Se realizadas com métodos apropriados, estas estimativas permitem a aplicação de conhecimentos estruturados para resolver os problemas de decisão nos projetos. Ainda que nem sempre estejam precisas, as estimativas ajudam a gerenciar o projeto e seus riscos da melhor forma possível.

O PMI (2004) define gerenciamento de riscos em projetos como o conjunto de processos para identificar, analisar, responder, monitorar e controlar os riscos do projeto, com o objetivo de maximizar a probabilidade e as consequências dos eventos positivos e minimizar a probabilidade e as consequências dos eventos adversos aos objetivos do projeto.

Gray e Larson (2003) descrevem que através do gerenciamento de riscos procura-se identificar os possíveis eventos de risco (o que pode dar errado), minimizar seus 
impactos (o que pode ser feito antes), gerenciar respostas para aqueles eventos que efetivamente se concretizarem (planos de contingência) e prover fundos para cobrilos.

Ainda, Chapman e Ward (1997) dizem que o propósito essencial do gerenciamento de riscos é melhorar o desempenho do projeto através de condução sistemática da identificação, avaliação e gerenciamento dos riscos relativos ao projeto.

Não obstante as pequenas diferenças de conceituação há uniformidade entre os autores na caracterização dos riscos de projeto através de três fatores:

- o evento de risco;

- a probabilidade de ocorrência deste evento e

- o impacto no projeto causado pela ocorrência do evento de risco (consequência).

Associado à probabilidade de ocorrência do evento e ao impacto de sua conseqüência, um outro fator é de vital importância na avaliação dos riscos: a percepção de quem o avalia frente aos fatores citados, posto que a tolerância a riscos varia de indivíduo para indivíduo.

Kerzner (2003) aponta que o grau de tolerância a riscos que uma pessoa ou organização está disposta a aceitar está associado ao benefício vislumbrado (utilidade) em relação ao valor a ser pago ou quantidade em jogo (amount at stake) e, portanto, introduz um caráter subjetivo na avaliação do risco.

Este fato é explicado pela Teoria da Utilidade, uma abordagem para medir a disposição de um indivíduo ou organização para correr risco frente aos diferentes níveis de recompensa, seja esta recompensa para si própria ou para outros potenciais beneficiários (WARD, 2000).

\subsubsection{Exposição a Risco}

Para viabilizar a análise e tratamento do risco é necessário poder calcular ou estimar a importância de cada risco frente aos objetivos do projeto, ou seja, a extensão a que o projeto está vulnerável ao risco. Ward (2000) utiliza o termo exposição a risco para este valor; Royer (2000) chama de fator de severidade-probabilidade do risco; 
Kerzner (2003), de impacto do risco e Smith e Merritt (2002), de perda esperada - o que evidencia que não há consenso na bibliografia quanto à terminologia.

Para efeito deste trabalho, o termo exposição a risco foi adotado para definir a extensão a que o projeto está vulnerável ao risco e o termo impacto foi adotado para a consequência causada pela ocorrência do evento de risco.

A exposição ao risco é geralmente calculada através da multiplicação do valor do impacto sobre os objetivos do projeto caso o evento de risco ocorra, pela sua probabilidade de ocorrência (KERZNER, 2003):

Exposição a risco $=$ Probabilidade do risco ocorrer (\%) * Impacto causado

O impacto pode ser estimado em valores monetários ou outras medidas de recursos como, por exemplo, horas trabalhadas ou meses de atraso.

Smith e Merritt (2002) sugerem uma fórmula com três variáveis, considerando que a ocorrência do risco não necessariamente leva à máxima perda possível:

Exposição a risco $=$ Probabilidade do risco $(\%)^{*}$ Probabilidade do impacto (\%) *Perda total

Nesta equação, a probabilidade do impacto representa a probabilidade de se atingir a perda total possível ou magnitude do impacto, caso o risco aconteça.

A exposição a risco pode ser estimada também através de métodos qualitativos, utilizando-se escalas relativas de avaliação de probabilidade e de impacto, com classificações do tipo alta, média e baixa em conjunto com matrizes de impacto e probabilidade conforme será exposto no item 3.7.3.2 deste capítulo.

\subsubsection{Categorias de Riscos do Projeto}

Os riscos do projeto podem ser organizados em categorias que representam fontes de riscos. É possível classificar riscos com base em diferentes aspectos. Uma classificação bem simples, feita por Cleland e Ireland (2000), é a de riscos internos, 
que estão sob controle da equipe do projeto, e riscos externos, que estão fora do controle da equipe do projeto. Outras classificações mais detalhadas incluindo subníveis de categorias estão descritas na literatura (KERZNER, 2003), PRITCHARD (2001), WIDEMAN (1992).

A Tabela 3-3 retrata a classificação sugerida por Pritchard (2001), considerando cinco tipos de risco na administração de custo, programação e desempenho num projeto:

- riscos técnicos (relativos ao desempenho);

- riscos programáticos (relativos ao desempenho);

- riscos de sustentação (relativos ao ambiente do projeto);

- riscos de custos e

- riscos de programação

Tabela 3-3 - Fontes típicas de riscos em projetos

\begin{tabular}{|c|c|c|}
\hline Facetas de Risco & Fol & tes de Risco \\
\hline Técnicos & $\begin{array}{l}\text { Propriedades físicas } \\
\text { Propriedades de material } \\
\text { Teste e modelagem } \\
\text { Integração e interfaces } \\
\text { Projeto de software } \\
\text { Segurança }\end{array}$ & $\begin{array}{l}\text { Mudanças nos requisitos } \\
\text { Detecção de falha } \\
\text { Ambiente de operação } \\
\text { Tecnologia conhecida ou não } \\
\text { Complexidade de sistema } \\
\text { Recursos especiais }\end{array}$ \\
\hline Programáticos & $\begin{array}{l}\text { Disponibilidade de material } \\
\text { Disponibilidade de pessoas } \\
\text { Habilidades das pessoas } \\
\text { Segurança } \\
\text { Impactos ambientais } \\
\text { Problemas de comunicação }\end{array}$ & $\begin{array}{l}\text { Greves } \\
\text { Mudanças nos requisitos } \\
\text { Apoio político } \\
\text { Estabilidade do contratado } \\
\text { Perfil de financiamento } \\
\text { Modificações legais }\end{array}$ \\
\hline Sustentação & $\begin{array}{l}\text { Confiança e sustentabilidade } \\
\text { Treinamento } \\
\text { Equipamentos } \\
\text { Considerações de recursos humanos } \\
\text { Segurança de sistemas } \\
\text { Dados técnicos }\end{array}$ & $\begin{array}{l}\text { Considerações de instalações } \\
\text { Considerações de Interoperabilidade } \\
\text { Transportabilidade } \\
\text { Suporte de recursos computacionais } \\
\text { Embalagem, manuseio, armazenamento }\end{array}$ \\
\hline Custos & $\begin{array}{l}\text { Sensibilidade a riscos técnicos } \\
\text { Sensibilidade a riscos programáticos } \\
\text { Sensibilidade a riscos de sustentação }\end{array}$ & $\begin{array}{l}\text { Sensibilidade a riscos de programação } \\
\text { Overhead e rateios administrativos } \\
\text { Erros de estimativa }\end{array}$ \\
\hline Programação & $\begin{array}{l}\text { Sensibilidade a riscos técnicos } \\
\text { Sensibilidade a riscos programáticos } \\
\text { Sensibilidade a riscos de sustentação } \\
\text { Erros de estimativa }\end{array}$ & $\begin{array}{l}\text { Sensibilidade a riscos de custos } \\
\text { Grau de concorrência } \\
\text { Quantidade de itens no caminho crítico }\end{array}$ \\
\hline
\end{tabular}

Fonte: Adaptado de Pritchard (2001) 
Diferentes classificações podem ser utilizadas de acordo com o tipo de projeto e a organização. A classificação facilita o processo de identificação de riscos, provendo uma base estruturada, detalhada e completa de análise. Estas classificações também podem ser representadas em forma hierárquica, chamadas estruturas analíticas de riscos, como ilustra o exemplo da Figura 3.13.

Figura 3.13 - Exemplo de estrutura analítica de riscos

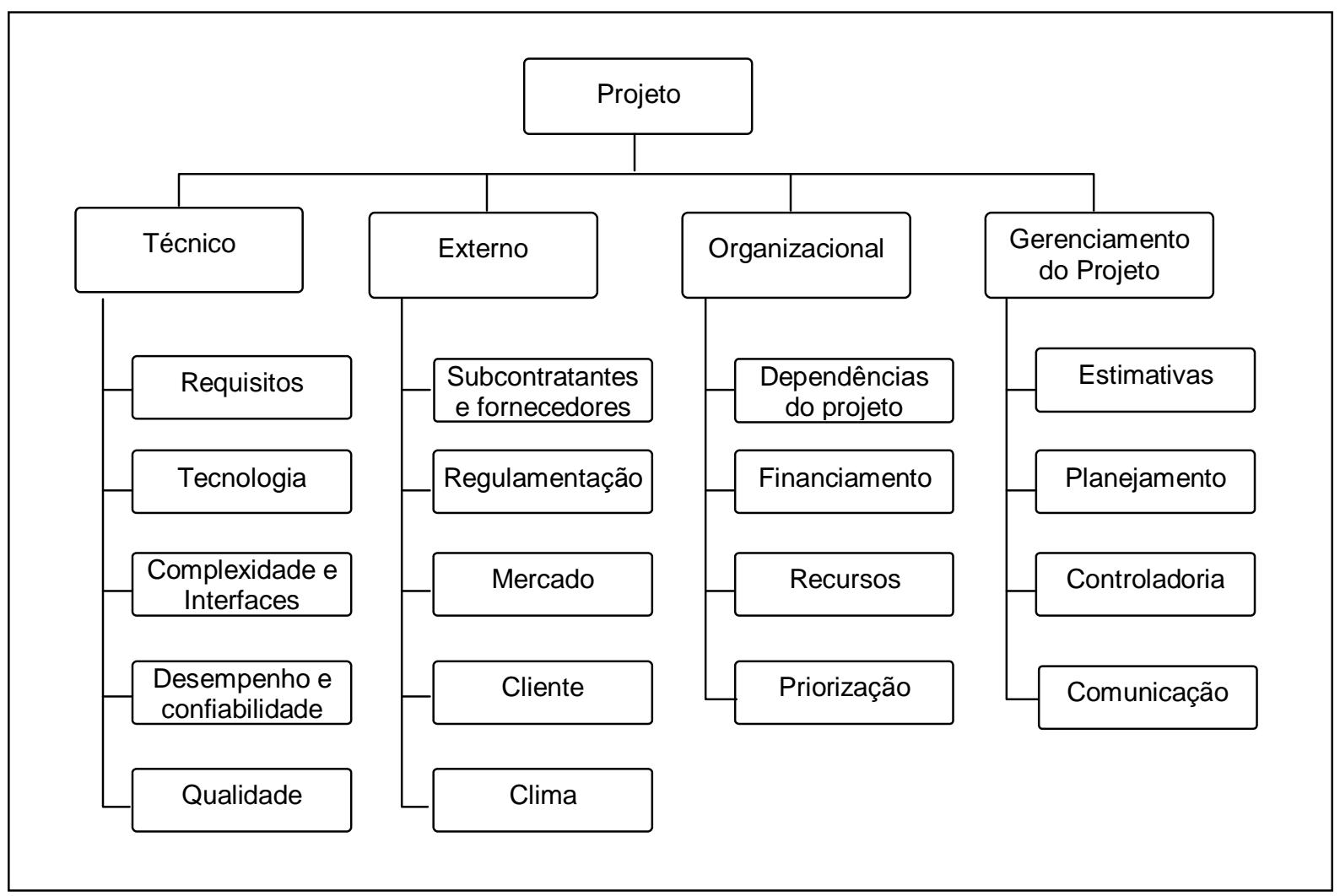

Fonte: Project Management Institute (2004)

\subsubsection{Processos de Gerenciamento de Riscos em Projetos}

Pritchard (2001) estrutura o gerenciamento de riscos em quatro processos essenciais: planejamento de riscos, avaliação de riscos, desenvolvimento de respostas aos riscos e controle de respostas aos riscos. Kerzner (2003) estrutura o gerenciamento de riscos através dos seguintes processos: planejamento dos riscos, avaliação dos riscos (identificação e análise), tratamento dos riscos, respostas aos riscos e monitoramento dos riscos. O PMI (2004) tem uma abordagem mais detalhada, organizando o gerenciamento de riscos em projetos em seis processos: 
planejamento do gerenciamento de riscos, identificação dos riscos, análise qualitativa de riscos, análise quantitativa de riscos, planejamento de respostas a riscos, e monitoramento e controle de riscos.

Os diversos autores organizam os processos de gerenciamento de riscos de forma bastante semelhante e pode-se dizer que os principais passos são: planejamento, avaliação, respostas e controle. A Tabela 3-4 apresenta uma visão geral dos processos de gerenciamento de riscos, segundo a estrutura definida pelo PMI (2004), organizada de acordo com estes principais passos.

É muito importante destacar que, apesar dos benefícios de gerenciar riscos no projeto ocorram logo nas fases iniciais, os processos devem se repetir continuamente durante todo o ciclo de vida do projeto (WIDEMAN, 1992).

Tabela 3-4 - Visão geral dos processos de gerenciamento de riscos em projetos

\begin{tabular}{|c|c|c|c|}
\hline Passos & \multicolumn{2}{|c|}{ Processo } & Descrição \\
\hline Planejamento & \multicolumn{2}{|c|}{$\begin{array}{l}\text { Planejamento do } \\
\text { gerenciamento de } \\
\text { riscos }\end{array}$} & $\begin{array}{l}\text { Abrange as decisões e documentação de como abordar, } \\
\text { planejar e executar as atividades de gerenciamento de riscos } \\
\text { no projeto. }\end{array}$ \\
\hline \multirow[t]{3}{*}{ Avaliação } & \multicolumn{2}{|c|}{$\begin{array}{l}\text { Identificação dos } \\
\text { riscos }\end{array}$} & $\begin{array}{l}\text { Abrange a determinação de quais riscos podem afetar } 0 \\
\text { projeto e a documentação de suas respectivas características. }\end{array}$ \\
\hline & $\begin{array}{l}\text { Análise dos } \\
\text { riscos }\end{array}$ & $\begin{array}{l}\text { Análise } \\
\text { qualitativa }\end{array}$ & $\begin{array}{l}\text { Priorização dos riscos identificados através determinação das } \\
\text { probabilidades e impactos dos riscos de forma qualitativa. }\end{array}$ \\
\hline & & $\begin{array}{l}\text { Análise } \\
\text { quantitativa }\end{array}$ & $\begin{array}{l}\text { Medição das probabilidades e impactos dos riscos e } \\
\text { estimativa de suas implicações nos objetivos do projeto. }\end{array}$ \\
\hline Respostas & \multicolumn{2}{|c|}{$\begin{array}{l}\text { Planejamento de } \\
\text { respostas a riscos }\end{array}$} & $\begin{array}{l}\text { Desenvolvimento de opções ações para aumentar as } \\
\text { oportunidades e reduzir as ameaças aos objetivos do projeto. }\end{array}$ \\
\hline Controle & \multicolumn{2}{|c|}{$\begin{array}{l}\text { Monitoramento e } \\
\text { controle de riscos }\end{array}$} & $\begin{array}{l}\text { Acompanhamento dos riscos identificados, identificação de } \\
\text { novos riscos, execução e avaliação da eficácia das respostas } \\
\text { planejadas. }\end{array}$ \\
\hline
\end{tabular}

Fonte: Project Management Institute (2004)

Estes processos são descritos a seguir. 


\subsubsection{Planejamento do Gerenciamento de Riscos}

Segundo Kerzner (2003), o planejamento do gerenciamento de riscos compreende:

- o desenvolvimento e documentação de uma estratégia organizada, abrangente e interativa de gerenciamento de riscos a ser adotada para o projeto;

- a determinação dos métodos a serem usados nesta estratégia e

- o planejamento adequado de recursos.

O PMI (2004) destaca que um planejamento cuidadoso aumenta a possibilidade de sucesso dos demais processos de gerenciamento de risco, garantindo que os esforços de gerenciamento de risco sejam compatíveis com a dimensão do projeto, a disponibilidade dos recursos necessários para estas atividades e estabelecendo uma base sólida para avaliação dos riscos.

Neste processo são definidas as responsabilidades dos envolvidos no gerenciamento de riscos do projeto, as técnicas, instrumentos e escalas de pontuação a serem utilizadas na avaliação dos riscos, as métricas de monitoramento, as necessidades e formatos da documentação a ser produzida, os processos de comunicação e a necessidade de treinamento adicional.

\subsubsection{Avaliação dos Riscos}

Para Kerzner (2001) a avaliação dos riscos é o estágio de "definição do problema" em gerenciamento de riscos, ou seja, o estágio em que os riscos são identificados, analisados e quantificados em termos de probabilidade e conseqüências. $O$ autor complementa que, apesar de complexa, esta é uma das partes mais importantes do gerenciamento de riscos, já que a abrangência e a qualidade das avaliações podem ter um impacto muito grande nos demais processos.

A avaliação dos riscos é composta pelos processos de identificação dos riscos e análise dos riscos, que por sua vez, pode ser qualitativa e quantitativa. 


\section{. Identificação dos Riscos}

A identificação dos riscos é o processo através do qual a percepção de um problema potencial é convertida em informação registrada (MURRAY, 1998). A identificação dos riscos requer o entendimento de quais são os objetivos do projeto.

O objetivo deste processo é gerar uma lista com todos os possíveis riscos que possam afetar o projeto. Tipicamente a identificação dos riscos do projeto é realizada por uma equipe constituída pelo gerente do projeto, os membros da equipe do projeto, e outros envolvidos que possam contribuir, garantindo que perspectivas diversas sejam representadas e consideradas. Kerzner (2003) lembra a importância de se contar com o conhecimento e a experiência de especialistas.

As técnicas e ferramentas mais utilizadas para a identificação de riscos são:

- revisão da documentação do projeto (descrição do produto do projeto, planos do projeto, descritivos técnicos, estimativas realizadas, premissas adotadas e informações históricas de projetos já realizados);

- análise de checklists ou estruturas analíticas de risco;

- técnicas de obtenção de informações como brainstorming, técnica de Delphi, entrevistas, identificação de causa-raiz, análise SWOT (pontos fortes e fracos, oportunidades e ameaças) e

- técnicas de diagramação como fluxogramas, diagrama de causa e efeito, e diagramas de influência.

Royer (2000) realça a importância de se poder contar com registros confiáveis de informações de riscos de projetos já realizados, que possam servir de base para a identificação de riscos num projeto semelhante.

\section{. Análise dos Riscos}

Neste processo, cada risco identificado é analisado e priorizado por importância. Para isto utiliza-se a probabilidade de ocorrência, os impactos correspondentes nos objetivos do projeto caso o risco ocorra, a urgência do tratamento e o grau de tolerância a riscos que a organização está disposta a correr no projeto (PMI, 2004).

Esta priorização permite identificar quais riscos serão abordados com qual profundidade, já que, como lembra Wharton (1992), o desempenho do projeto pode 
ser maximizado concentrando-se os recursos no tratamento dos riscos mais significativos.

Meredith e Mantel (2000) apontam que a principal contribuição da análise dos riscos é focar a atenção do tomador de decisão na compreensão da natureza e da extensão da incerteza associada com as variáveis usadas no processo de tomada de decisão.

Cooper e Chapman (1987) destacam que a análise de riscos proporciona os seguintes benefícios principais:

- percepção melhor e mais definida dos riscos, seus efeitos no projeto e suas interações;

- melhor planejamento de contingência e seleção de respostas aos riscos que ocorrerem e mais flexibilidade na avaliação da forma como tratar os impactos dos riscos;

- realimentação para o processo de design e planejamento em termos de maneiras de prevenir ou evitar riscos;

- alimentação para a construção e operação do projeto referente a formas de mitigar os impactos dos riscos, com a escolha da resposta e planejamento da contingência;

- redução global da exposição a riscos do projeto;

- documentação e integração do conhecimento da organização que, geralmente, permanece na mente dos indivíduos e

- conhecimento e confiança para uma melhor tomada de decisão.

A análise dos riscos pode ser realizada de forma qualitativa e/ou quantitativa.

\section{.. Análise Qualitativa dos Riscos}

Segundo o PMI (2004), a análise qualitativa dos riscos tem por objetivo avaliar o impacto e a probabilidade dos riscos identificados e priorizar estes riscos de acordo com seus efeitos nos objetivos do projeto, de forma rápida e com baixo custo.

Aqui a probabilidade e os impactos de cada risco identificados são descritos através de uma escala qualitativa, como por exemplo: muito alto, alto, moderado, baixo e muito baixo. 
O instrumento mais utilizado na avaliação qualitativa de riscos é a matriz de impacto e probabilidade. Esta matriz atribui fatores de avaliação aos riscos através da combinação da avaliação de impacto e de probabilidade. A matriz é dividida em zonas representando os riscos agrupados pelo grau de severidade. A classificação dos riscos segundo sua severidade vai guiar a forma como serão desenvolvidas as respostas aos riscos

A Figura 3.14 ilustra um exemplo de uma matriz de impacto e probabilidade bastante simples. As áreas sombreadas definem os grupos de severidade, aos quais são atribuídos valores numéricos e, logo abaixo da matriz encontra-se a recomendação de tratamento segundo a classificação de severidade.

Figura 3.14 - Exemplo de matriz de impacto e probabilidade

\begin{tabular}{|l|c|c|c|}
\hline Probabilidade & Baixo & Médio & Alto \\
\hline Alta & 2 & 2 & 3 \\
\hline Média & 1 & 1 & 2 \\
\hline Baixa & 0 & 1 & 2 \\
\hline Severidade & Recomendação & \\
\hline 3 & & \\
\hline 2 & desenvolver tratamento e plano de contingência detalhado e monitorar triggers \\
\hline 1 & desenvolver tratamento e plano de contingência \\
\hline 0 & tratar como uma premissa do projeto \\
\hline
\end{tabular}

Fonte: Adaptado de Royer (2000)

As escalas utilizadas para probabilidade, impacto e agrupamento dos riscos são definidas pela organização com base em seu grau de tolerância a riscos. Os riscos mais significativos podem ser submetidos à análise quantitativa.

Esta priorização permite que, por um lado, a equipe do projeto não desperdice recursos tratando riscos que podem não ser tão importantes e, por outro lado, não dê atenção suficiente aos riscos mais significativos.

\section{.. Análise Quantitativa dos Riscos}

O PMI (2004) define a análise quantitativa dos riscos como o processo no qual a probabilidade, os impactos do risco nos objetivos do projeto, bem como a extensão 
do risco do projeto como um todo são analisados numericamente. É possível analisar as interações entre os riscos e alguns dos possíveis resultados para o projeto, em termos de custo, prazo e escopo.

Este processo permite:

- determinar a probabilidade de atingir um objetivo específico do projeto;

- quantificar a exposição a risco do projeto e determinar as reservas de contingência adequadas de custo e prazo;

- identificar riscos que requerem maior atenção, quantificando sua contribuição relativa ao risco do projeto e

- identificar metas realistas de custo, prazo e escopo.

A análise quantitativa requer a utilização de técnicas e modelos matemáticos específicos tais como:

- identificação das distribuições de probabilidade a serem adotadas para os eventos de riscos;

- análise de sensibilidade, que ajuda, a determinar quais riscos têm o maior potencial de impacto no projeto. O impacto no projeto da incerteza de cada elemento é examinado, enquanto todos os outros elementos incertos são mantidos em seus valores de base;

- simulações do projeto: que através de modelos matemáticos traduzem as incertezas especificadas em impactos potenciais nos objetivos do projeto, expressas para o projeto como um todo (aqui se destaca a utilização da simulação de Monte Carlo);

- árvores de decisão: que descrevem, através de um diagrama em forma de árvore, as combinações possíveis nos pontos de decisão. Considera as implicações de escolher cada uma das alternativas possíveis, incorporando as probabilidades dos riscos e o custo ou recompensa de cada caminho lógico da decisão;

- análise do valor monetário esperado: utilizada em conjunto com as árvores de decisão, calcula, para cada caminho da árvore, a somatória da multiplicação do valor de cada decisão pela probabilidade de ocorrência na árvore de decisão, permitindo identificar a melhor escolha através de um valor monetário e

- análise da rede de precedências do projeto, incluindo análise de cenários. 


\subsubsection{Planejamento de Respostas aos Riscos}

O planejamento de respostas aos riscos é o processo voltado a definir as ações necessárias para aproveitar as oportunidades e para responder às ameaças ao projeto, ou seja, selecionar das várias possíveis respostas, a mais adequada a cada um dos riscos.

O PMI (2004) destaca que as respostas aos riscos devem ser compatíveis com sua severidade, devem ter custo justificável, acontecer em tempo hábil, ser realistas no contexto do projeto e estar em concordância com as partes envolvidas. Além disso, é importante eleger um ou mais responsáveis para implementar e controlar cada resposta definida.

Várias estratégias podem ser usadas para o tratamento dos riscos, devendo-se escolher a estratégia mais adequada para cada risco. Algumas vezes é possível utilizar uma combinação de estratégias.

As principais estratégias para tratamento de riscos negativos ao projeto são:

- Evitar: é o ato de eliminar a causa do evento de risco ou os impactos decorrentes nos objetivos do projeto. Alguns riscos que ocorrem no início do projeto podem ser evitados através do esclarecimento dos requisitos do projeto, da melhora na comunicação, da obtenção de recursos mais capacitados, da coleta de informações adicionais, da seleção adequada de fornecedores, por exemplo. Kerzner (2003) lembra, entretanto, que nem todos os riscos podem ser evitados.

- Transferir: nesta estratégia a responsabilidade pelo gerenciamento do risco e pelos impactos totais ou parciais do mesmo é transferida para terceiros, geralmente sob a forma de contrato. Fazem parte deste tipo de estratégia, tipicamente, seguros, cláusulas de incentivo, modalidades de contratação, garantias, fianças, premiação por desempenho. Gray e Larson (2003) destacam que neste tipo de estratégica, os riscos não são eliminados, apenas o seu gerenciamento é entregue a uma outra parte, que assume a responsabilidade mediante remuneração.

- Mitigar: significa realizar ações para reduzir a probabilidade de ocorrência e/ou o impacto do risco a um determinado nível considerado aceitável, por exemplo, 
adicionando recursos ao projeto, realizando mais testes, escolhendo um fornecedor mais confiável, desenvolvendo sistemas redundantes.

- Aceitar: algumas vezes é tomada a decisão consciente de não se alterar o plano do projeto para tratar determinados riscos. Isto pode acontecer quando o custo de tratar o risco é muito alto em relação aos impactos gerados (e estes são aceitáveis), ou quando não há outra estratégia viável. Nestes casos, planos de contingência podem ser desenvolvidos. Um plano de contingência é um plano alternativo, para entrar em ação caso o evento de risco venha a ocorrer (WARD, 2000). Quando a estratégia de aceitação inclui um plano de contingência é chamada de aceitação ativa. Caso contrário, a aceitação é chamada passiva e a equipe do projeto só toma alguma ação quando e se o risco ocorrer.

O desenvolvimento de planos de contingência com antecedência pode reduzir significativamente o prazo e o custo das ações a serem tomadas caso um risco ocorra. Algumas vezes, o plano de contingência pode incluir um segundo plano alternativo, a ser colocado em ação caso o primeiro não se mostre eficaz (fallback plan).

Hillson (2002), assim como o PMI (2004), sugere que, da mesma forma como os riscos, as oportunidades também devem ser gerenciadas para maximizar a probabilidade e os impactos positivos. Nesta abordagem a estratégia "evitar" transforma-se em "explorar", para garantir que a oportunidade de fato ocorra; a estratégia "transferir" transforma-se em "compartilhar" com terceiros mais capacitados a converter a oportunidade para o projeto; a estratégia "mitigar" transforma-se em "ampliar", aumentando a probabilidade e/ou os impactos da oportunidade; e, finalmente, a estratégia "aceitar" transforma-se em "ignorar".

Kerzner (2003) lembra que as atividades, prazos e recursos necessários para o tratamento dos riscos devem ser incluídos no plano do projeto.

\subsubsection{Monitoramento e Controle dos Riscos}

Kerzner (2003) define controle de riscos como o processo de perceber continuamente as condições de um projeto e desenvolver opções e posições 
alternativas para permitir soluções de menor risco. Ward (2000) o descreve como o processo de implementar as estratégias de risco.

O PMI (2004) destaca que este é o processo através do qual os riscos identificados e analisados são acompanhados, os planos de risco são executados, a eficácia da implantação destes planos é medida, novos riscos são identificados e as mudanças em relação aos riscos são analisadas, documentadas e respondidas.

Kerzner (2003) também inclui neste processo a documentação das lições aprendidas no gerenciamento de riscos para beneficiar futuras decisões.

Este processo deve ser executado durante todo o ciclo de vida do projeto, considerando a evolução dos fatos e as mudanças de risco ao longo do desenvolvimento do projeto.

Royer (2000) sugere que um monitoramento eficaz deve dispor, para cada risco, de indicadores ou sintomas de risco (triggers), a serem monitorados continuamente, e que apontam que um risco ocorreu ou está prestes a ocorrer. Ao atingir níveis préestabelecidos, estes sinais de alerta determinam quando o plano de contingência deve ser implementado (PMI, 2004).

\subsubsection{Exposição de um Projeto a Riscos}

Poucas referências de gerenciamento de riscos abordam a avaliação da exposição a riscos do projeto como um todo (HILLSON, 2007b).

Smith e Merritt (2002) definem exposição do projeto a riscos como a somatória do valor da exposição do projeto a cada risco.

Kendrick (2003) alerta que esta somatória proporciona uma base de avaliação, porém tende a subestimar o risco total do projeto, uma vez que assume que os riscos do projeto são independentes e, portanto, sem correlação. Hillson (2007b) também alerta que pode haver inter-relacionamentos entre os riscos de um projeto, sugerindo este assunto como um dos temas a serem melhor desenvolvidos no futuro do gerenciamento de riscos. 
Numa abordagem qualitativa, Royer (2000) sugere a seguinte equação para determinação da exposição a riscos do projeto como um todo:

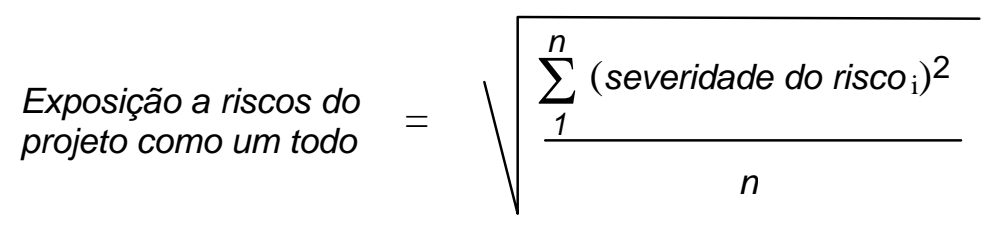

onde i representa cada risco avaliado no projeto, $\mathrm{n}$ representa o número total de riscos avaliados, e os valores de severidade de cada risco são extraídos de uma matriz de impacto e probabilidade como a descrita na Figura 3.14.

Segundo Royer (2000), a utilização da potência quadrada no cálculo desta média tem o intuito de atribuir peso maior para os riscos de maior intensidade, já que estes influenciam mais fortemente o projeto como um todo.

Kendrick (2003) sugere, ainda, uma forma qualitativa de avaliar a exposição do projeto a riscos, através de um questionário e um modelo de pontuação (scoring model) atribuindo pesos e notas às questões respondidas.

\subsection{Gerenciamento de Riscos em Portfolio de Projetos}

O Federal CIO Council (2002) destaca a importância de se entender as diferenças e os relacionamentos entre $o$ gerenciamento de portfolio de projetos $e$ gerenciamento de projetos e utilizar adequadamente cada um deles.

O foco do gerenciamento de projetos é fazer com que cada projeto específico atinja seus próprios objetivos (técnicos, de desempenho, de custo, de prazo). Já o gerenciamento de portfolio tem foco num nível mais agregado. Seu objetivo principal é identificar, selecionar, financiar, monitorar e manter o conjunto apropriado de projetos necessários a atingir os objetivos e metas da organização. Envolve a consideração de custos, riscos e retornos de todos os projetos no conjunto, sem desconsiderar a saúde de cada um dos projetos individuais.

A mesma diferenciação deve ser observada quando se trata de riscos. 
No âmbito do projeto, a avaliação dos riscos está inserida no gerenciamento individual do projeto. No âmbito do portfolio, a avaliação dos riscos dos projetos influenciará as decisões de escolha e priorização dos projetos que irão compor o portfolio, bem como a repriorização dos projetos em andamento. Neste nível, as interações, convergências e propagações dos riscos de cada projeto em relação aos demais projetos do portfolio também precisam ser consideradas, o que torna necessária uma abordagem integrada e aumenta a complexidade do gerenciamento de riscos.

De acordo com McFarlan (1981), os gestores deveriam utilizar uma abordagem baseada em risco para a seleção e gerenciamento do portfolio de projetos. Ele observa que portfolios desbalanceados em relação a riscos podem levar a organização a sofrer quebras operacionais ou deixar espaço livre para a concorrência.

Benko e McFarlan (2003) defendem que o portfolio de projetos de uma organização pode ser gerenciado de forma similar a um portfolio de investimentos, fazendo uma analogia com a teoria de Markowitz (1959). Esta teoria, denominada Modern Portfolio Theory, afirma que, num universo de possíveis investimentos, dado um determinado nível de risco que o investidor está disposto a correr, é possível compor um portfolio eficiente para obter o máximo benefício, considerando as combinações de valor e risco destes possíveis investimentos.

Entre os princípios básicos desta teoria estão:

- um portfolio ótimo gera o máximo retorno possível para um determinado nível de risco;

- os riscos esperados provêm de duas fontes: o risco do próprio investimento e o risco dos relacionamentos, este último derivado de como o investimento se relaciona com os demais no portfolio e

- a diversificação reduz o risco do portfolio como um todo através da minimização dos relacionamentos de dependência entre os diferentes investimentos.

Segundo Benko e McFarlan (2003), estes princípios podem ser estendidos a um portfolio de projetos de uma organização da seguinte forma:

- projetos individuais são semelhantes a investimentos: são investimentos que a organização faz em seu futuro; 
- risco para um projeto individual inclui os desvios no alcance dos benefícios do projeto (tanto financeiros como não financeiros), atrasos nos prazos e estouro de orçamento;

- o risco esperado do portfolio é a combinação dos riscos de investimentos: os riscos de cada projeto individualmente, o risco decorrentes de como os projetos se relacionam entre si e a complexidade do portfolio como um todo. Por exemplo: dois ou mais projetos podem depender um do outro de forma que sua programação tenha que ser seqüencial; da mesma forma, sem a devida coordenação dois ou mais projetos podem concorrer pelos mesmos recursos simultaneamente. Os riscos só podem ser totalmente compreendidos e mitigados através da análise conjunta de todos os projetos do portfolio e

- as organizações, assim como os indivíduos, escolhem entre múltiplos portfolios ótimos. A preferência pelo risco/retorno é dirigida pelo seu contexto competitivo e pelo perfil de risco de sua liderança.

A prática de utilizar técnicas de gerenciamento de portfolio de investimentos para gerenciar portfolio de projetos não é algo novo. O próprio McFarlan (1981) defende esta abordagem há mais de 20 anos, como expressa seu artigo publicado na Harvard Business Review em 1981. Entretanto grande parte das organizações ainda gerencia seus portfolios como uma coleção de projetos independentes e não como um portfolio integrado e coeso. De acordo com uma pesquisa do Gartner Group (2001), apenas $10 \%$ das grandes empresas utilizam o gerenciamento de portfolio como uma ferramenta de valor. Numa pesquisa mais recente, Reyck et al. (2005) também observaram que apenas $33 \%$ das empresas pesquisadas confirmaram examinar a diversificação para reduzir o risco do portfolio, enquanto $59 \%$ realizam análise de risco-retorno ao nível do portfolio como um todo.

O gerenciamento do portfolio de forma não integrada leva a problemas como duplicidade na avaliação dos benefícios, perda de oportunidades de compartilhamento de idéias e conhecimento ou de reutilização de trabalhos já desenvolvidos, agravamento de problemas comuns a vários projetos, proliferação de duplicidades e até mesmo projetos trabalhando em direções opostas. Como resultado desta situação o risco do portfolio como um todo aumenta e, por conseguinte, o retorno sobre o investimento cai. 


\subsubsection{A Exposição a Riscos e as Fases de Gerenciamento de Portfolio}

A exposição a riscos e a disposição da organização para correr riscos influenciam cada uma das grandes fases do gerenciamento de portfolio de projetos sintetizadas no item 3.3.4 deste trabalho.

Esta influência é esquematizada na Figura 3.15 e será detalhada a seguir.

Figura 3.15 - A exposição a riscos e as fases do gerenciamento de portfolio de projetos

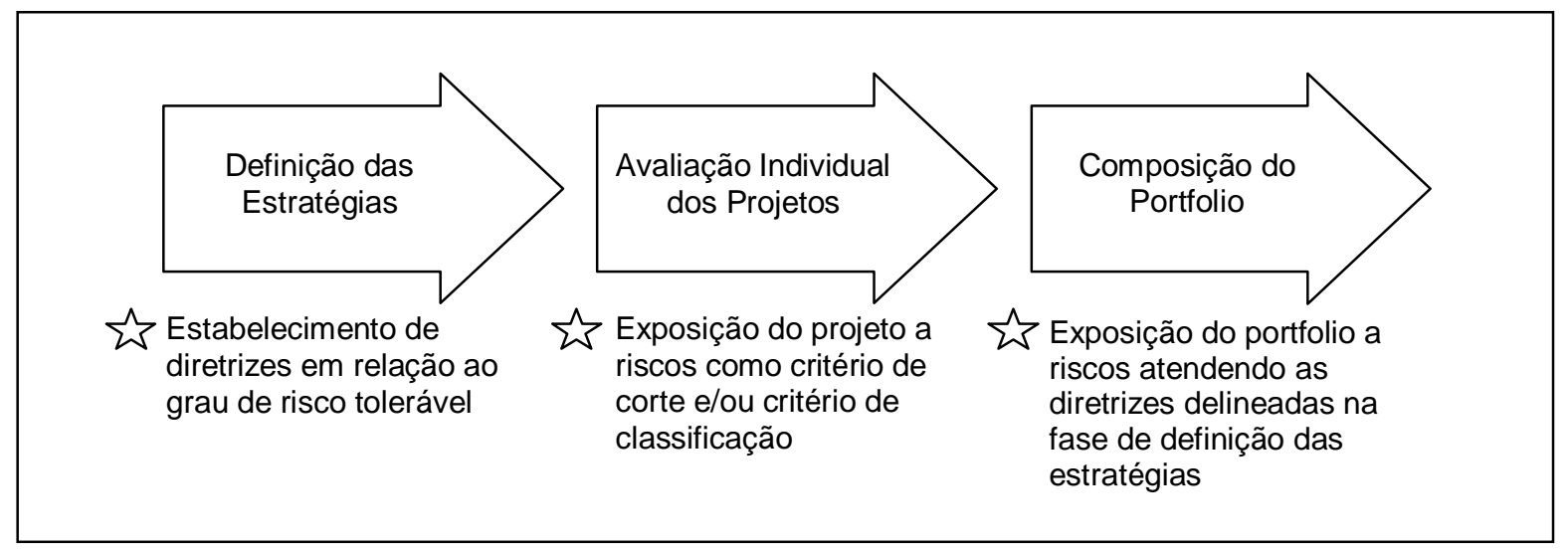

Fonte: Elaborado pela autora

É importante lembrar que o processo de decisão em gerenciamento de portfolio de projetos é baseado em múltiplos critérios e, portanto, o grau de exposição a riscos deve ser sempre considerado em conjunto com os demais critérios eleitos, o que torna o processo fortemente interativo. A escolha dos critérios utilizados faz parte do processo de planejamento do gerenciamento de portfolio de projetos e é direcionada pelo foco estratégico da organização.

\subsubsection{Definição das Estratégias}

Levine (2005) lembra que toda organização gerencia tipos de projetos com características diferentes, como por exemplo:

- projetos de manutenção e utilidades: que geralmente dão o suporte necessário aos produtos ou serviços em operação; 
- projetos de crescimento ou melhoria: que geralmente suportam as iniciativas estratégicas e representam a manutenção da organização em posição competitiva;

- projetos de transformação: que são oportunidades para levar a organização a um novo patamar ou para introduzir novos produtos ou serviços que irão proporcionar maiores fatias de mercado ou a conquista de novos mercados;

- projetos para clientes externos: cujo benefício primário é gerar lucro.

Cada uma destas categorias de projetos tem perfis de risco diferentes. Uma organização cujo foco está mais voltado ao crescimento no longo prazo pode por mais ênfase em projetos de transformação e, portanto, assumir maior grau de risco. Já uma organização com foco em diminuição de custos pode por mais ênfase em projetos de manutenção e melhorias, que têm relativamente menores riscos. Algumas organizações, ainda, têm como negócio principal, a venda de projetos para clientes. Para estas organizações, o sucesso destes projetos está diretamente ligado ao sucesso da empresa como um todo e a preocupação com riscos tende a levar a um perfil mais conservador.

$\mathrm{Na}$ fase de Definição das Estratégias, é atribuição do nível executivo da organização a alocação do orçamento disponível entre as diferentes categorias de projetos e o estabelecimento de diretrizes em relação ao grau de risco que se dispõe a correr. Um exemplo destas diretrizes pode ser visto na Figura 3.16.

Figura 3.16 - Estratégias de distribuição de orçamento e perfil de risco

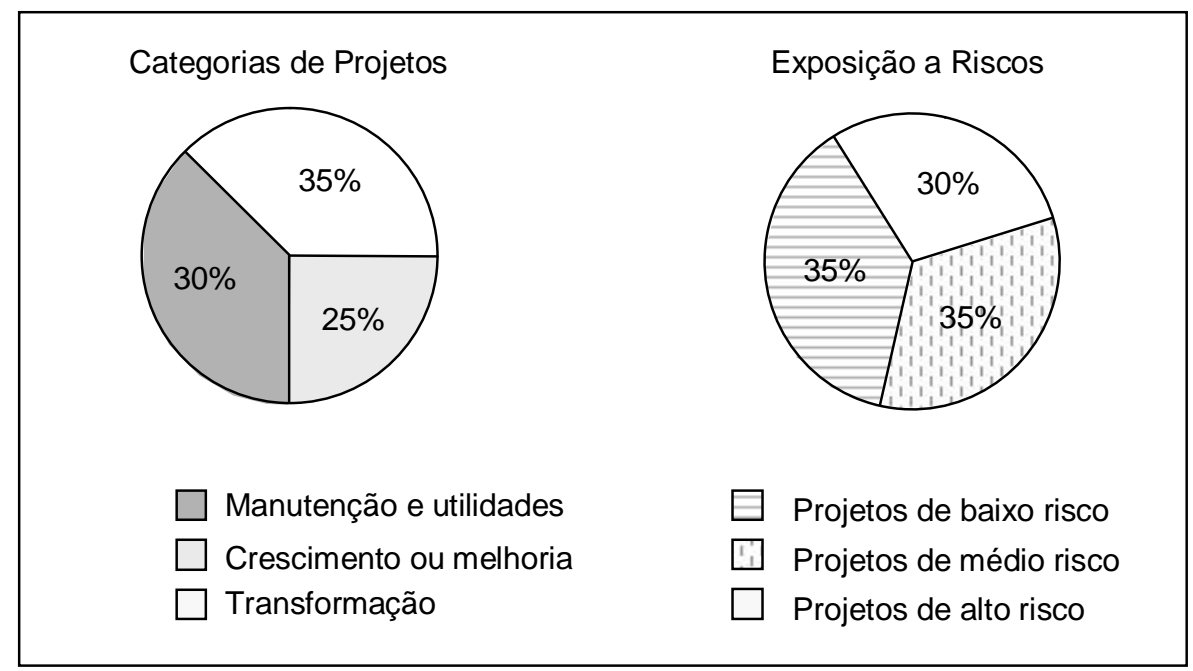

Fonte: Elaborado pela autora 
Estas diretrizes vão nortear, mais tarde, o balanceamento do portfolio no que tange à exposição a riscos, levando à composição adequada de projetos com grau de exposição a riscos diferentes.

\subsubsection{Avaliação Individual dos Projetos}

Nesta fase cada projeto é avaliado segundo critérios pré-estabelecidos. O objetivo aqui é produzir uma lista priorizada dos projetos que tragam valor à organização. Como lembra Levine (2005), a definição de valor certamente difere de acordo com o foco, as estratégias e os tipos de projetos da organização e esta deve escolher os critérios de avaliação que melhor reflitam o seu conceito de valor.

Podem ser utilizados dois tipos de critérios: critérios de corte ou pré-filtragem (aqueles cujo não atendimento implica na desclassificação do projeto) e critérios de classificação (aqueles que direcionarão a pontuação de cada projeto e a conseqüente priorização).

Nesta fase, a exposição a riscos pode ser um critério escolhido de avaliação, como critério de corte e/ou como critério de classificação. Por exemplo, os projetos que envolvem um grau excessivo de risco ou não estão em linha com a cultura da organização podem ser desclassificados. Da mesma forma, o grau de exposição a riscos do projeto pode ser considerado na classificação do projeto em conjunto com os demais critérios de avaliação.

Neste caso é importante que se possa avaliar qual o grau de exposição a riscos de cada projeto, idealmente conduzindo uma avaliação formal dos riscos do projeto:

- identificando os eventos de risco potenciais;

- avaliando a probabilidade de ocorrência de cada risco;

- estimando o impacto causado pelos riscos, caso ocorram;

- identificando possíveis ações para redução das probabilidades e impactos;

- calculando o custo destas ações e o efeito nos impactos e

- incorporando estes custos na valorização do projeto.

Dependendo da técnica de avaliação escolhida, a exposição a riscos do projeto pode ser utilizada diretamente como critério, por exemplo, numa abordagem com 
modelos de pontuação ou balanced scorecard, ou como um modificador de oportunidade, onde o valor ou benefícios esperados do projeto podem ser modificados pelo risco de que estes benefícios não aconteçam, por exemplo, numa abordagem de avaliação com índices financeiros.

\subsubsection{Composição do Portfolio}

Esta fase inclui a análise conjunta dos projetos avaliados e priorizados com vistas à identificação dos inter-relacionamentos: similaridades, sinergias, competição por recursos, prazos e outras restrições.

O balanceamento entre os projetos selecionados é realizado através de análises interativas em dimensões pré-estabelecidas do portfolio, tais como riscos, tamanho dos projetos e horizontes de curto e longo prazo. Os projetos selecionados sofrem, então, os ajustes de prioridade e recursos necessários.

Aqui, portanto, também a exposição a riscos é um fator determinante, na medida em que a composição do portfolio deve atender as diretrizes de riscos delineadas na fase de definição das estratégias.

A avaliação do grau de exposição a riscos do portfolio como um todo deve abranger:

- os riscos individuais de cada projeto tratados na fase de avaliação individual dos projetos;

- a identificação de riscos comuns a vários projetos, cujas ações de mitigação podem ser únicas, levando a uma diminuição no custo total do tratamento de riscos do portfolio e minimizando a exposição a riscos do portfolio como um todo;

- a identificação de propagações de riscos entre projetos, ou seja, quando riscos de um projeto podem agravar os riscos dos demais, levando a um aumento na exposição a riscos do portfolio como um todo, o que acontece tipicamente quando há uma relação de dependência sequencial entre os projetos;

- a identificação de riscos relativos a sobreposições de benefícios esperados, quando mais de um projeto tem como objetivo o alcance do mesmo conjunto de benefícios, cuja magnitude não pode superar um certo limite, ou seja, a soma 
total dos benefícios esperados é menor do que a soma dos benefícios individuais dos projetos;

- a identificação de riscos relativos à competição simultânea pelos mesmos recursos, quando planejado individualmente cada projeto é capaz de terminar com sucesso, mas coletivamente não, o que pode afetar vários projetos;

- a estimativa do impacto causado por estes novos riscos, caso ocorram;

- a identificação de possíveis ações para redução das probabilidades e impactos dos novos riscos;

- o cálculo do custo destas ações e o efeito nos impactos estimados e

- a incorporação destes custos na valorização do portfolio.

Vale lembrar que os projetos são geralmente avaliados e balanceados dentro de sua categoria, com um conjunto de critérios que podem divergir de categoria para categoria de acordo com as respectivas características.

Um dos instrumentos mais utilizados para mostrar graficamente o balanceamento do portfolio é o digrama de bolhas. A Figura 3.17 ilustra um diagrama de bolhas de risco/benefício, onde cada projeto é representado por uma bolha. O tamanho da bolha expressa os recursos alocados ao projeto e as cores mostram a categoria de projeto, por exemplo.

Figura 3.17 - Exemplo de diagrama de bolhas risco/benefício

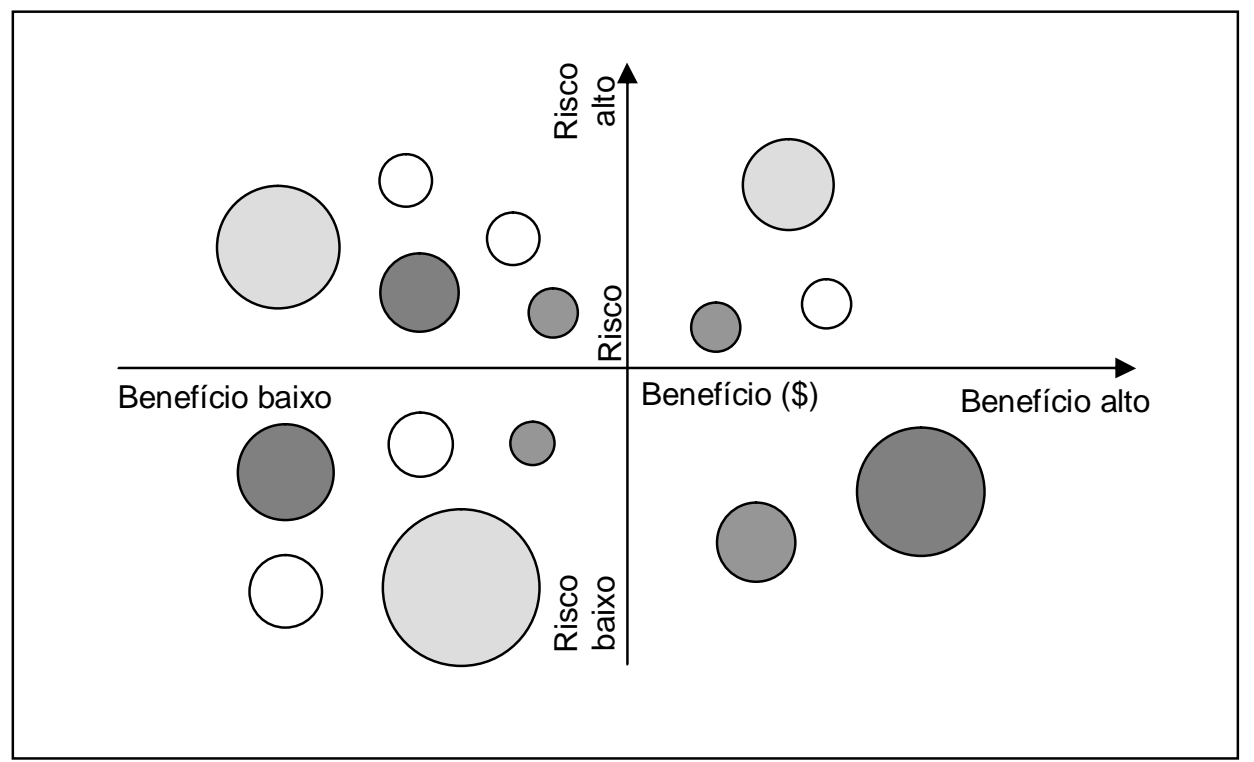

Fonte: Adaptado de Cooper; Edgett e Kleinschmidt (2001) 


\section{PROCEDIMENTO PARA DETERMINAÇÃO DO GRAU DE EXPOSIÇÃO A RISCOS DO PORTFOLIO DE PROJETOS}

\subsection{Estrutura Geral do Procedimento}

A seguir é apresentado um procedimento estruturado que permite avaliar o grau de exposição a riscos de um portfolio de projetos, considerando os interrelacionamentos entre os riscos dos projetos individuais e outros riscos decorrentes da composição do portfolio.

$O$ procedimento parte da identificação $e$ análise dos riscos que afetam $O$ atendimento dos objetivos estratégicos do portfolio. A análise dos efeitos dos riscos no atendimento de cada objetivo estratégico permite determinar o grau de exposição a riscos a que cada objetivo está exposto. A ponderação dos graus de exposição a riscos de cada um dos objetivos estratégicos conduz à determinação do grau de exposição a riscos do portfolio de projetos como um todo. Estas as análises são guiadas pela tolerância a riscos da organização.

O procedimento foi elaborado com base nos conceitos, técnicas e instrumentos descritos na revisão bibliográfica efetuada, combinando as idéias dos diversos autores sobre $o$ assunto.

Neste contexto, o termo risco está sendo empregado para referenciar um evento incerto que, se ocorrer, causa um efeito negativo no atendimento dos objetivos desejados.

O procedimento toma como referência as três grandes fases do gerenciamento de portfolio descritas no item 3.3.4 do capítulo anterior e os processos do gerenciamento de riscos em projetos descritos no item 3.7.3 e sintetizados na Tabela 3-4, considerados suficientes para os propósitos deste tratamento.

Foi considerado também, que os mesmos processos, técnicas e ferramentas de gerenciamento de riscos em projetos podem ser aplicados ao gerenciamento de portfolio de projetos, desde que adequados ao foco deste último, conforme exposto no item 3.6.1. 
A Figura 4.1, a seguir, apresenta o fluxo do procedimento proposto e destaca sua correspondência com a estrutura dos processos de gerenciamento de riscos em projetos, representada pelas áreas sombreadas.

Figura 4.1 - Procedimento para determinação do grau de exposição a riscos de um portfolio de projetos

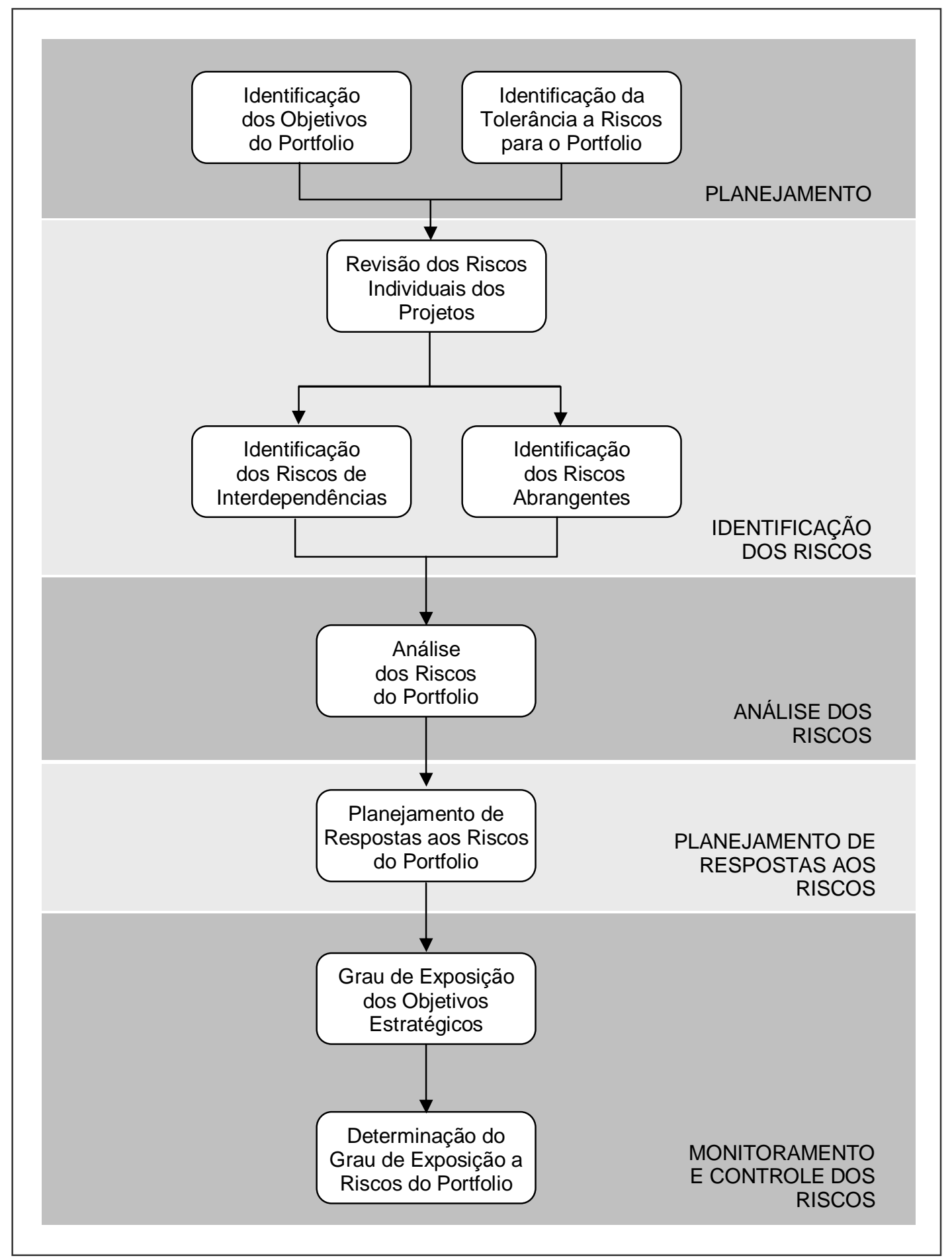

Fonte: Elaborado pela autora 
O procedimento proposto visa ser aplicável pelas organizações que estejam adotando as técnicas de gerenciamento de portfolio de projetos, mesmo que não disponham de processos maduros ou dos recursos necessários para 0 gerenciamento quantitativo de riscos. Por este motivo, o procedimento alia abordagens numéricas e qualitativas, sem fazer uso de técnicas mais sofisticadas como análise de Monte Carlo, análise de sensibilidade, árvores de decisão ou outros tratamentos probabilísticos que requerem maior nível de conhecimento, informação e esforço.

A Figura 4.2 representa a contextualização do procedimento na integração entre o planejamento estratégico, o gerenciamento do portfolio de projetos, o gerenciamento de riscos dos projetos e o gerenciamento de riscos no portfolio de projetos.

Figura 4.2 - Contexto do procedimento proposto

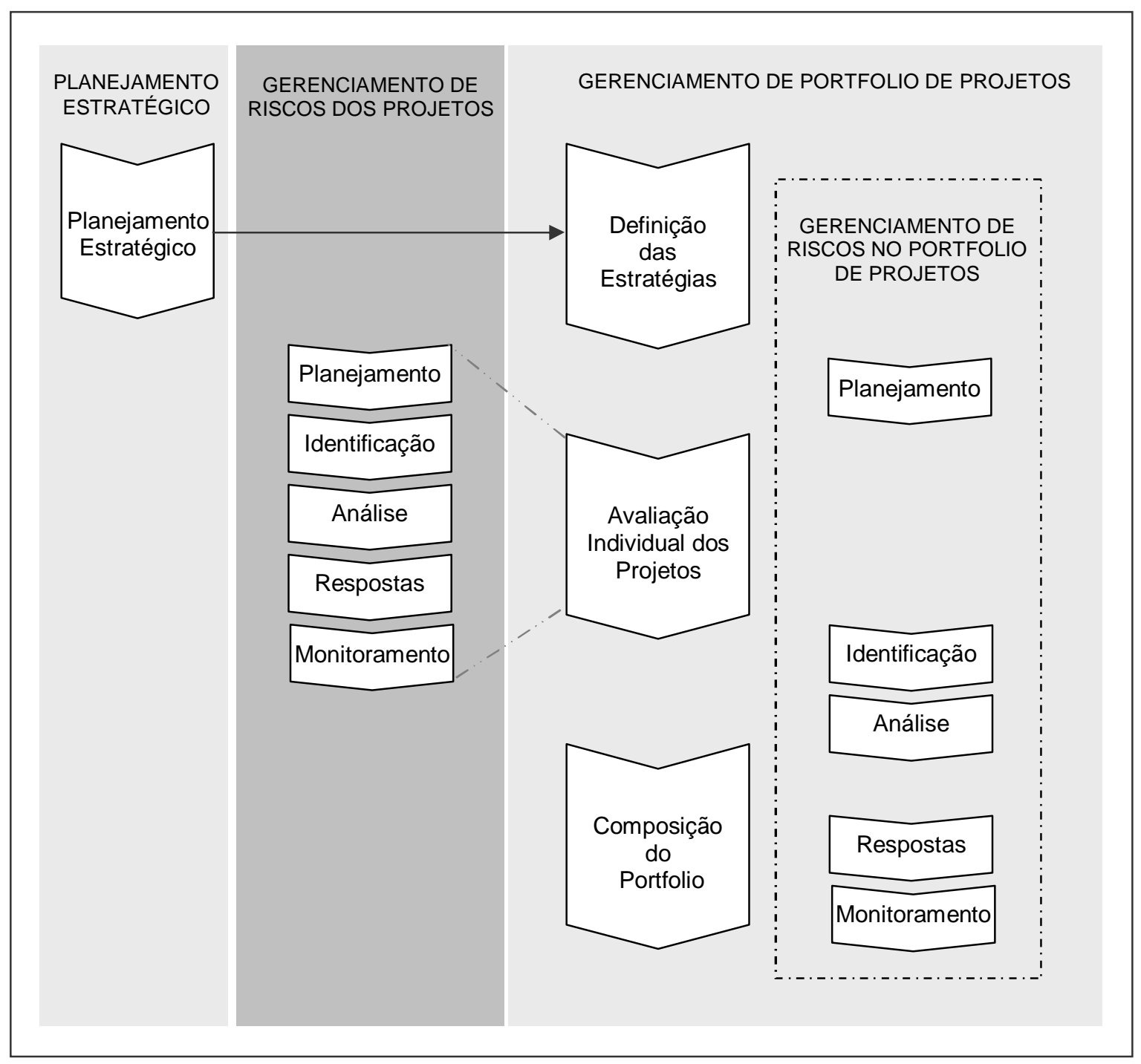

Fonte: Elaborado pela autora 
A utilização do procedimento pressupõe que:

- a organização tem um plano estratégico com objetivos claros e metas mensuráveis;

- a organização tem processos definidos para o gerenciamento de portfolio de projetos;

- os objetivos do portfolio de projetos estão ligados aos objetivos estratégicos definidos no planejamento estratégico;

- os projetos candidatos a compor o portfolio de projetos, bem como os projetos em andamento são analisados e selecionados segundo critérios pré-definidos e

- a organização tem processos definidos para o gerenciamento de projetos, que incluem o gerenciamento dos riscos dos projetos, mesmo que de forma simplificada.

A seguir são detalhados os passos deste procedimento.

\subsection{Identificação dos Objetivos Estratégicos do Portfolio de Projetos}

Neste passo são identificados os objetivos estratégicos que o portfolio de projetos visa atender e os benefícios esperados de cada projeto para o atendimento destes objetivos, ou seja, qual a parcela de contribuição de cada projeto.

Os objetivos estratégicos vinculados ao portfolio provêm da Definição das Estratégias. Nesta fase do gerenciamento de portfolio de projetos, os objetivos estratégicos da organização foram desdobrados em possíveis projetos capazes de transformar as estratégias em resultados. Um exemplo de objetivo estratégico é: "aumentar a participação de mercado em 10\%".

Os benefícios esperados representam a ligação entre os projetos e os objetivos estratégicos. Cada projeto proporciona novas competências, conhecimentos, melhorias e resultados que permitem à organização alcançar o que foi definido através de seu planejamento estratégico. Assim, não é somente o produto final do projeto (o que terá sido prontificado ao final do projeto) que o liga aos objetivos estratégicos, mas principalmente os benefícios que ele proporciona. Um projeto para desenvolvimento de um novo produto, por exemplo, pode ter como benefício 
esperado "proporcionar um aumento nas vendas", elevando em 5\% a participação de mercado, ou seja, atendendo $50 \%$ do objetivo estratégico "aumentar a participação de mercado em 10\%”.

Os benefícios esperados de cada projeto em relação aos objetivos estratégicos provêm da Avaliação Individual dos Projetos, em que os projetos foram categorizados, avaliados e submetidos à filtragem e que resultou na lista dos projetos com maior valor potencial para a organização.

Os resultados deste passo são documentados em uma matriz como a da Tabela 4-1.

Tabela 4-1 - Relacionamento entre os projetos e os objetivos estratégicos do portfolio

\begin{tabular}{|c|c|c|c|c|}
\hline Projeto & $\begin{array}{l}\text { Objetivo } \\
\text { Estratégico } 1\end{array}$ & $\begin{array}{l}\text { Objetivo } \\
\text { Estratégico } 2\end{array}$ & $\cdots$ & $\begin{array}{l}\text { Objetivo } \\
\text { Estratégico j }\end{array}$ \\
\hline Projeto 1 & Benefício 1,1 & & & \\
\hline Projeto 2 & & Benefício 2,2 & & \\
\hline Projeto 3 & Benefício 3,1 & Benefício 3,2 & & \\
\hline \multicolumn{5}{|l|}{$\ldots$} \\
\hline Projeto i & & & & Benefício i,j \\
\hline
\end{tabular}

Fonte: Elaborado pela autora

Esta tabela mostra que o projeto 1 está ligado ao atendimento do objetivo estratégico 1 através do benefício esperado 1,1, enquanto o projeto 3 está ligado ao atendimento dos objetivos estratégicos 1 e 2 através dos benefícios esperados 3,1 e 3,2. Sempre que possível, os benefícios esperados devem ser quantificados.

\subsection{Identificação da Tolerância a Riscos para o Portfolio de Projetos}

A tolerância a riscos define a disposição da organização de correr riscos frente à possibilidade de obter os benefícios esperados. (KERZNER, 2003).

Para o portfolio de projetos, a tolerância a riscos determina quais desvios são considerados aceitáveis em relação ao atendimento de cada objetivo estratégico.

Neste passo são definidas as tolerâncias da organização a riscos para cada objetivo do portfolio de projetos. 
A tolerância a riscos para o portfolio de projetos pode ser expressa:

- através de um índice numérico, que representa o limite tolerado de exposição a riscos do portfolio de projetos relativamente a uma escala qualitativa, dividida em faixas de graduação de exposição a riscos ou

- através do desvio máximo tolerado para cada objetivo estratégico do portfolio de projetos, em termos quantitativos, também acompanhado de faixas de graduação.

Um exemplo de cada uma destas formas é apresentado na Figura 4.3.

Figura 4.3 - Exemplo de representação da tolerância a riscos para o portfolio de projetos

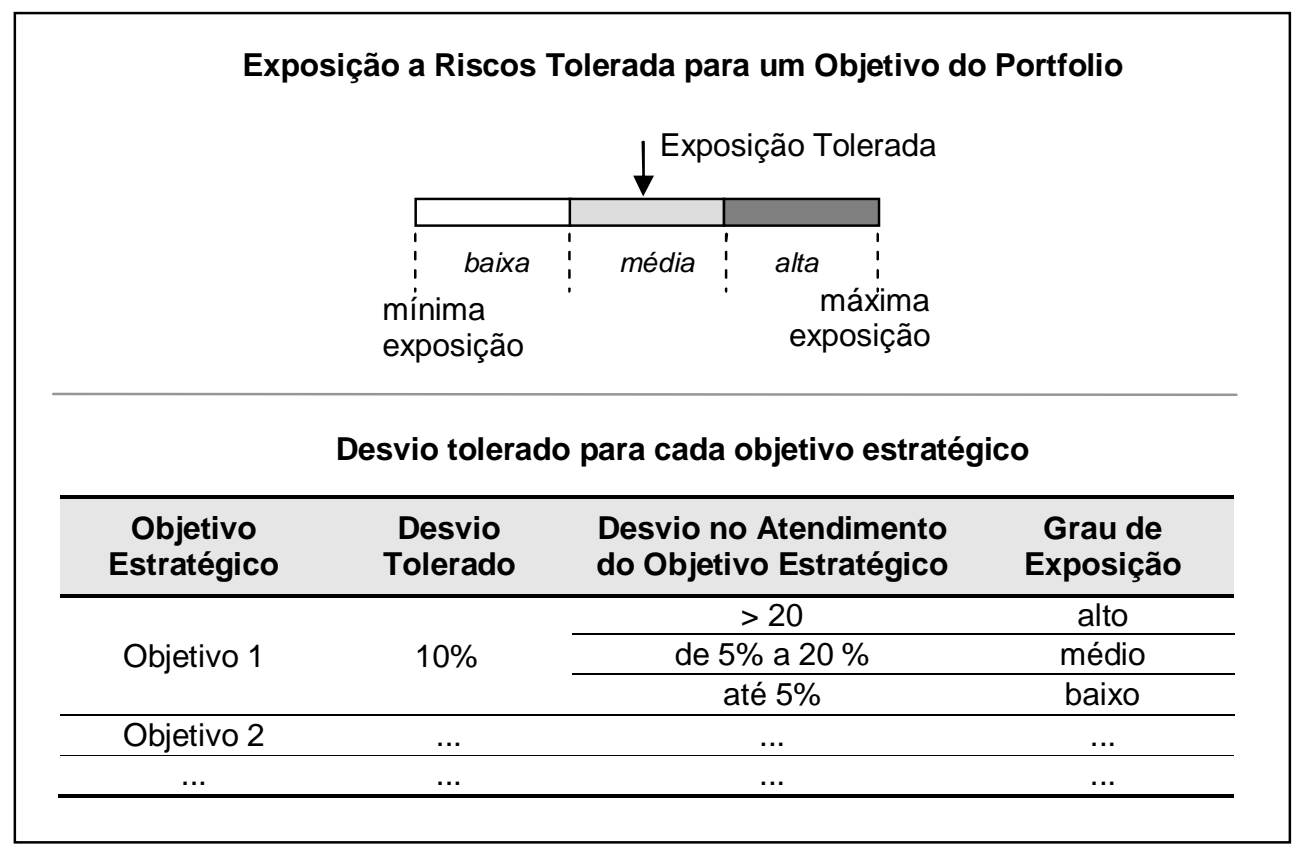

Fonte: Elaborado pela autora

A tolerância a riscos influencia diretamente a percepção de quem avalia os riscos, bem como direciona as decisões de tratamento. Os instrumentos utilizados na análise dos riscos, descritos nos passos seguintes, devem ser capazes de refletir a sensibilidade da organização frente aos impactos causados de forma coerente com os instrumentos utilizados para expressar a tolerância a riscos. A definição consistente das escalas, critérios de avaliação, faixas de graduação e modelos de pontuação utilizados garante esta coerência. Estas definições também fazem parte deste passo, porém, para facilitar o entendimento, estes instrumentos são apresentados nos passos a seguir, na medida em que são requeridos. 


\subsection{Identificação dos Riscos}

A identificação dos riscos visa produzir uma relação dos riscos que podem afetar o portfolio de projetos no atendimento de seus objetivos e documentar suas características.

A identificação dos riscos considera três diferentes grupos de riscos que afetam o portfolio:

- riscos individuais de cada um dos projetos que compõem o portfolio;

- riscos de interdependências entre os projetos que compõem o portfolio e

- riscos abrangentes, que não têm origem nos projetos em si, mas em fatores ligados ao ambiente em que o portfolio está inserido.

Geralmente as informações resultantes dos processos de gerenciamento de riscos aplicados sobre cada projeto são concentradas num documento ou banco de dados denominado registro de riscos do projeto (PMI, 2004).

O mesmo tipo de documento é utilizado, agora, para o portfolio e é denominado registro de riscos do portfolio. Este documento concentra todas as informações sobre os riscos do portfolio geradas em todos os passos deste procedimento. Isto significa que o registro de riscos do portfolio é evolutivo, ou seja, vai sendo complementado assim que novas informações tornam-se disponíveis ou informações já disponíveis tornam-se mais detalhadas. Algumas das informações do registro de riscos do portfolio são:

- descrição do risco identificado;

- categoria dos riscos;

- projetos afetados;

- condições ou eventos causadores do risco;

- probabilidade de ocorrência;

- impactos causados pela ocorrência do risco em cada objetivo estratégico;

- respostas aos riscos;

- impactos das respostas aos riscos;

- exposição do portfolio ao risco;

- responsável por gerenciar o risco; 
- reservas de contingência;

- planos de ação;

- riscos residuais;

- riscos secundários.

Os passos para a identificação dos riscos são descritos a seguir.

\subsubsection{Revisão dos Riscos Individuais dos Projetos}

Os riscos individuais de cada um dos projetos que compõem o portfolio foram identificados e analisados dentro do âmbito dos projetos e na fase de Avaliação Individual dos Projetos. Estes riscos geralmente estão associados aos objetivos dos projetos de escopo, prazo, custo e qualidade, mas podem ter relevância no atendimento dos objetivos do portfolio.

Os riscos individuais dos projetos que têm relevância para o portfolio são aqueles que podem causar desvios nos benefícios esperados do projeto e, por conseguinte, no atendimento dos objetivos estratégicos do portfolio.

Dentre estes, pode haver riscos comuns, ou seja, um mesmo risco pode afetar mais de um projeto, como por exemplo, um risco ligado a um determinado fornecedor de matéria prima utilizada em vários projetos. Individualmente, cada projeto pode ter identificado, analisado e planejado um tratamento para o risco, e contabilizado o custo correspondente. Quando examinado sob a ótica do portfolio, porém, uma ação de mitigação pode ser suficiente para tratar o risco em todos os projetos afetados, com um custo menor do que a somatória dos tratamentos individualizados, minimizando a exposição a riscos do portfolio.

Neste passo, os registros de riscos de cada projeto são analisados, buscando identificar os riscos relevantes para o portfolio de projetos e se há a ocorrência de duplicidades ou riscos comuns.

Os riscos triados são inseridos no registro de riscos do portfolio, com as informações dos projetos afetados por ele. Os riscos comuns são agregados e registrados apenas uma vez. 


\subsubsection{Identificação dos Riscos de Interdependências}

Como conseqüência do inter-relacionamento entre os projetos que compõem o portfolio, as propagações de riscos entre projetos - que ocorrem quando riscos de um projeto podem agravar os riscos dos demais projetos - aumentam a exposição a riscos do portfolio. Esta situação acontece tipicamente quando há uma relação de dependência sequencial entre os projetos

De acordo com Sanchez, Robert e Pellerin (2008), as interdependências entre os projetos podem ter origem em recursos, conhecimento e geração de benefícios. Em algumas situações, os recursos e conhecimentos podem ser gerados por um projeto e necessários para o desenvolvimento de outro; em outras, recursos com disponibilidade limitada podem estar sendo utilizados por um projeto num determinado momento e, portanto, indisponíveis a outro; além disto, alguns dos benefícios podem somente ser obtidos quando um conjunto completo de projetos for realizado com sucesso, como é o caso dos programas.

O objetivo deste passo é identificar riscos gerados pela interdependência entre os projetos e que, portanto, podem gerar novos riscos ou agravamentos de outros riscos nos projetos dependentes.

Para facilitar a identificação de dependências entre projetos pode-se utilizar uma matriz como a apresentada na Figura 4.4. Os projetos são analisados por pares e, as dependências entre eles são identificadas na matriz. É importante descrever também o tipo de dependência para facilitar a identificação dos riscos dela decorrentes.

Figura 4.4 - Dependências entre projetos

\begin{tabular}{|c|c|c|c|c|c|c|c|}
\hline & \multicolumn{4}{|c|}{ Matriz de dependências entre projetos } & \multicolumn{3}{|c|}{ Descrição das dependências entre projetos } \\
\hline & $\begin{array}{c}\text { Projeto } \\
1\end{array}$ & $\begin{array}{c}\text { Projeto } \\
\mathbf{2} \\
\end{array}$ & $\cdots$ & $\begin{array}{c}\text { Projeto } \\
\mathbf{i}\end{array}$ & $\begin{array}{l}\text { Relação } \\
\text { Dependê }\end{array}$ & $\begin{array}{l}\text { le } \\
\text { ncia }\end{array}$ & Descrição \\
\hline Projeto 1 & & * & & & Projeto 1 & Projeto 2 & \\
\hline Projeto 2 & & & & * & Projeto 2 & Projeto i & \\
\hline$\ldots$ & & & & & $\cdots$ & & \\
\hline Projeto i & * & & & & Projeto i & Projeto 1 & \\
\hline
\end{tabular}

Fonte: Elaborado pela autora 
Com base na reavaliação dos riscos identificados no passo anterior e com o apoio da matriz de dependências entre projetos, os riscos de propagações são identificados e incluídos no registro de riscos do portfolio de projetos.

\subsubsection{Identificação dos Riscos Abrangentes}

Os riscos abrangentes não têm origem nos projetos em si, mas podem afetar alguns ou todos os projetos que compõem o portfolio. Estes tipos de riscos são geralmente associados ao ambiente em que a organização e o portfolio de projetos estão inseridos.

Neste passo, a influência de fatores como situação do mercado, cenário político, os envolvidos nos projetos, economia, relações internacionais e o ambiente interno da organização (processos, competências, operações, sistemas de informação) são analisados, com vistas à identificação de riscos abrangentes.

Estes novos riscos também são inseridos no registro de riscos do portfolio.

Ao final dos passos de identificação, o registro de riscos do portfolio deve conter a relação de riscos que afetam o portfolio, conforme exemplificado na Tabela 4-2.

Tabela 4-2 - Registro de riscos do portfolio

\begin{tabular}{|c|c|c|c|c|c|c|c|c|c|c|c|}
\hline \multirow{2}{*}{ 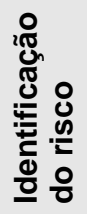 } & \multirow{2}{*}{ 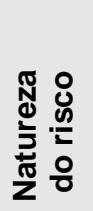 } & \multirow{2}{*}{$\begin{array}{l}\text { Descrição do } \\
\text { risco }\end{array}$} & \multirow{2}{*}{$\begin{array}{l}\text { Categoria } \\
\text { do risco }\end{array}$} & \multicolumn{4}{|c|}{ Projetos afetados } & \multicolumn{4}{|c|}{$\begin{array}{c}\text { Objetivos estratégicos } \\
\text { afetados }\end{array}$} \\
\hline & & & & P1 & P2 & $\ldots$ & $\mathbf{P i}$ & 01 & 02 & $\ldots$ & Oj \\
\hline 1 & $\mathrm{I}$ & Risco 1 & & * & & & & $\bar{x}$ & & & \\
\hline 2 & I & Risco 2 & & & * & & & & $x$ & & \\
\hline 3 & I & Risco 3 & & & * & & & & $x$ & & \\
\hline 4 & I & Risco 4 & & & & & * & & & & $x$ \\
\hline 5 & I & Risco 5 & & * & * & & * & $x$ & & & \\
\hline 6 & 1 & Risco 6 & & & * & & * & & & & $x$ \\
\hline 7 & $\mathrm{D}$ & Risco 7 & & & * & & * & & & & \\
\hline 8 & $\mathrm{D}$ & Risco 8 & & * & * & & & $x$ & & & \\
\hline--- & $\ldots$ & $\ldots$ & & & & & & & & & $x$ \\
\hline $\mathrm{n}$ & $A$ & Risco $n$ & & * & * & & * & $x$ & & & \\
\hline
\end{tabular}

Fonte: Elaborado pela autora 
A coluna [Natureza] registra o grupo ao qual o risco pertence: individual (I), dependência (D) ou abrangente (A).

É importante registrar os projetos afetados por cada um dos riscos e também os objetivos estratégicos atingidos.

Estes riscos serão submetidos à análise no passo seguinte deste procedimento.

\subsection{Análise dos Riscos do Portfolio}

Cada um dos riscos do portfolio identificados nos passos anteriores é analisado para estimar a probabilidade de ocorrência e os impactos causados em cada um dos objetivos do portfolio, caso venha a ocorrer. Estas estimativas permitem determinar as exposições de cada objetivo do portfolio associadas ao risco (ER).

A exposição ao risco é calculada através da multiplicação da probabilidade pelo impacto, conforme definido por Kerzner (2003) e Ward (2000) e indica a perda média que se pode esperar como consequência deste risco.

Exposição a risco $(E R)=$ Probabilidade do risco ocorrer (\%) *Impacto causado

O impacto é estimado em valores monetários ou em outras medidas compatíveis com a mensuração do objetivo estratégico.

As probabilidades normalmente têm natureza subjetiva e suas estimativas serão mais apuradas se puderem se basear em dados históricos ou na análise cuidadosa das causas que podem materializar o evento de risco.

Para amenizar o anseio de ser muito "preciso" na estimativa das probabilidades, que são subjetivas, um número limitado de valores discretos pode ser adotado como, por exemplo: $10 \%, 30 \%, 50 \%, 70 \%$ e $90 \%$. Para casos onde há maior incidência de riscos com probabilidade baixa e impacto alto, uma escala logarítmica pode ser mais apropriada. 
Os valores de exposição a riscos podem ser utilizados para comparar os riscos identificados, priorizar o tratamento e orientar eventuais ações adicionais a serem tomadas.

As ações a serem tomadas devem ser direcionadas por critérios claros associados à classificação de severidade dos riscos, como exemplificado na Tabela 4-3. Neste procedimento, o termo severidade está sendo usado para indicar a importância do risco em termos qualitativos.

É importante destacar, porém, que alguns riscos podem demandar ações diferentes das indicadas pela classificação de severidade em função, por exemplo, da urgência de tratamento decorrente de outros fatores que não o valor de exposição.

Tabela 4-3 - Exemplo de critérios de classificação de severidade dos riscos

\begin{tabular}{cll}
\hline Exposição ao Risco & $\begin{array}{l}\text { Severidade } \\
\text { do Risco }\end{array}$ & \multicolumn{1}{c}{ Ações a seres tomadas } \\
\hline$>\$ 5000$ & muito alta & $\begin{array}{l}\text { desenvolver tratamento e plano de contingência detalhado e } \\
\text { monitorar os triggers }\end{array}$ \\
\hline entre $\$ 1000$ e 5000 & alta & desenvolver tratamento e plano de contingência \\
\hline entre $\$ 100$ e $\$ 1000$ & média & desenvolver tratamento \\
\hline$<\$ 100$ & baixa & tratar como uma premissa do projeto \\
\hline
\end{tabular}

Fonte: Elaborado pela autora

Através da ordenação descendente dos valores de exposição, por exemplo, os riscos podem ser visualizados e agrupados por faixas de classificação de severidade.

Smith e Merritt (2002) sugerem que as exposições a riscos sejam representadas num mapa de riscos como o exemplificado na Figura 4.5, onde os eixos $x$ e y indicam, respectivamente, o impacto e a probabilidade do risco. Este mapa é semelhante a uma matriz de impacto e probabilidade, porém utiliza escalas numéricas ao invés de escalas qualitativas, o que produz uma representação mais sensível dos valores de exposição.

O mapa de riscos pode incluir, ainda, as faixas de classificação de severidade dos riscos, representadas pelos intervalos entre as curvas com valores de exposição fixos que expressam os limites de classificação. 
Figura 4.5 - Mapa de riscos

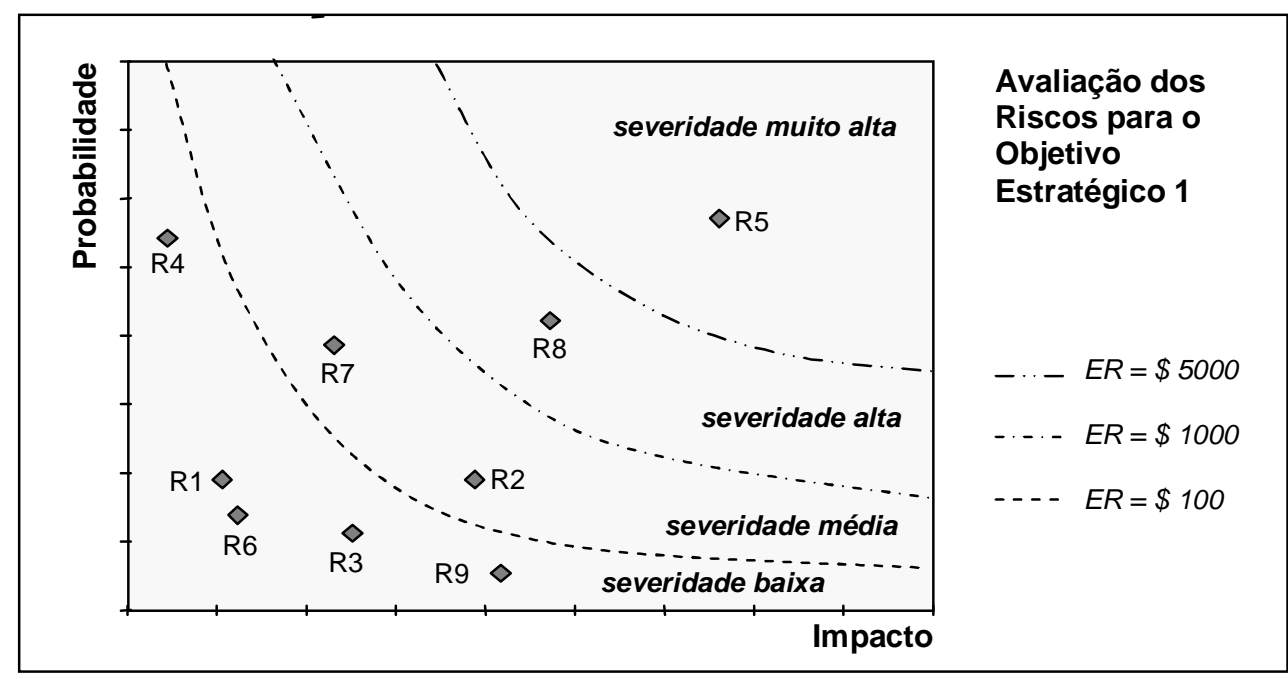

Fonte: Adaptado de Smith e Merritt (2002)

Ao final deste passo, as estimativas de probabilidade e impacto, os valores de exposições a risco e as severidades são inseridos no registro de riscos do portfolio de projetos, conforme representado na Tabela 4-4, onde $\operatorname{Pr}_{n}$ é a probabilidade do risco n ocorrer; $l_{j, n}$ é o impacto causado pelo risco n no objetivo estratégico j; $E R_{j, n}$ é a exposição do objetivo j do portfolio face ao risco $\mathrm{n}$ e $S_{j, n}$ é a severidade do risco n para o objetivo estratégico j.

Tabela 4-4 - Registro de riscos do portfolio de projetos

\begin{tabular}{|c|c|c|c|c|c|c|c|c|c|c|c|c|c|c|c|c|c|}
\hline \multirow{3}{*}{ 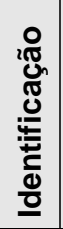 } & \multirow{3}{*}{$\begin{array}{l}\frac{\mathbb{N}}{d} \\
\frac{\mathbb{J}}{5} \\
\frac{\pi}{\mathbb{N}} \\
\mathbf{Z}\end{array}$} & \multirow{3}{*}{$\begin{array}{l}\text { Descrição } \\
\text { do risco }\end{array}$} & \multirow{2}{*}{\multicolumn{4}{|c|}{$\begin{array}{l}\text { Projetos } \\
\text { afetados }\end{array}$}} & \multirow{3}{*}{$\begin{array}{l}\frac{0}{0} \\
\frac{0}{0} \\
\frac{\pi}{0} \\
\overline{0} \\
\frac{0}{0} \\
\frac{0}{0} \\
0\end{array}$} & \multicolumn{9}{|c|}{ Objetivos estratégicos afetados } & \multirow{3}{*}{ 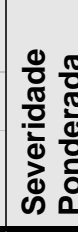 } \\
\hline & & & & & & & & \multicolumn{3}{|c|}{01} & \multicolumn{3}{|c|}{$\mathrm{O2}$} & \multicolumn{3}{|c|}{ Oj } & \\
\hline & & & P1 & P2 & $\ldots$ & $\mathbf{P i}$ & & । & ER & S & 1 & ER & $S$ & 1 & ER & $S$ & \\
\hline 1 & 1 & Risco 1 & * & & & & $\operatorname{Pr}_{1}$ & $\mathrm{I}_{1,1}$ & $\mathrm{ER}_{1,1}$ & $S_{1,1}$ & & & & $\mathrm{I}_{\mathrm{j}, 1}$ & $E R_{j, 1}$ & $\mathrm{~S}_{\mathrm{j}, 1}$ & $\mathrm{Sp}_{1}$ \\
\hline 2 & 1 & Risco 2 & & * & & & $\mathrm{Pr}_{2}$ & & & & $\mathrm{I}_{2,2}$ & $\mathrm{ER}_{2,2}$ & $\mathrm{~S}_{2,2}$ & & & & $\mathrm{Sp}_{2}$ \\
\hline 3 & 1 & Risco 3 & & * & & & $\mathrm{Pr}_{3}$ & & & & $\mathrm{I}_{2,3}$ & $\mathrm{ER}_{2,3}$ & $\mathrm{~S}_{2,3}$ & & & & $\mathrm{Sp}_{3}$ \\
\hline 4 & 1 & Risco 4 & & & & * & $\mathrm{Pr}_{4}$ & & & & & & & $\mathrm{l}_{\mathrm{j}, 4}$ & $E R_{j, 4}$ & $S_{\mathrm{j}, 4}$ & $\mathrm{Sp}_{4}$ \\
\hline 5 & 1 & Risco 5 & * & * & & $*$ & $\mathrm{Pr}_{5}$ & $I_{1,5}$ & $\mathrm{ER}_{1,5}$ & $\mathrm{~S}_{1,5}$ & & & & & & & $\mathrm{Sp}_{5}$ \\
\hline 6 & 1 & Risco 6 & & * & & * & $\mathrm{Pr}_{6}$ & & & & & & & $\mathrm{l}_{\mathrm{j}, 6}$ & $\mathrm{ER}_{\mathrm{j}, 6}$ & $\mathrm{~S}_{\mathrm{j}, 6}$ & $\mathrm{Sp}_{6}$ \\
\hline 7 & $\mathrm{D}$ & Risco 7 & & * & & * & $\operatorname{Pr}_{7}$ & & & & $I_{2,7}$ & $\mathrm{ER}_{2,7}$ & $S_{2,7}$ & & & & $S p_{7}$ \\
\hline 8 & $D$ & Risco 8 & * & * & & & $\mathrm{Pr}_{8}$ & $I_{1,8}$ & $\mathrm{ER}_{1,8}$ & $\mathrm{~S}_{1,8}$ & & & & & & & $S p_{8}$ \\
\hline.. &.. & $\ldots$ & & & & & & & & & & & & & & & $\ldots$ \\
\hline $\mathrm{n}$ & A & Risco $n$ & * & * & & $*$ & $\operatorname{Pr}_{n}$ & $I_{1, \mathrm{n}}$ & $\mathrm{ER}_{1, \mathrm{n}}$ & $S_{1, n}$ & & & & & & & $S p_{n}$ \\
\hline
\end{tabular}

Fonte: Elaborado pela autora 
Para cada objetivo estratégico do portfolio de projetos, a combinação das exposições a cada um dos riscos que o afetam permitirá calcular a sua exposição total a riscos, representada na tabela pela sigla $E R O_{j}$ (exposição total a riscos do objetivo j do portfolio). O cálculo do ERO é detalhado mais à frente, no item 4.7.

Adicionalmente à análise por objetivo estratégico, também a severidade de cada risco em relação ao portfolio como um todo pode ser avaliada, através das combinações dos efeitos do risco no conjunto dos objetivos estratégicos, representada na Tabela 4-4 como $S p_{n}$ (severidade ponderada do risco $\mathrm{n}$ ).

Utilizando um modelo de pontuação, como o exemplificado na Tabela 4-5, as severidades do risco frente a cada objetivo estratégico do portfolio são ponderadas, com a atribuição de pesos aos objetivos e pontos às severidades.

Neste exemplo, o risco n está afetando 3 objetivos estratégicos.

Tabela 4-5 - Exemplo de avaliação da severidade ponderada para o risco $n$

\begin{tabular}{|c|c|c|c|c|c|}
\hline $\begin{array}{l}\text { Pontuação da } \\
\text { Severidade }\end{array}$ & $\begin{array}{c}\text { Objetivo } \\
\text { Estratégico }\left(\mathrm{O}_{\mathrm{j}}\right)\end{array}$ & Peso & $\begin{array}{l}\text { Severidade do } \\
\text { Risco }\left(S_{\mathrm{j}, \mathrm{n}}\right)\end{array}$ & Pontuação & $\begin{array}{l}\text { Pontuação Ponderada } \\
\text { (Peso x Pontuação) }\end{array}$ \\
\hline \multirow{3}{*}{$\begin{array}{l}\text { muito alta = } 4 \\
\text { alta }=3 \\
\text { média }=2 \\
\text { baixa }=1\end{array}$} & O1 & 5 & Alta & 3 & 15 \\
\hline & $\mathrm{O} 2$ & 3 & Alta & 3 & 9 \\
\hline & O3 & 2 & Baixa & 1 & 2 \\
\hline \multicolumn{3}{|c|}{$\Sigma$ Pontuações Ponderadas / $\Sigma$ Pesos } & $=$ Pontuação G & ral : & 2,6 \\
\hline
\end{tabular}

Fonte: Elaborado pela autora

A severidade ponderada do risco $\left(S p_{n}\right)$ é obtida através da classificação da pontuação geral numa escala qualitativa como, por exemplo, a da Tabela 4-6.

A severidade ponderada permite, então, um direcionamento único das ações, baseado no conjunto das severidades do risco para cada objetivo do portfolio.

No exemplo, a severidade ponderada do risco com pontuação 2,6 é classificada como alta. 
Tabela 4-6 - Exemplo de critérios de classificação de severidade ponderada dos riscos

\begin{tabular}{cll}
\hline Pontuação Geral & Severidade Ponderada & Ações a seres tomadas \\
\hline$>3$ & muito alta & $\begin{array}{l}\text { desenvolver tratamento e plano de contingência } \\
\text { detalhado e monitorar os triggers }\end{array}$ \\
\hline entre 2 e 3 & alta & desenvolver tratamento e plano de contingência \\
\hline entre 1 e 2 & média & desenvolver tratamento \\
\hline$<1$ & baixa & tratar como uma premissa do projeto \\
\hline
\end{tabular}

Fonte: Elaborado pela autora

\subsection{Planejamento de Respostas aos Riscos}

O estabelecimento de planos de respostas aos riscos do portfolio que foram avaliados no passo anterior é realizado de acordo com as ações definidas pela classificação de severidade e tem o objetivo de reduzir a probabilidade de ocorrência e/ou os impactos causados por estes riscos nos objetivos do portfolio de projetos, o que geralmente resulta na diminuição do valor de exposição a riscos.

As possíveis estratégias de tratamento de risco descritas no item 3.7.3.3 podem também ser aplicadas aqui.

Por vezes a implementação de um plano de resposta a riscos leva ao surgimento de novos riscos, os chamados riscos secundários. Além disso, nem sempre o tratamento elimina o risco por completo, permanecendo, então, os chamados riscos residuais (PMI, 2004).

Desta forma, o tratamento de cada risco demanda uma reavaliação e um novo cálculo do valor de exposição. Esta reavaliação deve contemplar também os impactos dos recursos, tempo e orçamento adicionais necessários para o tratamento do risco, bem como os riscos residuais e secundários. 


\subsection{Determinação do Grau de Exposição de um Objetivo Estratégico}

Smith e Merritt (2002) sugerem que a exposição total a riscos de um projeto é a somatória dos valores de exposição do projeto a cada risco que o afeta, conforme exposto no item 3.7.4.

Estendendo este conceito para o portfolio de projetos, a exposição total a riscos de um objetivo estratégico do portfolio $(E R O)$ é calculada a partir dos valores de exposição deste objetivo face aos riscos que o impactam $(E R)$, através da seguinte equação:

$$
E R O_{j}=\sum_{i=1}^{n} E R_{j, i}
$$

onde:

- $E R O_{j}$ é a exposição total a riscos do objetivo estratégico $j$ do portfolio de projetos;

- $E R_{j, i}$ é a exposição a risco do objetivo $j$ frente ao risco $i$;

- $n$ é a quantidade total de riscos identificados que afetam o objetivo específico $j$

O $E R O_{j}$ é, portanto, a somatória da coluna $E R$ da Tabela 4-4 e representa a perda média que se pode esperar no atendimento do objetivo estratégico j.

Quando expresso em valores percentuais do valor total que o portfolio deve atingir, este número indica o desvio médio esperado no atendimento deste objetivo.

O grau de exposição a risco do portfolio frente a este objetivo é definido em termos qualitativos, através da escala de classificação que reflete o perfil de risco da organização, de acordo com o que foi apresentado anteriormente na Figura 4.3.

A Tabela 4-7 exemplifica uma escala de classificação do grau de exposição a riscos para um objetivo estratégico do portfolio. Para um valor de $E R O_{j}$, por exemplo, de $12 \%$, o grau de exposição a riscos do portfolio com relação ao atendimento do objetivo j é médio. 
Tabela 4-7 - Escala de classificação do grau de exposição a riscos do portfolio

\begin{tabular}{cc}
\hline $\begin{array}{c}\text { Desvio no Atendimento do Objetivo } \\
\text { Estratégico do portfolio }\end{array}$ & Grau de Exposição \\
\hline até $5 \%$ & baixo \\
\hline maior do que $5 \%$ menor do que $20 \%$ & médio \\
\hline acima de $20 \%$ & alto \\
\hline
\end{tabular}

Fonte: Elaborado pela autora

Ainda de acordo com o que foi apresentado anteriormente na Figura 4.3, o posicionamento do valor calculado para o desvio no atendimento do objetivo do portfolio, quando comparado com a tolerância definida pela organização, indica que, no caso do exemplo, o desvio está dentro do limite tolerado, conforme ilustrado na Figura 4.6.

Figura 4.6 - Exposição a riscos do objetivo do portfolio x tolerância definida

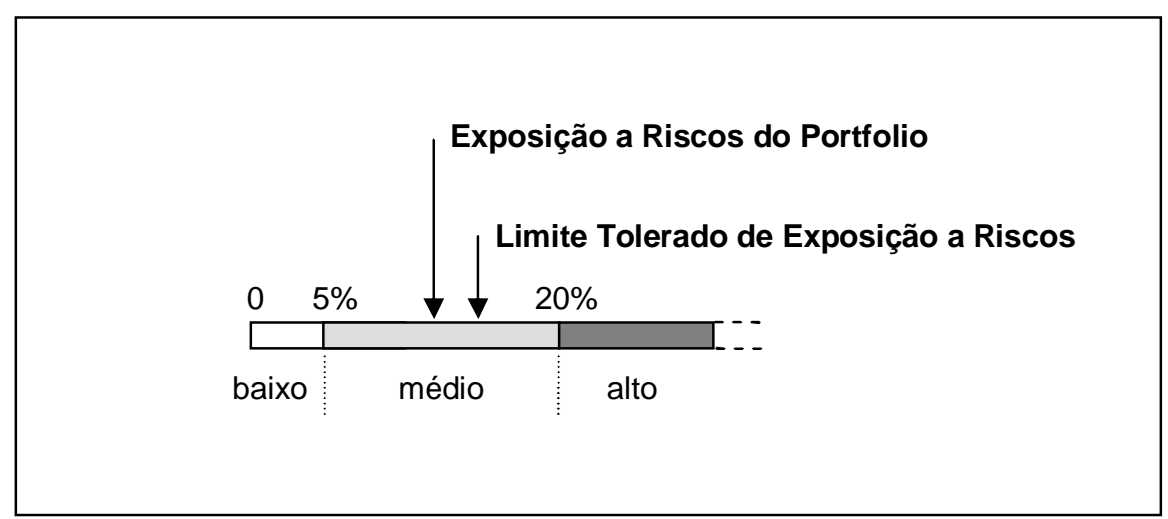

Fonte: Elaborado pela autora

\subsection{Determinação do Grau de Exposição a Riscos do Portfolio}

Os graus de exposição a riscos de todos os objetivos estratégicos do portfolio permitem, por fim, avaliar a situação geral do portfolio que pode ser representada, por exemplo, através de um gráfico radar como o da Figura 4.7, onde a área hachurada indica a exposição geral do portfolio a riscos e a área sombreada representa a tolerância a riscos. 
Figura 4.7 - Grau de exposição a riscos de um portfolio

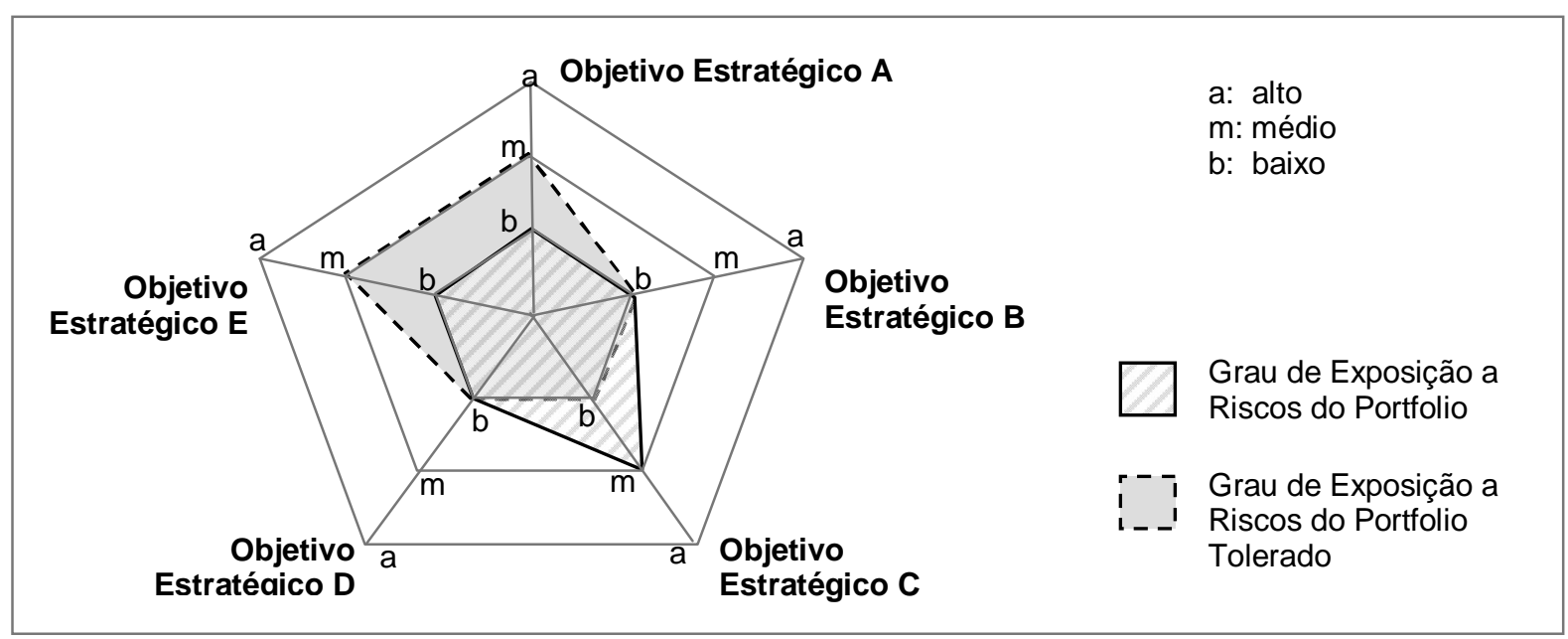

Fonte: Elaborado pela autora

Um índice único para o grau de exposição a riscos do portfolio pode, então, ser obtido, através da media ponderada dos índices individuais, com o mesmo modelo de pontuação utilizado para avaliação da severidade ponderada de cada risco (ver Tabela 4-5 e Tabela 4-6).

\subsubsection{Monitoramento e Controle dos Riscos do Portfolio}

O processo de monitoramento e controle dos riscos descritos no item 3.7.3.4 pode e deve ser aplicado também para os riscos do portfolio.

Ao longo dos respectivos ciclos de vida dos projetos que compõem o portfolio, novos riscos surgem, riscos identificados ocorrem ou perdem a chance de ocorrer, as condições que geraram os riscos se agravam, minimizam ou deixam de existir, e assim, inúmeras mudanças podem acontecer.

Este cenário dinâmico, no qual o portfolio de projetos está inserido, leva à necessidade de revisões constantes nos dados de riscos de projetos e à repetição dos processos de gerenciamento de riscos. Os efeitos destas mudanças vão também ser refletidos na exposição a riscos do portfolio, levando à necessidade de sua periódica reavaliação e balanceamento. 


\section{ESTUDO DE CASO}

A seguir é apresentado o estudo de caso realizado para atender o objetivo do trabalho de testar o procedimento proposto para a determinação do grau de exposição a riscos de um portfolio de projetos.

O procedimento foi aplicado numa empresa com a qual a pesquisadora já tinha um relacionamento de confiança profissional e as informações necessárias para a condução do estudo de caso foram obtidas junto ao gestor do portfolio de projetos da empresa escolhida, que exerce cargo de diretor, com o apoio de gerentes de projeto.

Como parte de um acordo de confidencialidade, a identificação da empresa e outras informações consideradas confidencias foram preservadas. Neste sentido, nas descrições a seguir, a empresa passa a ser denominada apenas como EMPRESA, os projetos são identificados com nomes genéricos e os valores apresentados foram tratados, mantendo, porém, a proporcionalidade com os valores reais, o que garante a consistência dos resultados apresentados.

\subsection{Caracterização da Empresa}

A empresa em que o procedimento foi aplicado é uma das líderes mundiais no setor de máquinas e equipamentos, cujo foco é o fornecimento de bens e serviços integrados.

Com sede na Europa, está presente em 70 países, empregando cerca de 65.000 pessoas e, em 2008, obteve um faturamento de cerca de 18 bilhões de euros a nível mundial.

Presente no Brasil há mais de 50 anos, conta atualmente com cerca de 4.000 colaboradores no país, em diversas instalações fabris e administrativas, e um faturamento da ordem de 1,4 bilhão de reais em 2008.

A empresa está dividida em unidades de negócio e o presente estudo focou uma destas unidades, com sede no Brasil, mas que inclui as operações em toda a 
América Latina, e que responde por cerca de $45 \%$ do faturamento brasileiro, empregando cerca de 2.500 pessoas.

\subsection{Os Projetos da Empresa}

A empresa classifica seus projetos, num primeiro nível, como projetos internos e projetos externos.

Os projetos internos são aqueles cujo cliente final é a própria empresa e que são subdivididos como segue:

- projetos de infra-estrutura, destinados a prover a infra-estrutura necessária para a operação, a sustentação e o crescimento da organização, como a construção de novas fábricas, reformas de sítios existentes e expansão de escritórios;

- projetos de novos produtos e

- projetos de melhorias, ligados ao aumento da produtividade e redução de custos.

Os projetos externos são aqueles realizados para entregar aos clientes externos um equipamento ou um conjunto de equipamentos feitos sob encomenda e que geralmente demandam, além da fabricação, serviços de montagem e instalação, testes, comissionamento e partida assistida. Todo o faturamento da empresa é decorrente da execução de projetos externos.

O estudo de caso foi direcionado para o portfolio de projetos externos da unidade de negócio mencionada no item anterior. Esta escolha foi direcionada pela disponibilidade de informações relativas a este tipo de projeto e pelo interesse demonstrado pelo gestor deste portfolio.

\subsection{Portfolio de Projetos Externos}

Os projetos externos são classificados em 3 grandes categorias: pequenos fornecimentos, grandes fornecimentos e reformas.

A caracterização destes projetos está descrita na Tabela 5-1 a seguir. 
Tabela 5-1 - Caracterização dos projetos da Empresa

\begin{tabular}{lcccc}
\hline Tipo de Projeto & $\begin{array}{c}\text { Quantidade } \\
\text { Relativa }\end{array}$ & $\begin{array}{c}\text { Duração } \\
\text { Média }\end{array}$ & $\begin{array}{c}\text { Representatividade } \\
\text { no Faturamento }\end{array}$ & $\begin{array}{c}\text { Equipe Típica de } \\
\text { Gerenciamento }\end{array}$ \\
\hline $\begin{array}{l}\text { Pequenos } \\
\text { fornecimentos }\end{array}$ & $50 \%$ & 20 meses & $25 \%$ & 7 pessoas \\
\hline $\begin{array}{l}\text { Grandes } \\
\text { fornecimentos }\end{array}$ & $25 \%$ & 48 meses & $60 \%$ & 20 pessoas \\
\hline Reformas & $25 \%$ & 36 meses & $15 \%$ & 7 pessoas \\
\hline
\end{tabular}

Fonte: Elaborado pela autora com base nas informações obtidas nos levantamentos

\subsubsection{Planejamento Estratégico}

O planejamento estratégico é realizado anualmente para um horizonte de 3 anos, sendo o primeiro ano mais detalhado.

Semestralmente, é realizado um estudo de mercado, que mapeia as possíveis demandas para os próximos 10 anos e destaca os projetos com maiores chances de concretização, separados por categorias (grandes fornecimentos, pequenos fornecimentos e reformas). Também semestralmente, acontece uma reunião entre os diretores de desenvolvimento de negócios e o comitê executivo para analisar as perspectivas de negócio e focar esforços na concretização daquelas que melhor atendam os objetivos estratégicos.

O portfolio de projetos externos visa atender objetivos estratégicos ligados a metas de faturamento anual, margem bruta, geração de fluxo de caixa e ocupação da capacidade de fábrica, que serão mais detalhados no item 5.4.2 deste capítulo.

\subsubsection{Gerenciamento de Projetos}

A empresa possui uma metodologia de gerenciamento de projetos própria, madura e sedimentada a nível mundial, que trata todas as áreas de conhecimento descritas no PMBOK Guide e é utilizada em todos os projetos da companhia.

O perfil dos projetos - complexos, de alto custo, produção não seriada, com times internacionais - exige gerentes de projeto bem capacitados e experientes. 
Existe uma diretoria responsável pelo gerenciamento dos projetos, composta por 3 gerências, cada uma delas responsável pelo gerenciamento de um tipo de projeto: pequenos fornecimentos, grandes fornecimentos e reformas. Além destas gerências, outras 5 áreas apóiam os projetos: Técnica, Planejamento, Contratos, Financeiro e Qualidade, totalizando 250 pessoas nesta diretoria.

Cada projeto é gerenciado por uma equipe matricial liderada por um gerente de projetos que conta, ainda, com 0 apoio de coordenadores que fazem 0 interfaceamento com as outras áreas envolvidas no projeto, tanto internas quando externas. A equipe pode estar distribuída em localidades diferentes, apoiadas por estruturas locais. O gerente do projeto tem plena autoridade e responsabilidade sobre o projeto e responde para o diretor da área.

Tipicamente os projetos têm um ciclo de vida como o representado na Figura 5.1.

Figura 5.1 - Ciclo de vida do projeto da Empresa

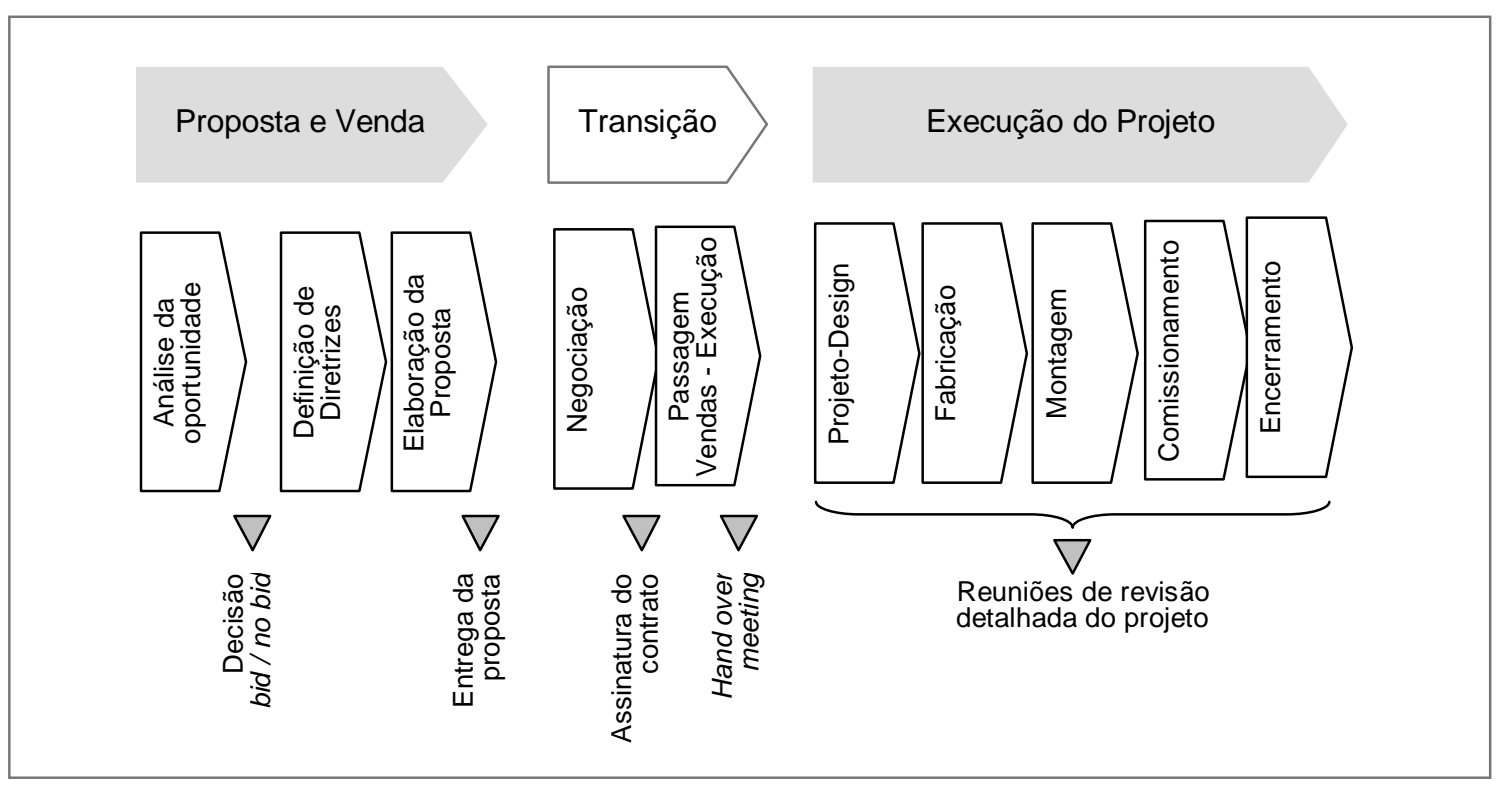

Fonte: EMPRESA

A empresa conta ainda com um PMO - Project Management Office corporativo mundial, que é um centro de excelência em gerenciamento de projetos, responsável pela escolha, desenvolvimento e implantação das metodologias, procedimentos, padrões e ferramentas utilizadas. Alguns gerentes de projeto brasileiros também participam deste $\mathrm{PMO}$. 
Os softwares utilizados atualmente para o gerenciamento dos projetos são: Primavera $\mathrm{P}^{4}$, SAP/R3 ${ }^{5}{ }^{5}$ e diversas outras ferramentas em forma de planilhas eletrônicas.

Existe uma base mundial de informações desta unidade de negócio que mantém as informações atualizadas de todos os projetos com valor de venda superior a um determinado valor.

\subsubsection{Gerenciamento de Portfolio de Projetos}

O portfolio de projetos desta unidade de negócio é gerido pelo diretor da área de projetos.

O número de projetos externos que compõe o portfolio atualmente é de 38 e estes projetos representam praticamente todo o faturamento da unidade de negócios.

Existe uma metodologia interna de gerenciamento de portfolio de projetos apoiada por ferramentas de software que permitem a agregação dos dados dos projetos, através de diversas planilhas eletrônicas.

Estas ferramentas proporcionam ao gestor do portfolio uma visão centralizada de seus projetos, tanto das informações de planejamento como das informações de desempenho real.

Quando uma oportunidade de negócio se concretiza, ou seja, quando há a possibilidade de apresentar uma proposta de venda, caracteriza-se a existência de um projeto candidato a entrar para o portfolio. Neste momento é realizada a avaliação individual do projeto candidato, visando decidir por seguir para a elaboração da proposta ou por declinar, ou seja, tentar incluir ou não o projeto no portfolio, já que a inclusão definitiva depende da aceitação da proposta pelo cliente e da concretização da venda.

\footnotetext{
${ }^{4}$ Primavera P6 é um software de gerenciamento de projetos da multinacional americana Oracle Corp.

${ }^{5}$ SAP/R3 $®$ é um software de gestão empresarial da multinacional alemã SAP AG e é uma marca registrada da SAP AG na Alemanha e diversos outros países
} 
Os critérios utilizados nesta avaliação são:

- disponibilidade de recursos;

- carga da empresa;

- mercado;

- viabilidade técnica;

- viabilidade comercial;

- fluxo de caixa e

- risco individual.

Uma vez aceita a proposta pelo cliente e com a conseqüente assinatura do contrato, o projeto é autorizado e entra efetivamente para o portfolio de projetos em execução.

Mensalmente são realizadas reuniões de acompanhamento dos projetos nas quais os gerentes de projetos apresentam os dados de desempenho dos projetos, incluindo o monitoramento de riscos. Trimestralmente este reunião se repete com diretores da matriz européia, seguindo um protocolo mundial.

Estes reportes mensais abastecem o gestor do portfolio de projetos com informações de desempenho de todos os projetos do portfolio e viabilizam a análise do portfolio como um todo.

Esta análise possibilita as tomadas de decisão ligadas ao balanceamento do portfolio, que geralmente levam à redefinição de prioridades e raramente à decisão de cancelamento. Isto é decorrente das características do negócio e do peso das multas fixadas nos contratos que, geralmente, inviabilizam sua interrupção ou cancelamento. Este tipo de decisão fica, então, restrita aos casos extremos que envolvam situações tais como guerra, terrorismo, retaliações políticas e inadimplência irreversível.

\subsubsection{Gerenciamento de Riscos}

O gerenciamento de riscos dos projetos na empresa faz parte dos processos mundiais padronizados de gerenciamento de projetos. 
Os riscos são avaliados em momentos pré-definidos durante o ciclo de vida do projeto, conforme destacados na Figura 5.2.

Na fase de Proposta e Venda, a avaliação de riscos é utilizada como um critério de filtragem. Se o projeto for aprovado, entra para o portfolio de projetos como candidato, cuja decisão de realização dependerá da aceitação da proposta pelo cliente e consequente assinatura do contrato.

$\mathrm{Na}$ fase de Transição, quando a responsabilidade pelo projeto é transferida da equipe de vendas para a equipe de gerenciamento do projeto, a avaliação de riscos é utilizada para antever possíveis desvios do projeto em relação ao desempenho esperado, preparar respostas e dimensionar adequadamente os recursos necessários ao tratamento dos riscos identificados.

$\mathrm{Na}$ fase de Execução do Projeto, as avaliações de riscos são utilizadas como critérios de avaliação e monitoramento individual do projeto.

Figura 5.2 - Avaliação de riscos durante o ciclo de vida do projeto

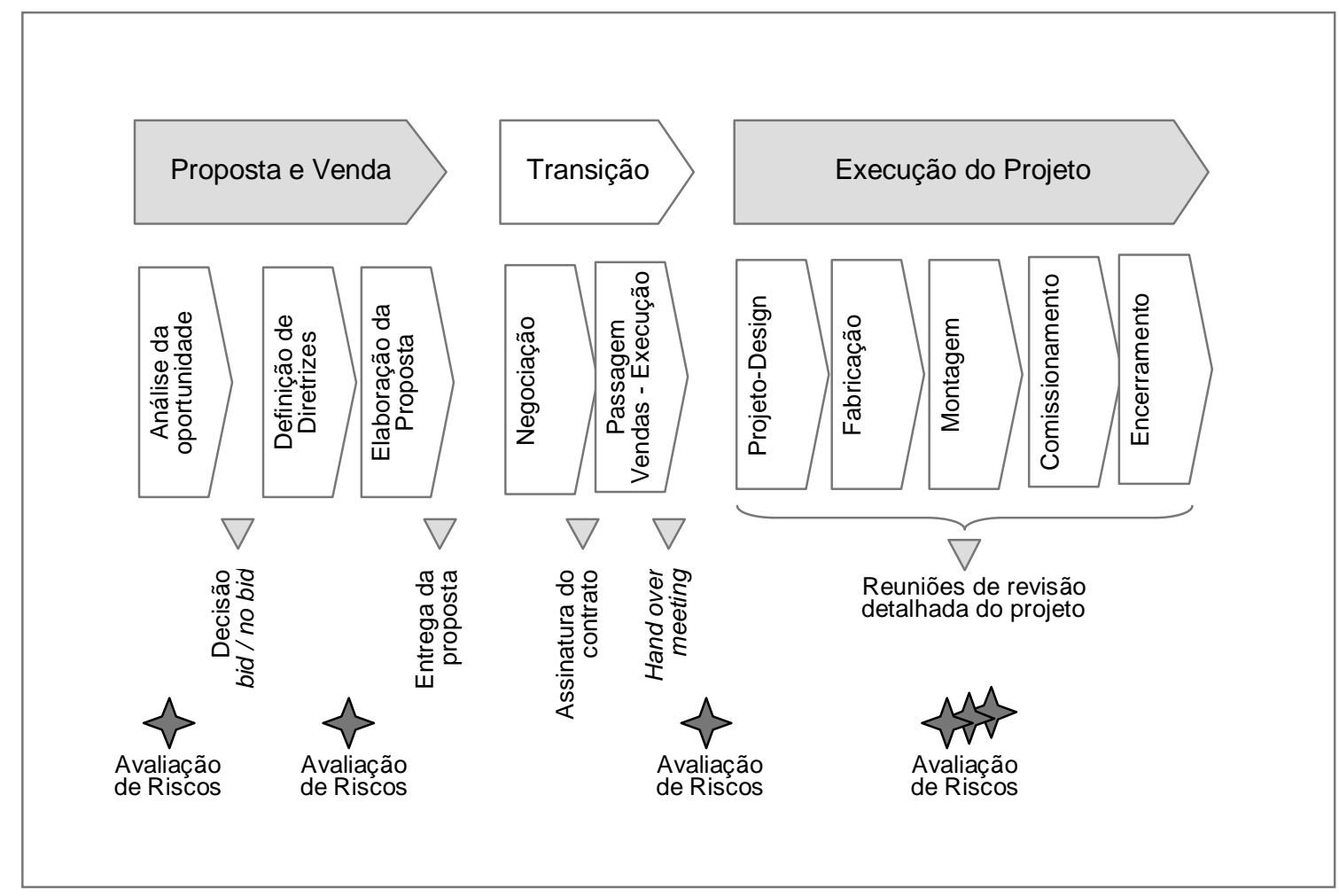

Fonte: Elaborado pela autora 


\subsubsection{Avaliação de Riscos como Critério de Filtragem}

A primeira avaliação de riscos é realizada na fase de desenvolvimento do negócio, durante a análise da oportunidade de venda, para apoiar a decisão de apresentar uma proposta para o cliente ou declinar (bid / no bid).

Neste momento, a análise de riscos é qualitativa e realizada através modelos de pontuação com critérios ponderados (scoring models) em planilhas eletrônicas. São avaliadas as seguintes categorias de risco:

- riscos financeiros;

- riscos técnicos;

- riscos de prazos;

- riscos de localização;

- riscos de seguros e

- riscos jurídicos.

Para cada uma destas categorias de risco existe uma lista de pontos a serem avaliados, através da atribuição de índices dentro de escalas pré-definidas. A média ponderada destes índices leva a um indicador qualitativo para cada uma das categorias de risco: baixo, médio e alto. Os modelos de pontuação não foram incluídos por serem considerados confidenciais.

Os resultados destas análises são apresentados em forma de tabela como a exemplificada na Figura 5.3.

Figura 5.3 - Avaliação de riscos de um projeto candidato

\begin{tabular}{|l|l|l|l|}
\hline Riscos & Baixo & Médio & Alto \\
\hline Financeiros & & & \\
\hline Técnicos & & & \\
\hline Prazos & & & \\
\hline Jurídicos & & & \\
\hline Seguros & & & \\
\hline Localização & & & \\
\hline
\end{tabular}

Fonte: Elaborado pela autora 
O critério da empresa determina que, se um destes indicadores for classificado como alto, ou mais de dois forem classificados com médios, a oportunidade é descartada. Após a definição das diretrizes da proposta, quando um estudo mais aprofundado proporciona maior detalhe de informações, a análise é refeita.

\subsubsection{Avaliação de Riscos como Critério de Monitoramento Individual}

No início da execução do projeto, já na reunião de passagem de responsabilidade da área de vendas para a área de projetos (hand over meeting), é feita uma sessão de avaliação de riscos do projeto que se inicia.

A identificação dos riscos é auxiliada por uma estrutura analítica de riscos semelhante àquela exemplificada na Figura 3.13 e composta por 3 níveis.

À identificação dos riscos segue, primeiramente, a análise qualitativa, utilizando a matriz de impacto e probabilidade da Figura 5.4.

Figura 5.4 - Instrumentos para avaliação qualitativa de riscos do projeto

\begin{tabular}{|l|l|l|l|l|l|l|}
\hline & & & & \\
\hline
\end{tabular}

Fonte: Empresa 
O objetivo desta análise é identificar para quais riscos do projeto deve ser definido um plano de tratamento. Para aqueles riscos cuja análise quantitativa apontou como necessário (classificados na área mais escura da matriz da Figura 5.4), planos de respostas são desenvolvidos, visando eliminar ou diminuir probabilidade e/ou impacto.

A análise qualitativa é seguida por uma análise quantitativa simplificada. Para cada risco são estimados: probabilidade e impacto em valores monetários. (custos adicionais).

A exposição ao risco é calculada, então, multiplicando a probabilidade pelo impacto após mitigação. Os custos decorrentes dos planos de ação são contabilizados nos custos do projeto.

As informações sobre todos os riscos do projeto são registradas numa planilha eletrônica, que contém os seguintes dados:

- Código de Identificação do risco

- Descrição do risco

- Classificação do risco (categoria)

- Status (mitigado, ocorrido, em andamento, fechado)

- Probabilidade estimada

- Impacto estimado antes do tratamento

- Ações de tratamento

- Custo estimado da mitigação

- Probabilidade estimada depois do tratamento

- Impacto estimado depois do tratamento

- Exposição ao risco

- Observações relativas aos critérios utilizados na avaliação

- Responsável pelo risco

- Época esperada para acontecer o risco

- Contingência alocada

Todas as sessões de avaliação de riscos são conduzidas por um grupo de 3 especialistas em riscos. 


\subsection{Aplicação do Procedimento}

\subsubsection{O Portfolio Estudado}

Em função do tipo de informações disponíveis sobre os riscos dos projetos e do tempo disponível dos entrevistados, o portfolio escolhido para a aplicação do procedimento foi o subconjunto dos projetos externos, em andamento, da categoria grandes fornecimentos, composto atualmente de 9 projetos.

O estudo foi direcionado para a avaliação dos riscos associados ao atendimento de dois dos quatro objetivos estratégicos aos quais o portfolio está vinculado e a aplicação do procedimento utilizou as informações dos projetos atualizadas até o momento da última revisão trimestral detalhada.

Este universo de análise foi considerado suficiente para os objetivos deste trabalho.

\subsubsection{Objetivos Estratégicos do Portfolio}

O portfolio de projetos objeto deste estudo de caso tem a missão de atender os seguintes objetivos estratégicos, para os quais todos os projetos têm benefícios esperados pré-definidos ${ }^{6}$ :

- alcançar um determinado valor de faturamento para o ano fiscal corrente e

- proporcionar uma determinada margem bruta média sobre o valor das vendas.

Há outros dois objetivos estratégicos aos quais este portfolio também está ligado, cuja análise só seria possível se o procedimento se estendesse para o portfolio completo de projetos externos da unidade de negócios, razão pela qual não foram incluídos neste estudo:

- proporcionar fluxo de caixa positivo, de forma que a entrada total de recursos financeiros dê sustentação à saída total destes recursos;

- evitar capacidade ociosa dos recursos fabris.

\footnotetext{
${ }^{6}$ Por questão de confidencialidade os valores absolutos não foram apresentados.
} 
A margem bruta esperada para cada projeto (preço de venda - custos do projeto) é definida na ocasião da formação de preço da proposta para o cliente, na fase de Proposta e Venda, e revista após a negociação, quando o contrato é assinado, na fase de Transição.

Os valores de margem definidos variam de projeto para projeto, de acordo com sua importância, tamanho e complexidade. A expectativa da empresa é obter determinada margem bruta média para o portfolio, definida percentualmente como a diferença entre a somatória dos valores de venda e de custos de todos os projetos dividida pela somatória dos valores de venda.

O faturamento anual total esperado para o portfolio é função dos preços de vendas dos projetos e dos eventos de pagamento. Os eventos de pagamento são distribuídos ao longo do ciclo de vida do projeto e geralmente estão condicionados às entregas. A previsão de pagamentos totalizada para o período fiscal determina 0 faturamento anual esperado.

Para o conjunto de projetos do portfolio estudado, a soma dos valores esperados de faturamento e a soma dos valores esperados de margem bruta (em valores monetários) mostraram que a composição do portfolio estava bem próxima dos valores alvo para os objetivos estratégicos, permitindo, portanto, assumir a participação percentual de cada projeto nestes totais como os benefícios esperados para o portfolio. A Tabela 5-2 apresenta estes valores. Esta tabela corresponde à Tabela 4-1 descrita no procedimento proposto.

Tabela 5-2 - Benefícios esperados dos projetos para os objetivos estratégicos do portfolio

\begin{tabular}{ccc}
\hline \multirow{2}{*}{ Projeto } & \multicolumn{2}{c}{ Contribuição Percentual } \\
\cline { 2 - 3 } & para Margem Bruta & para Faturamento \\
\hline Projeto 1 & $4,3 \%$ & $3,0 \%$ \\
\hline Projeto 2 & $6,8 \%$ & $10,6 \%$ \\
\hline Projeto 3 & $7,6 \%$ & $5,5 \%$ \\
\hline Projeto 4 & $7,4 \%$ & $8,2 \%$ \\
\hline Projeto 5 & $18,0 \%$ & $16,9 \%$ \\
\hline Projeto 6 & $23,5 \%$ & $18,2 \%$ \\
\hline Projeto 7 & $5,8 \%$ & $7,2 \%$ \\
\hline Projeto 8 & $23,1 \%$ & $25,1 \%$ \\
\hline Projeto 9 & $3,5 \%$ & $5,3 \%$ \\
\hline Total & $100 \%$ & $100 \%$ \\
\hline
\end{tabular}

Fonte: Elaborado pela autora com base em valores fornecidos pela Empresa 


\subsubsection{Tolerância a Riscos para o Portfolio}

O perfil de tolerância a riscos no atendimento dos objetivos estratégicos ligados ao portfolio foi definido pela empresa conforme descrito na Tabela 5-3 a seguir. Nesta tabela também são apresentadas as escalas de classificação para o grau de exposição a riscos definidas para cada um dos objetivos, em analogia à Figura 4.3 do procedimento proposto.

Tabela 5-3 - Tolerância a riscos para o portfolio

\begin{tabular}{|c|c|c|c|}
\hline \multirow{2}{*}{$\begin{array}{l}\text { Objetivo } \\
\text { Estratégico }\end{array}$} & \multirow{2}{*}{$\begin{array}{c}\text { Tolerância a riscos } \\
\begin{array}{c}\text { Decréscimo Tolerado em } \\
\text { Relação à Meta }\end{array}\end{array}$} & \multicolumn{2}{|c|}{$\begin{array}{c}\text { Escalas de classificação do grau de } \\
\text { exposição a riscos }\end{array}$} \\
\hline & & $\begin{array}{l}\text { Decréscimo em } \\
\text { Relação à Meta }\end{array}$ & $\begin{array}{c}\text { Grau de } \\
\text { Exposição a } \\
\text { Riscos }\end{array}$ \\
\hline \multirow{3}{*}{ Faturamento } & \multirow{3}{*}{$15 \%$} & $>15 \%$ & alto \\
\hline & & entre 5 e $15 \%$ & médio \\
\hline & & $<5 \%$ & baixo \\
\hline \multirow{3}{*}{ Margem Bruta } & \multirow{3}{*}{$9 \%$} & $>9 \%$ & alto \\
\hline & & entre 3 e $9 \%$ & médio \\
\hline & & $<3 \%$ & baixo \\
\hline
\end{tabular}

Fonte: Elaborado pela autora com base em valores fornecidos pela Empresa

\subsubsection{Identificação dos Riscos do Portfolio de Projetos}

Os riscos que afetam o portfolio são aqueles que podem causar desvios no atendimento de seus objetivos e, portanto, nesta etapa, foram identificados os riscos que poderiam causar variações na margem bruta e/ou no faturamento anual.

Variações na margem bruta podem ocorrer em função da variação de custos do projeto. Como na grande maioria dos projetos o preço de venda é fixo - uma vez que as modalidades de contratação mais praticadas pelos clientes são chave-namão (turn key) e preço fechado (lump sum) - custos reais maiores dos que os planejados representam diminuições diretamente proporcionais na margem bruta.

Variações no faturamento previsto para o ano fiscal podem ocorrer em função de atrasos nos pagamentos pelo cliente; de postergações de pagamentos em função de atrasos nas entregas do projeto; e da diminuição dos valores pagos em função de 
penalidades contratuais, geralmente atreladas a atrasos nas entregas e a problemas de desempenho dos equipamentos fornecidos.

A identificação dos riscos do portfolio teve início com a revisão dos registros de riscos de cada um dos projetos, com o objetivo de identificar os riscos individuais dos projetos que apresentavam impacto sobre a margem bruta e/ou o faturamento. Esta análise indicou que a maioria dos riscos dos projetos apresentava impacto na margem bruta, e alguns riscos apresentavam impacto no faturamento.

A análise destes riscos levou à identificação de riscos comuns, ligados principalmente à disponibilidade de matéria prima, insumos e sub-contratados. Estes riscos foram agregados. A análise das interdependências entre os projetos permitiu identificar propagações de riscos, motivadas principalmente pelos recursos de produção, para os quais vários projetos concorrem entre si. Além disso, foram identificados também riscos abrangentes que, pela natureza dos projetos, estão mais ligados a aumento de preço de matéria prima e situação de mercado de alguns clientes, atualmente com problemas de liquidez e inadimplência.

Ao todo 66 riscos foram identificados.

\subsubsection{Análise dos Riscos do Portfolio de Projetos}

A análise dos riscos identificados produziu estimativas numéricas para as probabilidades e para os impactos dos riscos em cada um dos objetivos estratégicos definidos.

As probabilidades foram estimativas segundo uma escala discreta com os valores $10 \%, 30 \%, 50 \%, 70 \%$ e $90 \%$, seguindo uma prática já utilizada pela empresa na análise dos riscos dos projetos.

A ocorrência de cada um dos riscos podia causar impacto - decréscimo nos valores alvo - em um ou nos dois objetivos estratégicos e, assim, as estimativas de impacto em base monetária foram realizadas separadamente para cada um dos objetivos.

Os riscos individuais dos projetos já tinham sido avaliados no âmbito dos projetos e tiveram, então, as estimativas de probabilidade e impacto confirmadas ou revistas. 
Os impactos em base monetária foram convertidos para valores percentuais da seguinte forma:

$$
\begin{aligned}
& \begin{array}{l}
\text { Impacto do risco na } \\
\text { margem bruta do portfolio (\%) }
\end{array}=\frac{\text { Impacto do risco na margem bruta do portfolio (\$) }}{\sum \text { Valores de Venda dos Projetos (\$) }} \\
& \begin{array}{l}
\text { Impacto do risco no } \\
\text { faturamento do portfolio (\%) }
\end{array}=\frac{\text { Impacto do risco no faturamento do portfolio (\$) }}{\sum \text { Faturamentos dos Projetos (\$) }}
\end{aligned}
$$

A multiplicação da probabilidade do risco pelo impacto em cada objetivo estratégico - eq.(4.1) do procedimento - levou aos valores de exposição da margem bruta e do faturamento frente ao risco, indicando a perda média em valores percentuais ou desvio que se pode esperar como consequência do risco em cada um destes objetivos $\left(E R_{j, n}\right)$.

Com base nestes valores, os riscos foram classificados em faixas de severidade. A Figura 5.5 e a Figura 5.6 mostram os mapas de riscos e os critérios utilizados para classificar a severidade em relação ao objetivo de margem bruta e de faturamento respectivamente, em correspondência à Tabela 4-3 e Figura 4.5 do procedimento.

Figura 5.5 - Mapa de riscos para margem bruta

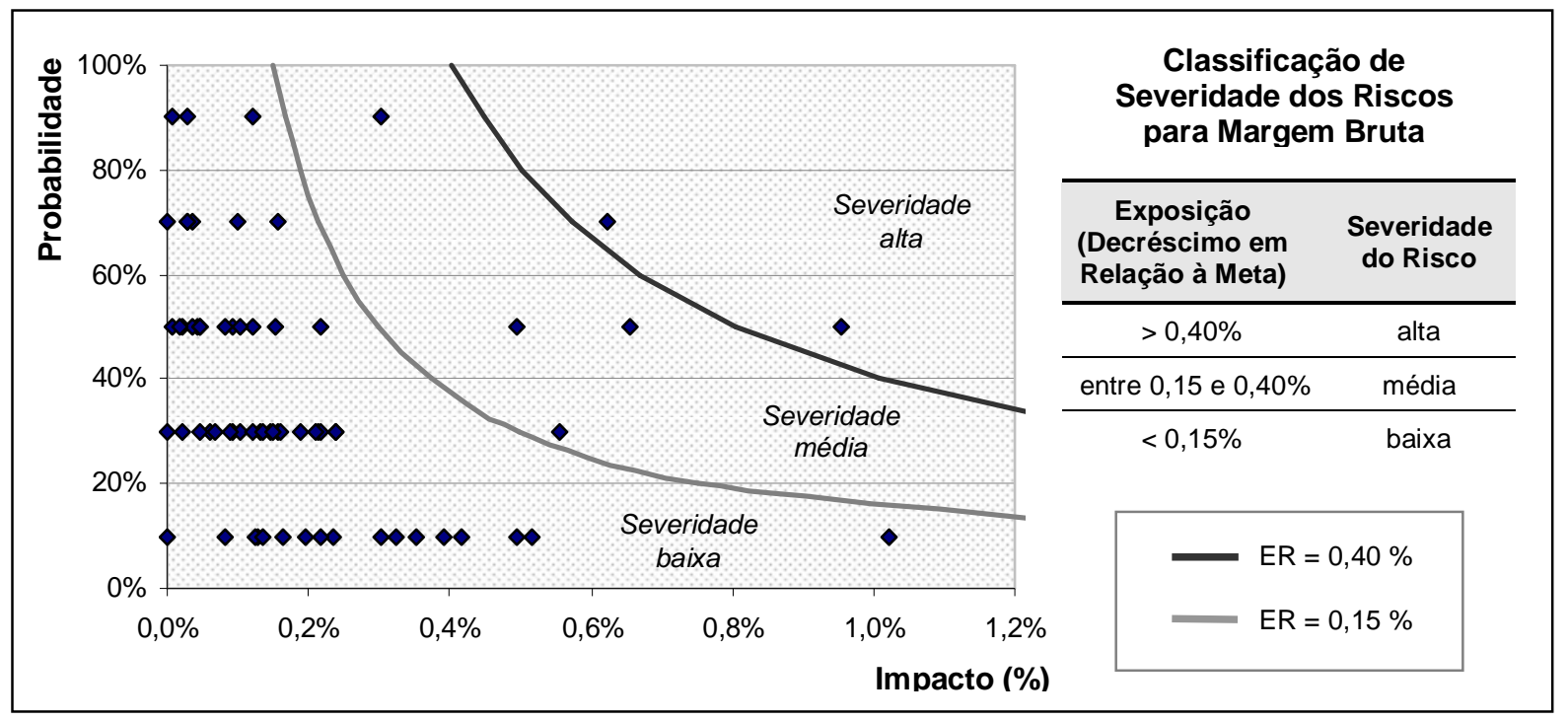

Fonte: Elaborado pela autora 
Em relação à margem bruta, 4 riscos foram classificados com severidade média e dois com severidade alta. Em relação ao faturamento, 3 riscos foram classificados com severidade média e nenhum com severidade alta. Os demais riscos foram classificados com severidade baixa.

Figura 5.6 - Mapa de riscos para faturamento

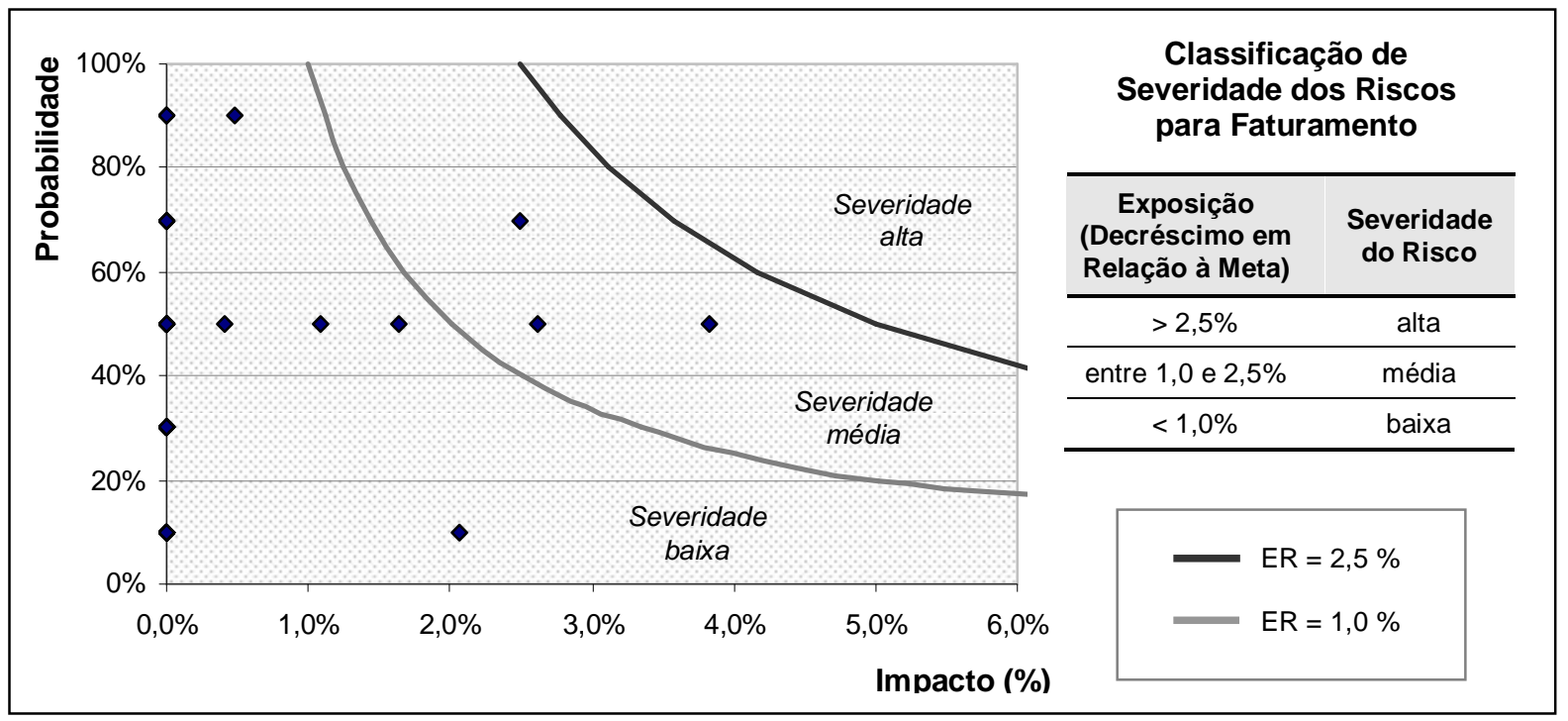

Fonte: Elaborado pela autora com base em valores fornecidos pela Empresa

Como apenas dois objetivos estratégicos estavam sendo analisados, foi possível determinar a severidade ponderada graficamente, ao invés de utilizar um modelo de pontuação como aquele descrito na Tabela 4-5 e na Tabela 4-6 do procedimento.

No gráfico da Figura 5.7, cada ponto representa um risco. O eixo x mostra a exposição da margem bruta ao risco e o eixo y mostra a exposição do faturamento ao risco. As faixas sombreadas representam as faixas de severidades ponderadas, obtidas através das combinações das faixas de severidade para cada objetivo estratégico.

A empresa elegeu os seguintes critérios para direcionar as ações de tratamento de acordo com a severidade ponderada (em correspondência à Tabela 4-6 do procedimento):

- severidade ponderada alta: desenvolver tratamento e plano de contingência;

- severidade ponderada média: desenvolver tratamento; 
- severidade ponderada baixa: monitoramento continuado.

Figura 5.7 - Mapa de riscos para severidade ponderada

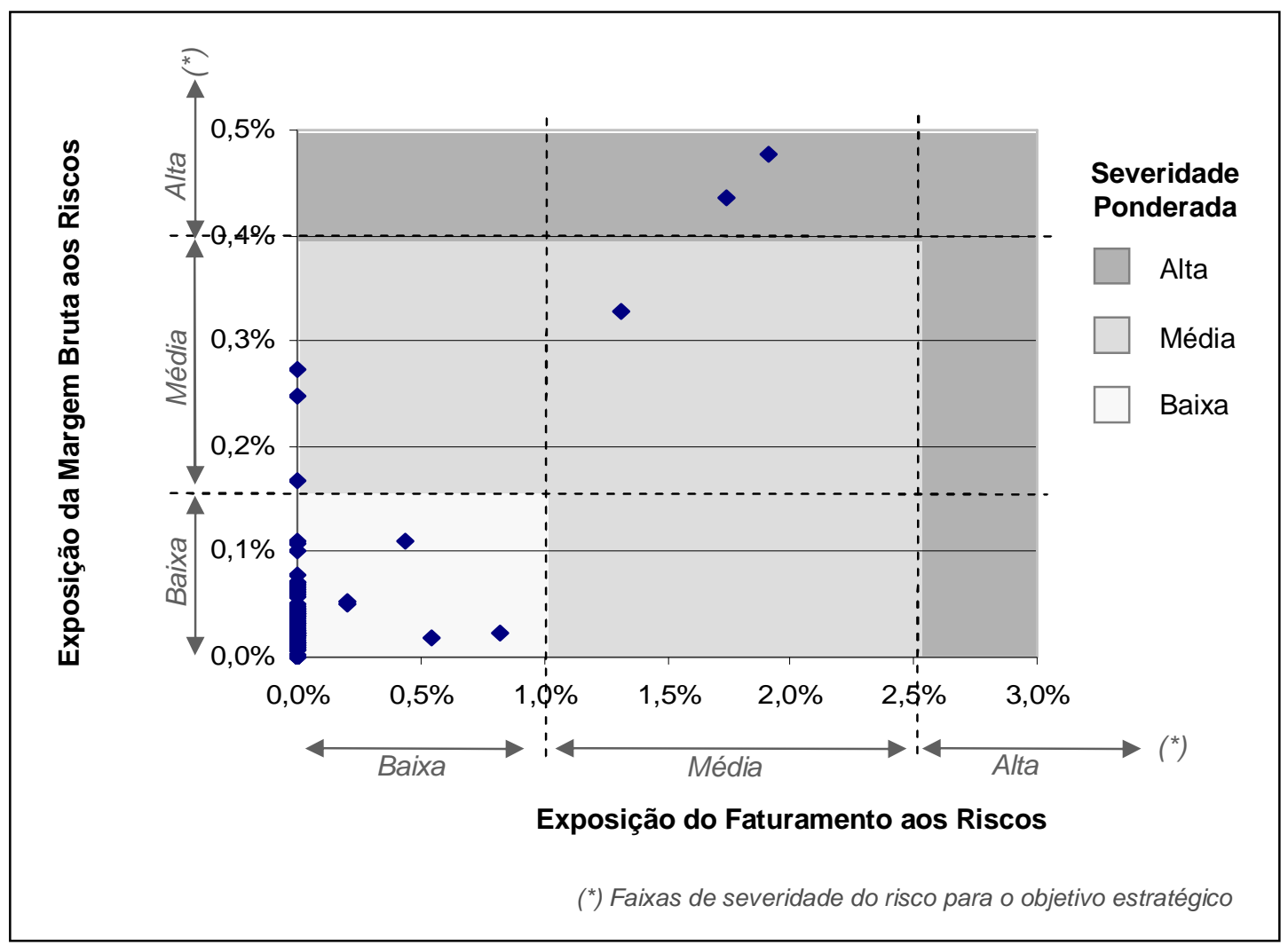

Fonte: Elaborado pela autora com base em valores fornecidos pela Empresa

Nesta classificação, então, 4 riscos foram classificados com severidade ponderada média e 2 com severidade ponderada alta.

\subsubsection{Planejamento de Respostas aos Riscos do Portfolio de Projetos}

A conclusão da avaliação dos riscos levou ao passo seguinte que foi o estabelecimento de planos de respostas aos riscos identificados, segundo os critérios listados no item anterior.

É importante observar que a maioria dos riscos individuais selecionados dos registros de riscos dos projetos já tinha sido tratada no âmbito dos projetos. Para estes riscos, a resposta anteriormente planejada foi validada ou, quando necessário, modificada. 
A escolha de respostas aos riscos identificados demandou nova análise, já que, através da redução de probabilidade e/ou impacto, o valor de exposição ao risco também se modificou.

Aos valores de exposição aos riscos recalculados foram somados os custos decorrentes do tratamento do risco. Para este portfolio especificamente, nenhum tratamento originou riscos secundários, porém, caso ocorressem, seriam incluídos no registro de riscos do portfolio com consequente cálculo do valor de exposição ao risco.

Os resultados destes passos foram registrados no registro de riscos do portfolio como exemplificado na Tabela 5-4.

Tabela 5-4 - Registro de riscos do portfolio

\begin{tabular}{|c|c|c|c|c|c|c|c|c|c|c|c|c|c|c|}
\hline \multirow{3}{*}{ 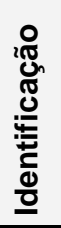 } & \multirow{3}{*}{$\begin{array}{l}\mathbb{N} \\
\mathbb{d} \\
\frac{1}{2} \\
\frac{\pi}{Z}\end{array}$} & \multirow{3}{*}{$\begin{array}{l}\text { Descrição } \\
\text { do risco }\end{array}$} & \multirow{2}{*}{\multicolumn{4}{|c|}{ Projetos afetados }} & \multirow{3}{*}{$\begin{array}{l}\frac{0}{0} \\
\frac{\pi}{\pi} \\
\frac{\underline{0}}{\overline{0}} \\
\frac{0}{\pi} \\
\frac{0}{0} \\
\frac{0}{0}\end{array}$} & \multicolumn{6}{|c|}{ Objetivos estratégicos afetados } & \multirow{3}{*}{ 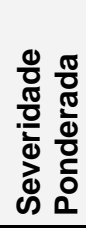 } \\
\hline & & & & & & & & \multicolumn{3}{|c|}{ Margem Bruta } & \multicolumn{3}{|c|}{ Faturamento } & \\
\hline & & & P1 & P2 & $\cdots$ & P9 & & I & ER & $\mathrm{S}$ & I & ER & $S$ & \\
\hline 1 & I & Risco 1 & $x$ & & & & $30 \%$ & $\begin{array}{c}0.09 \\
\%\end{array}$ & $0,03 \%$ & Baixa & $0,00 \%$ & $0 \%$ & Baixa & Baixa \\
\hline 2 & I & Risco 2 & & $x$ & & & $50 \%$ & $\begin{array}{c}0.04 \\
\%\end{array}$ & $0.02 \%$ & Baixa & $1.64 \%$ & $0,82 \%$ & Baixa & Baixa \\
\hline 3 & & Risco 3 & & & & & & & & & & & & \\
\hline 4 & & Risco 4 & & & & & & & & & & & & \\
\hline 5 & & Risco 5 & & & & & & & & & & & & \\
\hline 6 & & Risco 6 & & & & & & & & & & & & \\
\hline 7 & & Risco 7 & & & & & & & & & & & & \\
\hline 8 & & Risco 8 & & & & & & & & & & & & \\
\hline .. &.. & $\cdots$ & & & & & & & & & & & & \\
\hline 66 & & Risco 66 & & & & & & & & & & & & \\
\hline
\end{tabular}

Fonte: Elaborado pela autora

\subsubsection{Exposições a Riscos dos Objetivos Estratégicos}

A exposição total a riscos do portfolio em relação ao objetivo de margem bruta (ERO) foi calculada somando-se os valores de exposição deste objetivo frente a cada risco, conforme eq.(4.2) do procedimento. O mesmo foi feito para 0 faturamento, chegando-se aos seguintes resultados: 
- $E R O_{\text {margem bruta }}=4,15 \%$

- $E R O_{\text {faturamento }}=7,17 \%$

Estes resultados indicam que os desvios esperados no atendimento dos objetivos estratégicos do portfolio estão dentro dos limites de tolerância.

Com base nas faixas de classificação definidas pela empresa (ver Tabela 5-3), o grau de exposição a riscos deste portfolio frente ao atendimento de seus objetivos estratégicos foi considerado médio tanto para margem bruta como para faturamento.

Figura 5.8 - Exposição a riscos dos objetivos do portfolio

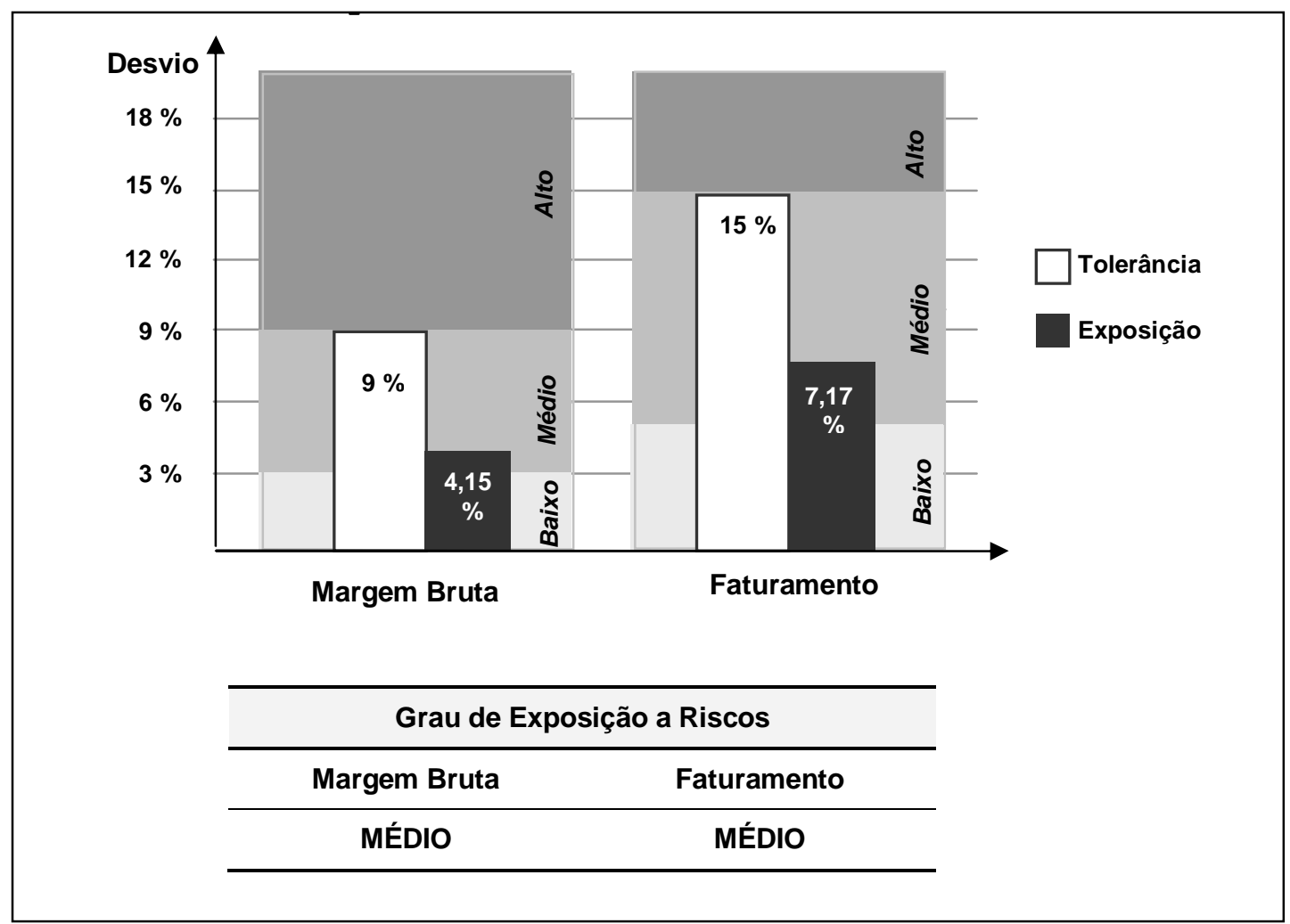

Fonte: Elaborado pela autora

\subsubsection{Grau de Exposição a Riscos do Portfolio}

A empresa considerou que ambos os objetivos estratégicos têm pesos iguais e, portanto, o grau de exposição a riscos do portfolio como um todo foi classificado 
como médio, utilizando o modelo de pontuação da Tabela 5-5 e os critérios de classificação da Tabela 5-6 (similares respectivamente, à Tabela 4-5 e à Tabela 4-6 do procedimento proposto).

Tabela 5-5 - Avaliação do grau de exposição a riscos do portfolio

\begin{tabular}{|c|c|c|c|c|c|}
\hline $\begin{array}{l}\text { Pontuação } \\
\text { do Grau de } \\
\text { Exposição }\end{array}$ & $\begin{array}{l}\text { Objetivo } \\
\text { Estratégico }\end{array}$ & Peso & $\begin{array}{l}\text { Grau de } \\
\text { Exposição }\end{array}$ & Pontuação & $\begin{array}{l}\text { Pontuação Ponderada } \\
\text { (Peso x Pontuação) }\end{array}$ \\
\hline \multirow{2}{*}{$\begin{array}{l}\text { alto }=3 \\
\text { médio = } 2 \\
\text { baixo }=1\end{array}$} & Margem Bruta & 5 & Médio & 2 & 10 \\
\hline & Faturamento & 5 & Médio & 2 & 10 \\
\hline \multicolumn{5}{|c|}{$\Sigma$ Pontuacões Ponderadas $/ \Sigma$ Pesos $=$} & 2,0 \\
\hline
\end{tabular}

Fonte: Elaborado pela autora

Tabela 5-6 - Critérios de classificação do grau de exposição a riscos do portfolio

\begin{tabular}{ccc}
\hline Pontuação & Classificação Geral & \\
\cline { 1 - 2 } 2 & alto & Grau de Exposição a Riscos do Portfolio \\
\cline { 1 - 2 } entre 1 e 2 & médio & MÉDIO \\
\hline$<1$ & baixo & \\
\hline
\end{tabular}

Fonte: Elaborado pela autora

\subsubsection{Representatividade dos Projetos nos Desvios Esperados do Portfolio}

Cada um dos 66 riscos identificados afetava um ou mais projetos do portfolio. A somatória dos valores de exposição de um projeto a cada risco que o afeta representa os desvios esperados oriundos deste projeto.

Através do cálculo destes valores foi possível estimar a representatividade de cada projeto na exposição a riscos do portfolio.

Estes valores também permitiram calcular a porcentagem de desvios esperados no atendimento dos benefícios individuais de cada projeto.

Estas relações foram representadas nos gráficos de bolhas da Figura 5.9, onde o eixo x mostra o desvio médio gerado pelo projeto num objetivo do portfolio, o eixo y 
representa o desvio médio no benefício esperado do próprio projeto e a área dos círculos representa o valor de venda do projeto.

Figura 5.9 - Comparação dos desvios no projeto e no portfolio

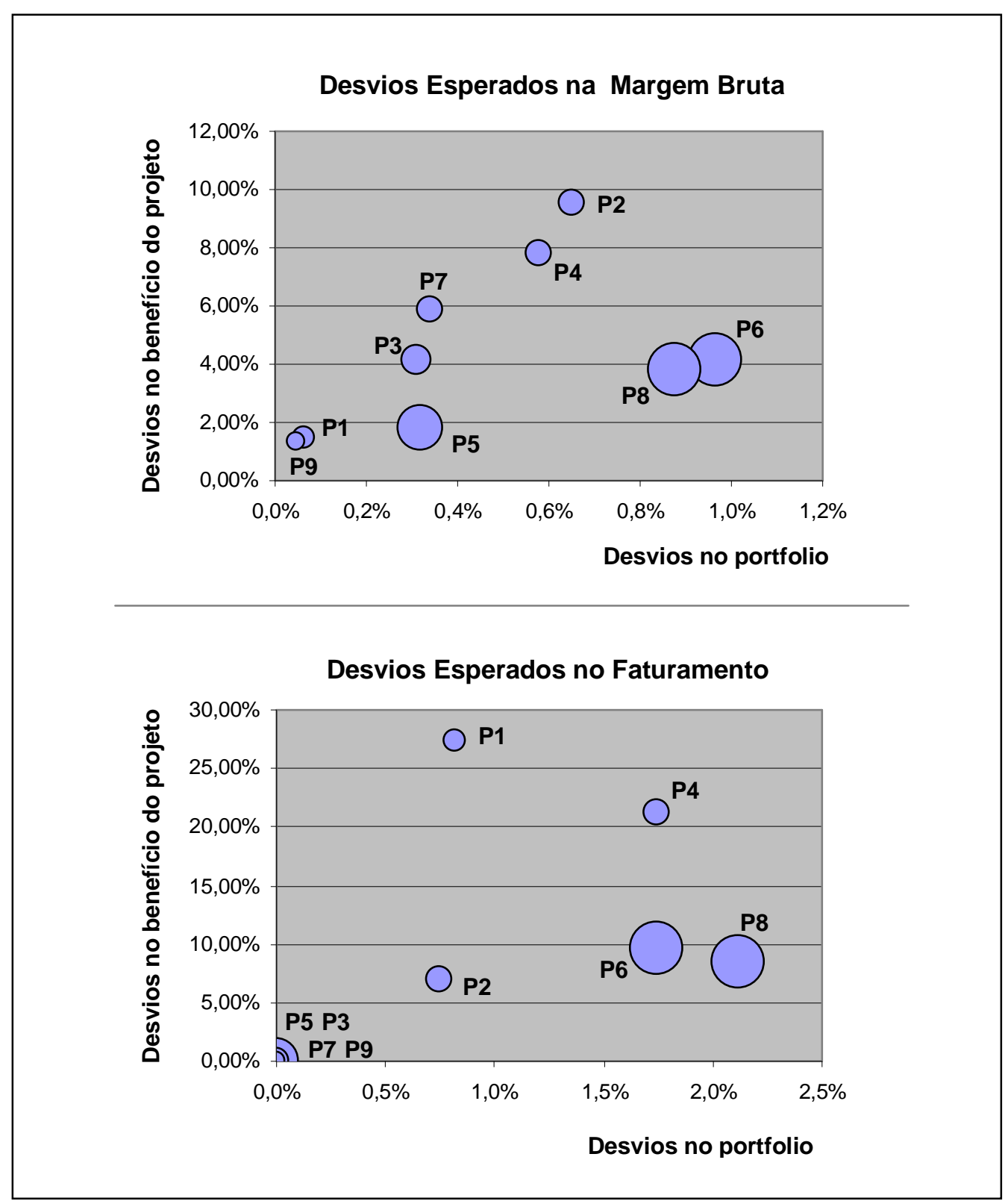

Fonte: Elaborado pela autora

Por fim, também foi possível comparar os benefícios esperados de cada projeto com a representatividade de cada projeto na exposição a riscos do portfolio, conforme Figura 5.10. Neste gráfico de bolhas, o eixo $x$ mostra o desvio médio gerado pelo projeto num objetivo do portfolio, o eixo y representa o benefício esperado do projeto e a área dos círculos representa o valor de venda do projeto. 
Figura 5.10 - Comparação entre benefícios e exposição a riscos

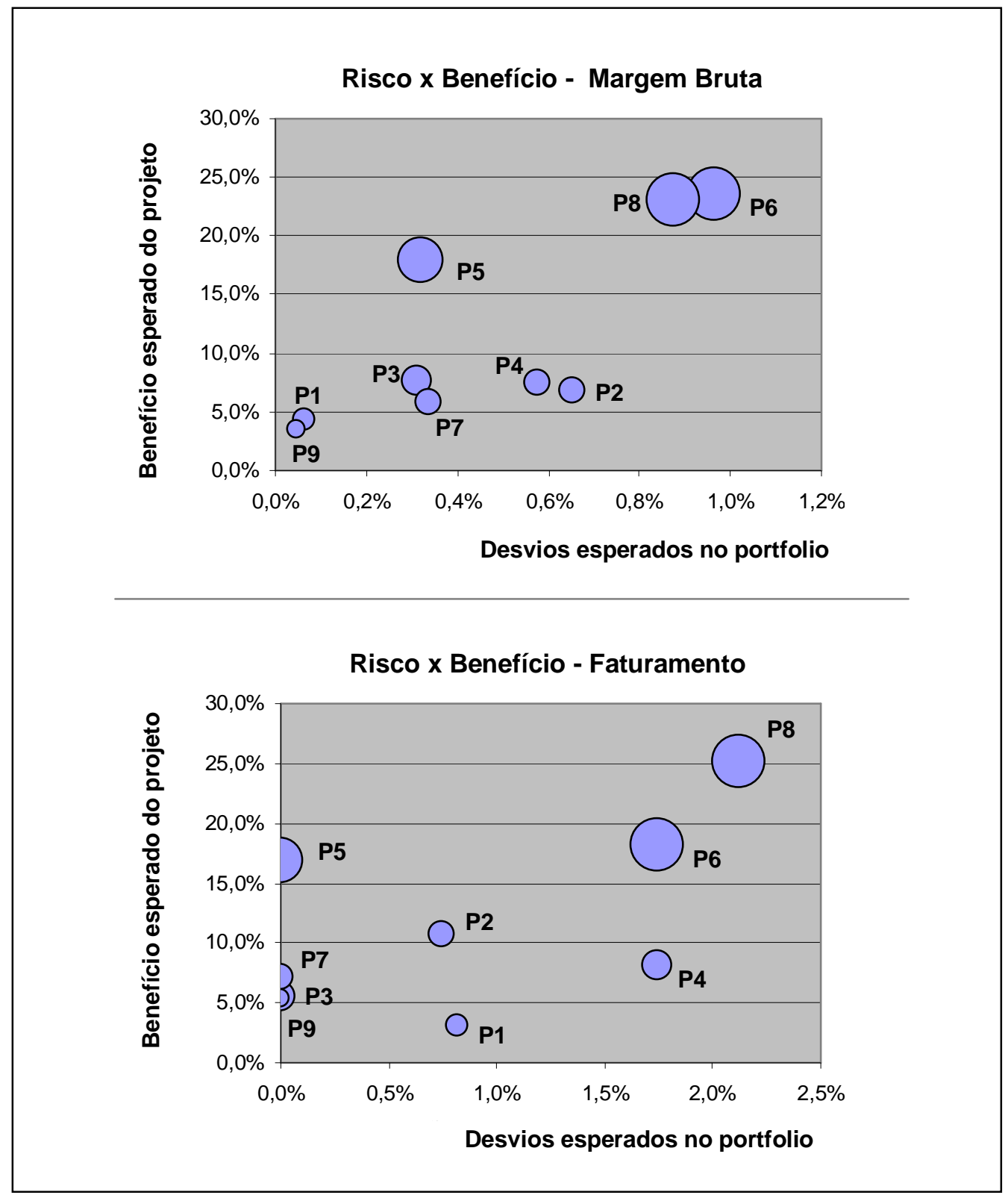

Fonte: Elaborado pela autora

\subsection{Análise dos Resultados}

O portfolio de projetos analisado tem objetivos claros e quantificáveis e está vinculado ao planejamento estratégico. Conforme listado na Tabela 5-2, foi possível identificar os benefícios de cada projeto para o atendimento das metas definidas de 
margem bruta de faturamento. A composição destes valores estava próxima dos valores alvo.

Os limites de tolerância a riscos e as faixas de classificação do grau de exposição a riscos para cada objetivo estratégico (Tabela 5-3) foram definidas em linha com o perfil conservador da organização. Este perfil, indicado pelo gestor do portfolio nas entrevistas, é explicado pela natureza do negócio, pelo alto valor dos projetos e pela sua representatividade no faturamento da organização.

A aplicação do procedimento foi viabilizada pela disponibilidade dos registros de riscos dos projetos em andamento. Através da análise destes registros foi possível constatar que existe um padrão no tratamento dos riscos pelos diversos gerentes de projeto. Os gerentes de projeto possuem os conhecimentos necessários para a utilização e compreendem as técnicas utilizadas na metodologia de gerenciamento de riscos em projetos.

Os riscos individuais dos projetos já haviam sido tratados anteriormente, no âmbito dos projetos, o que explica o fato da maioria dos riscos ter sido classificada com severidade baixa. A Figura 5.5 mostra que, dos 66 riscos identificados, apenas 4 estavam na faixas de severidade média e 2 na alta, quando analisados frente ao objetivo de margem bruta. Na Figura 5.6 pode-se observar para o objetivo de faturamento, 3 riscos estavam na faixa de severidade média e nenhum na alta. A análise combinada destes dois objetivos apontou, finalmente, 4 riscos classificados com severidade ponderada média e dois com severidade ponderada alta, conforme mostra a Figura 5.7. Isto significa que estes são os riscos que precisam de maior atenção.

A análise conjunta dos riscos do portfolio possibilitou identificar problemas recorrentes com atrasos gerados por duas áreas funcionais: fabricação e suprimentos. Ficou claro que se estas e outras funções envolvidas no projeto gerenciassem riscos dentro de suas áreas e também participassem das sessões de riscos dos projetos, haveria um ganho decorrente da integração entre os diversos envolvidos.

As exposições do portfolio a riscos em relação ao atendimento dos objetivos de margem bruta e faturamento foram calculadas em $4,15 \%$ e $7,17 \%$, respectivamente. 
Estes índices indicam o desvio médio esperado no atendimento destes objetivos do portfolio.

Conforme representado na Figura 5.8, os graus de exposição a riscos estimados para o portfolio analisado revelaram que, mesmo estando dentro dos limites de tolerância, ultrapassaram a faixa de magnitude de desvio considerada baixa, requerendo atenção. Quando avaliado de forma ponderada, o grau de exposição a riscos do portfolio como um todo foi classificado como médio (Tabela 5-5 e Tabela $5-6)$.

A possibilidade de identificar a contribuição de cada projeto para estes desvios, permite ao gestor do portfolio focar os esforços no sentido de apoiar os projetos que apresentam maior expressividade de desvio no âmbito do portfolio.

Os gráficos da Figura 5.9 mostram que os projetos P6 e P8 são os que têm maior representatividade no grau de exposição a riscos do portfolio, tanto para o atendimento do objetivo fixado para margem bruta como para faturamento, com desvios esperados de $1 \%$ e $0,9 \%$ respectivamente para margem bruta e 1,7\% e $2,1 \%$ respectivamente para faturamento. Estas representatividades estão proporcionais aos seus valores de venda relativamente mais elevados.

O projeto $\mathrm{P} 4$, no entanto, ainda que de valor bem menor, contribui com um desvio esperado de $0,6 \%$ na margem e de $1,7 \%$ no faturamento do portfolio. Estes mesmos gráficos permitem observar que este projeto está com riscos bastante expressivos frente aos valores de margem e faturamento esperados para seu próprio resultado (7,79\% e $21,29 \%$ respectivamente).

Em contrapartida, o projeto P5 tem valor de venda elevado, porém não apresenta riscos de faturamento e tem pouca participação no desvio esperado da margem bruta do portfolio. Já o projeto P1, por ter menor valor de venda não apresenta expressividade alta nos desvios esperado do portfolio, porém tem um desvio esperado de $27,27 \%$ no próprio faturamento.

Os gráficos da Figura 5.10 permitem comparar os benefícios e os desvios esperados de cada projeto no portfolio. É possível observar que os projetos P6 e P8 são os que têm a maior representatividade tanto nos benefícios como nos desvios esperados para o portfolio. São também os que têm os maiores valores de venda. Desta forma, estes são os projetos que demandam maior atenção do gestor do portfolio. 
O projeto P5 tem situação mais favorável, já que tem valor alto de venda, benefícios altos de margem e faturamento, baixa expressividade no desvio de margem esperada e não apresenta desvios de faturamento. O projeto $\mathrm{P} 4$, ao contrário, tem baixo valor de venda, pouca contribuição nos benefícios e alta contribuição nos desvios esperados.

Apesar de realizar o gerenciamento de riscos para todos os projetos, a gestão do portfolio de projetos não dispõe de uma metodologia estruturada para avaliar os riscos do portfolio como uma unidade e nem tampouco para estimar o grau de exposição a riscos. Neste sentido, o procedimento utilizado no estudo foi reconhecido pela organização como um meio de aprimorar as práticas de gerenciamento de portfolio de projetos que se encontram em amadurecimento.

O grau de exposição a riscos a que o portfolio de projetos está exposto, calculado através do procedimento proposto neste trabalho, reflete a situação do portfolio num determinado instante. A execução do portfolio, no entanto, traz modificações a esta situação. $O$ monitoramento e controle dos riscos do portfolio envolve atividades como:

- identificação, análise e planejamento de respostas a novos riscos;

- acompanhamento dos riscos identificados e da eficácia das respostas implantadas a eles;

- acompanhamento das condições que devem levar à execução do plano de contingência.

O cálculo do grau de exposição do portfolio a riscos também deve ser refeito periodicamente como uma atividade de monitoramento e controle.

A janela de tempo em que o trabalho foi realizado não permitiu realizar estes ciclos de recálculo, o que não significa, porém, que a importância deste passo tenha sido diminuída ou desconsiderada. 


\section{CONCLUSÕES}

\subsection{Validade e Significância}

Este trabalho teve por objetivo propor e testar um procedimento estruturado para avaliar o grau de exposição a riscos de um portfolio de projetos que, partindo dos riscos individuais de cada projeto, considerasse os inter-relacionamentos entre estes riscos, bem como outros riscos decorrentes da própria composição do portfolio.

A revisão bibliográfica realizada mostrou que o gerenciamento de portfolio de projetos é uma disciplina emergente e ainda em desenvolvimento. Esta disciplina oferece técnicas para selecionar e conduzir um conjunto ótimo de projetos, alinhado às estratégicas da organização, de acordo com a disponibilidade limitada de recursos.

A revisão bibliográfica mostrou também, que o gerenciamento de riscos em portfolio de projetos é um tema de importância amplamente reconhecida, porém ainda pouco explorado. Mesmo assim, são recorrentes as recomendações de utilização do grau de exposição a riscos como um dos critérios mais relevantes na composição e no balanceamento de portfolios.

Além disso, a revisão bibliográfica evidenciou barreiras relacionadas à insuficiência de informações, falta de conhecimento técnico e disponibilidade de recursos para lidar com o tema, que acabam, muitas vezes, por restringir ou mesmo inviabilizar a aplicação das técnicas de gerenciamento de riscos. Estas barreiras motivaram o desenvolvimento de um procedimento que fosse de possível aplicação, mesmo frente a estas frequentes insuficiências.

O referencial teórico construído a partir da revisão bibliográfica amparou a elaboração do procedimento e a pesquisa de campo.

A pesquisa, classificada como exploratória e qualitativa, com trabalho de campo, utilizou o método de estudo de caso para alcançar seus objetivos. A metodologia utilizada se mostrou adequada aos propósitos do trabalho, permitindo a obtenção das informações necessárias para seu desenvolvimento. 
O primeiro objetivo do trabalho foi alcançado através da construção do procedimento. Visando a facilidade de aplicação, abordagens quantitativas simples foram aliadas a abordagens qualitativas, evitando a utilização de técnicas mais sofisticadas como análise de Monte Carlo, análise de sensibilidade, árvores de decisão ou outros tratamentos probabilísticos que requerem maior grau de conhecimento técnico, de informação e de esforço.

Ainda que elaborado com base em conceitos, técnicas e instrumentos descritos na bibliografia consultada, nenhum trabalho publicado que oferecesse uma abordagem similar à proposta neste procedimento foi encontrado no universo pesquisado.

O procedimento desenvolvido permitiu responder conceitualmente as questões chave deste trabalho:

- Como determinar o grau de exposição a riscos de um portfolio de projetos?

- Que mecanismos poderiam ser utilizados para considerar simultaneamente os riscos individuais e as inter-relações entre os riscos de cada projeto na determinação do grau de exposição a riscos do portfolio?

A pesquisa de campo, realizada com o objetivo de validar o procedimento, comprovou sua aplicabilidade.

A organização estudada atendeu os requisitos considerados necessários para a aplicação do procedimento, já que adota processos estruturados para o gerenciamento de portfolio de projetos e para o gerenciamento de riscos em projetos. Os projetos desta organização visam atender objetivos definidos em seu planejamento estratégico, sendo analisados e selecionados segundo critérios prédefinidos.

O procedimento proposto foi aplicado em um dos portfolios em andamento na organização e permitiu determinar o grau de exposição a riscos deste portfolio frente aos objetivos estratégicos a que se propunha atender, utilizando como base os riscos previamente identificados no âmbito dos projetos e considerando também seus inter-relacionamentos.

Os resultados obtidos através da aplicação do procedimento se mostraram coerentes, confirmando o pressuposto de que os mesmos processos, técnicas e ferramentas de gerenciamento de riscos em projetos podem ser aplicados ao 
gerenciamento de portfolio de projetos, desde que adequados ao foco mais estratégico do portfolio.

Ainda que realizado em uma organização que emprega metodologias maduras de gerenciamento de projetos, o estudo de caso mostrou que a análise dos riscos no âmbito do portfolio estava restrita à agregação dos riscos dos projetos numa base de dados e que o grau de exposição a riscos do portfolio em andamento era estimado de forma subjetiva pelo seu gestor.

Neste sentido, a identificação tanto dos riscos em comum, das interdependências, como também dos riscos abrangentes, realizada de forma sistêmica e estruturada, proporcionou uma perspectiva mais gerencial, permitindo identificar causas comuns, proliferações indesejadas e, principalmente, racionalizar recursos no tratamento dos riscos. Estes ganhos foram reconhecidos pela organização pesquisada.

O estudo de caso possibilitou concluir, também, que o gerenciamento de riscos em portfolio de projetos ganha em eficácia, se contar com uma base de dados única com os riscos dos projetos consolidados. Da mesma forma, a participação de uma mesma equipe de apoio nas sessões de identificação e revisão dos riscos dos projetos potencializa a identificação dos riscos comuns e das interdependências nas sessões do portfolio, através da visão abrangente adquirida nestas atividades.

Além disso, o tratamento centralizado dos riscos do portfolio contribui diretamente para aumentar o compartilhamento das lições aprendidas entre os vários projetos.

Ficou claro também, que quanto maior a maturidade no gerenciamento de riscos no âmbito dos projetos, melhor a base para o gerenciamento dos riscos no âmbito do portfolio de projetos.

Este trabalho procurou abordar aspectos ainda pouco explorados do gerenciamento de riscos em portfolio de projetos, mas que constituem um componente essencial do gerenciamento de portfolio de projetos.

O trabalho apresenta uma forma estruturada para identificar, analisar e tratar os riscos do portfolio de projetos e permite estimar seu grau de exposição a riscos. Integra conceitos de gerenciamento de riscos com conceitos de gerenciamento de portfolio de projetos, oferecendo meios para maximizar o valor do portfolio e garantir o alinhamento estratégico dos projetos. 


\subsection{Limitações do Estudo}

Apesar da metodologia utilizada no estudo ter se mostrado adequada, uma dificuldade surgiu logo no início dos trabalhos de campo, quando tanto os aspectos de confidencialidade quanto a indisponibilidade de agenda das interfaces adequadas para a obtenção das informações necessárias, levaram à interrupção de dois levantamentos já iniciados. Somente numa terceira tentativa, foi possível obter as informações necessárias.

Embora o estudo de caso tenha produzido resultados satisfatórios, não é possível fazer generalizações acerca de seus resultados, sem estender a aplicação do procedimento a um número maior de organizações, de diferentes perfis, com projetos de características diversas.

É importante destacar também, que os valores de exposição a riscos calculados através da multiplicação do impacto pela probabilidade representam uma estimativa da perda média, onde o impacto total é atenuado pela probabilidade de ocorrência. $\mathrm{Na}$ prática, porém, só existem duas possibilidades: o evento ocorre ou não, respectivamente com impacto total ou com impacto nenhum. Além disso, as estimativas de probabilidade apresentam aspectos subjetivos e as estimativas de impacto podem ser imprecisas. Isto significa que os valores de exposição a riscos calculados no procedimento são apenas uma forma numérica de avaliar a magnitude dos riscos e não podem ser considerados como definitivos.

Embora o estudo tenha se limitado a uma situação pontual no ciclo de vida dos projetos que compõem o portfolio analisado, ficou evidente a importância das avaliações periódicas dos riscos do portfolio e o consequente balanceamento, com a entrada de novos projetos que possibilitem o constante alinhamento aos objetivos de negócio da organização.

É importante destacar que o procedimento proposto tratou apenas dos riscos negativos. Sabe-se, porém, que os projetos também apresentam oportunidades que devem ser gerenciadas com o objetivo de potencializar os ganhos. 
Finalmente, o procedimento proposto é apenas uma das maneiras possíveis de se determinar o grau de exposição a riscos no portfolio de projetos e não tem a pretensão de ser único ou definitivo.

\subsection{Recomendações para Futuros Trabalhos}

Este trabalho abordou um tema importante e ainda pouco explorado. Os aspectos do gerenciamento de riscos em portfolio de projetos tratados neste estudo constituem apenas uma parte deste campo de conhecimento, e podem servir como ponto inicial de estudos complementares.

A aplicação deste procedimento em outras organizações, por exemplo, com diferentes características de porte, área de atuação, objetivos estratégicos e níveis de maturidade em gerenciamento de portfolio de projetos, permitiriam comparar os resultados obtidos, servindo como base para aprimoramentos e complementações. Uma base mais ampla de resultados permitiria, também, o desenvolvimento de procedimentos com focos específicos de aplicação.

Por outro lado, a aplicação do procedimento numa mesma organização, de forma cíclica e regular num período mais prolongado, permitiria testar o comportamento dos riscos do portfolio ao longo do tempo, bem como inserir o procedimento nos processos de seleção dos projetos, avaliações periódicas e balanceamento do portfolio, integrado aos demais critérios de seleção e avaliação.

Ainda como continuidade do trabalho, o procedimento proposto poderia ser estendido para tratar também as oportunidades em contraposição aos riscos.

Por fim, a uma outra continuidade natural deste trabalho aponta para um estudo que aliasse o gerenciamento dos riscos com o gerenciamento das reservas de contingência no âmbito do portfolio de projetos. 


\section{REFERÊNCIAS BIBLIOGRÁFICAS}

ARCHER, N.P.; GHASEMZADEH, F. An integrated framework for project portfolio selection. International Journal of Project Management. Vol. 17, n. 4, p. 207-216, 1999.

BENKO, C.; MCFARLAN, F.W. Connecting the dots: aligning projects with objectives in unpredictable times. Watertown: Harvard Business School Publishing, 2003.

BERNSTEIN, P.L. Desafio aos deuses: a fascinante história do risco. Rio de Janeiro: Campus, 1997.

BERTRAND, J.W.; FRANSOO J.C. Operations management research methodologies using quantitative modeling. International Journal of Operations \& Product Management. Vol. 22, n.2, p.241-264, 2002.

BLAXTER, L.; HUGHES C.; TIGHT M. How to research. Buckingham: Open University Press, 1996.

BOSTON CONSULTING GROUP. Getting value from enterprise initiatives: a survey of executives. Boston Consulting Group, 2000, pp. 1-25.

BRYMAN, A. Research methods and organization studies. London: Routludge, 1995.

CENTER FOR BUSINESS PRACTICES. Project portfolio management: a benchmark of current business practice, 2003. Disponível em http://www.cbponline.com/product p/research-projcontrol.htm. Acesso em: 11.ago, 2008

CENTER FOR BUSINESS PRACTICES. Project portfolio management maturity benchmark, 2005. Disponível em http://www.cbponline.com/product p/researchppmmaturity.htm. Acesso em: 11.ago, 2008

CHAPMAN C., WARD S. Project risk management, processes, techniques and insights. John Wiley \&Sons, 1997. 
CHARETTE, R.N., Risk management 2006: a comprehensive survey, Cutter Consortium, 2006.

CLELAND D.I., IRELAND L.R. Project manager's portable handbook. New York: McGraw-Hill, 2000.

COOPER D.; CHAPMAN C. Risk analysis for large projects. New York: John Wiley \& Sons, 1987.

COOPER, R.G. Winning at new products: accelerating the process from idea to launch. ${ }^{\text {rd }}$ Ed. New York: Basic Books, 2001

COOPER, R.G. Product leadership: pathways to profitable innovation. $2^{\text {nd }}$ Ed. New York: Basic Books, 2005

COOPER, R.G.; EDGETT, S.J.; KLEINSCHMIDT, E.J. New product portfolio management: practices and performance. Journal of Product Innovation Management. Vol.16, p.333-351, 1999.

COOPER, R.G.; EDGETT, S.J.; KLEINSCHMIDT, E.J. Portfolio management for new products. $2^{\text {nd }}$ Ed. New York: Perseus Publishing, 2001

FEDERAL CIO COUNCIL, BEST PRACTICES COMMITTEE. A summary of fist practices and lessons learned in it portfolio management, 2002. Disponível em http://www.cio.gov/documents/BPC portfolio final.pdf. Acesso em: 17.jul, 2008.

GARTNER GROUP: ROSSER, B.; POTTER, K. IT portfolio management and survey results. Stamford: Gartner Group, 2001.

GIL, A.C. Como elaborar projetos de pesquisa. São Paulo: Editora Atlas, 1988.

GRAY, C.F.; LARSON, E.W. Project management: the managerial process. 2nd Ed. New York: McGraw-Hill//rwin, 2003.

HILLSON, D. Extending the risk process to manage opportunities. International Journal of Project Management, Vol. 20, n.3, pp. 235-240, 2002. 
HILLSON, D. Gerenciamento de riscos em projetos: melhores práticas e desenvolvimentos futuros. Revista Mundo PM. Vol.1, n.4, pp.38-42, 2006.

HILLSON, D. To quant or not to quant? Project Manager Today, pp. 30. November, 2007

HILLSON D., Understanding risk exposure using multiple hierarchies. Proceedings of the PMI Global Congress 2007 EMEA. Budapest, Project Management Institute, 15 May 2007.

KENDRICK, T. Identifying and managing project risk: essential tools for failureproofing your project. New York: AMACOM, 2003.

KERZNER H. Strategic planning for project management using a project management maturity model. New York: John Wiley \& Sons; 2001.

KERZNER, H. Project Management: a systems approach to planning, scheduling and controlling. 8th Ed. New York: John Wiley \& Sons, 2003.

KERZNER H. Gestão de projetos: as melhores práticas. 2a ed. Porto Alegre: Bookman; 2006.

LAKATOS E.M.; MARCONI, M.A. Metodologia do trabalho científico. 4ª Ed. São Paulo: Editora Atlas, 1992.

LEVINE, H.A. Project portfolio management: a practical guide to selecting projects, managing portfolios and maximizing benefits. San Francisco: Jossey-Bass, 2005.

MARCONI, M.A.; LAKATOS, E.M. Fundamentos de metodologia científica. São Paulo: Atlas, 2003.

MARKOWITZ, H.M. Portfolio selection: efficient diversification of investments. New York: Wiley, 1959.

MCFARLAN, F. W. Portfolio approach to information systems. Harvard Business Review, Vol.59, p.142-150, September-October 1981 
MEREDITH J.R., MANTEL S.J. Jr. Project management: a managerial approach. $4^{\text {th }}$ ed. New York: John Willey \& Sons; 2000.

MURRAY K. Risk management beyond the textbooks. PM Network, pp.53-57, June 1998.

NAPIER, R. The role of governance and program management in the $\mathrm{ClO}$ office. HP ClO Summit. New York, 2003.

NAKANO, D.N.; FLEURY, A. C. C. Métodos de pesquisa em engenharia de produção. (CD-ROM). In: Encontro Nacional de Engenharia de Produção, 16‥, Piracicaba: Unimep/Abepro/Multiview, 1996.

PATERSON, M.L.; FENOGLIO, J.A. Leading product innovation: accelerating growth in a product-based business. New York: John Wiley and Sons, 1999

PENNYPACKER, J.S.; SEPATE, P. Integrating project portfolio management with project management practices to deliver competitive advantage. In: LEVINE, H.A. Project portfolio management: a practical guide to selecting projects, managing portfolios and maximizing benefits. San Francisco: Jossey-Bass, 2005.

PORTER, M. Competitive strategy. Boston: Harvard Business School Press, 1986.

PRITCHARD, C.L. Risk Management: concepts and guidance. $2^{\text {nd }}$ Ed. Arlington: ESI International, 2001.

PROJECT MANAGEMENT INSTITUTE. A guide to the project management body of knowledge (PMBOK Guide). $3^{\text {rd }}$ Ed. Newtown Square: Project Management Institute, 2004.

PROJECT MANAGEMENT INSTITUTE. The standard for portfolio management. Newtown Square: Project Management Institute, 2006.

PROJECT MANAGEMENT INSTITUTE. The standard for program management. Newtown Square: Project Management Institute, 2006.

RAD, P.F.; LEVIN, G. Project portfolio management tools and techniques. New York: IIL Publishing, 2006. 
RAJEGOPAL, S.; MCGUIN, P.; WALLER, J. Project portfolio management: leading the corporate vision. New York: Palgrave Macmillan, 2007

REYCK , B.D et al. The impact of project portfolio management on information technology projects. International Journal of Project Management. Vol. 23, p.524537, 2005.

RHOADS, R. Risky business. [Depoimento à Revista PM Network]. Newtown Square: Project Management Institute. Vol. 20, n.3, p.18, March 2006.

ROYER, P.S. Risk management: the undiscovered dimension of project management. Project Management Journal., Vol. 31, n.1, p.6-13, March 2000.

SANCHEZ, H.; ROBERT, B.; PELLERIN, R. A project portfolio risk-opportunity identification framework. Project Management Journal., Vol. 39, n.3, p.97-109, September 2008.

SHTUB, A.; BARD, J.F.; GLOBERSON, S. Project management: engineering, technology and implementation. Englewood Cliffs: Prentice Hall,1994.

SMITH, P.G.; MERRITT, G.M. The risk management process: proactive risk management. New York: Productivity Press, 2002

SOUDER, W. E. Selecting projects that maximize profits: project management handbook. New York: Thomson, 1988.

THE STANDISH GROUP INTERNATIONAL. Chaos Report, 2001.

THOMAS, J.; MULLALY, M. Researching the value of project management. Newtown Square: Project Management Institute, 2008

THORP J. The information paradox - realizing the business benefits of IT. Revised edition. Toronto: McGraw-Hill; 2003.

TREGOE, B.; ZIMMERMAN, J. Top management strategy. New York: Simon \& Schuster, 1980. 
YELIN, K.C. Linking strategy and portfolio management. In: LEVINE, H.A. Project portfolio management: a practical guide to selecting projects, managing portfolios and maximizing benefits. San Francisco: Jossey-Bass, 2005.

YIN R.K. Estudo de caso: planejamento e métodos. Porto Alegre: Bookman; 2004.

WARD, J. L. Project management terms: a working glossary. $2^{\text {nd }}$ Ed. Arlington: ESI International, 2000.

WHARTON F. Risk management: basic concepts and general principles," in: ANSELL J.; WHARTON F. Risk: analysis, assessment and management. New York: John Wiley\&Sons, 1992.

WIDEMAN, R.M. Project and program risk management: a guide to managing project risks and opportunities. Newton Square: PMI, 1992.

WILLIAMS, D.; PARR, T. Enterprise programme management: delivering value. New York: Palgrave Macmillan, 2004. 


\section{APÊNDICE A Questionário de Apoio à Pesquisa}

\section{I - Dados da empresa}

1. Razão social

2. Histórico

3. Áreas de negócios

4. Faturamento anual

5. Número de funcionários

6. Tipo de capital (aberto/fechado)

\section{II - Caracterização dos projetos}

1. Tipologia dos projetos

2. Quantidade média de projetos por ano

3. Valor médio dos projetos

4. Duração média dos projetos

5. Representatividade dos projetos no faturamento da empresa

6. Ciclo de vida dos projetos

\section{III - Gerenciamento de projetos}

1. Existência de metodologia para o gerenciamento de projetos

2. Ferramentas utilizadas para o gerenciamento de projetos

3. Áreas de conhecimento abrangidas pela metodologia

4. Estrutura de gerenciamento dos projetos

5. Tamanho do time de projeto

6. Existência de PMO (Project Management Office)

7. Função do PMO

\section{IV - Gerenciamento de riscos em projetos}

1. Metodologia de gerenciamento de riscos em projeto

2. Ferramentas de gerenciamento de riscos em projeto

3. Principais riscos

4. Registro de riscos dos projetos

\section{V - Gerenciamento de portfolio de projetos}

1. Existe planejamento estratégico com objetivos quantificáveis e claros?

2. Periodicidade do planejamento estratégico

3. Quem participa do planejamento estratégico?

4. Como os projetos estão relacionados com o plano estratégico?

5. Metodologia de gerenciamento de portfolio de projetos

6. Ferramentas de gerenciamento de portfolio de projetos

7. Função do $P M O$ e integração com gerentes de projetos

8. Critérios de seleção dos projetos

9. Quem toma as decisões? 
10. Como é medido o desempenho do portfolio?

11. Como avalia se os projetos agregam valor?

12. Como é feito o balanceamento do portfolio de projetos?

13. Em quais situações um projeto pode ser cancelado ou paralisado?

VI - Gerenciamento de riscos no portfolio de projetos

1. Como os riscos direcionam a escolha do portfolio?

2. Tolerância a riscos da empresa/portfolio

3. Como os riscos do portfolio são gerenciados?

4. Instrumentos de apoio utilizados (RBS, checklist, matriz de impacto e probabilidade, critérios de avaliação, etc.) 


\section{APÊNDICE B Roteiro de Aplicação do Procedimento}

1. Delimitação do portfolio a ser estudado

2. Identificação dos objetivos estratégicos a que o portfolio está atrelado

3. Definição da tolerância a riscos para o portfolio

4. Identificação dos riscos do portfolio
a. Análise dos registros de riscos dos projetos
b. Identificação dos riscos individuais, comuns e de interdependência
c. Identificação dos riscos abrangentes

5. Definição dos instrumentos utilizados na análise de riscos

6. Análise dos riscos

7. Respostas a riscos

8. Cálculo da exposição a riscos do portfolio 